\title{
Representing Future Situations of Service \\ Prototyping in Service Design
}

by

\section{Johan Blomkvist}

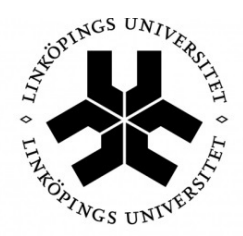

\section{Linköping University \\ FACULTY OF ARTS AND SCIENCES}

Department of Computer and Information Science

Linköping University

SE-58I 83 Linköping Sweden

Linköping 2014 
At the Faculty of Arts and Science at Linköping University, research and doctoral studies are carried out within broad problem areas. Research is organised in interdisciplinary research environments and doctoral studies mainly in graduate schools. Jointly, they publish the series at Linköping Studies in Arts and Science. This thesis comes from the Human-Centred Systems Division at the Department of Computer and Information Systems.

Copyright (C) 2014 Johan Blomkvist

ISBN: 978-9I-75I9-343-4

ISSN: 0282-9800

Printed by: LiU-Tryck 2014

\section{Cite as:}

Blomkvist, J. (2014). Representing Future Situations of Service: Prototyping in Service Design. Linköping Studies in Arts and Science, Dissertation No. 618. Linköping, Sweden: Linköping University Electronic Press.

\section{Typeset in:}

Calluna, http://www.exljbris.com/calluna.html by exljbris Fontin Sans RG and Fontin Sans SC, http://www.exljbris.com/fontinsans.html by exljbris

URL: http://urn.kb.se/resolve?urn=urn:nbn:se:liu:diva-I05499

The cover photos show service representations used for desktop prototyping. They were made by our students in the 'new' service design course 2009 (Blomkvist, Holmlid, \& Segelström, 201ra). 


\section{Abstract}

This thesis describes prototyping in service design through the theoretical lens of situated cognition. The research questions are what a service prototype is, what the benefits of service prototyping are, and how prototypes aid in the process of designing services. Four papers are included. Paper one suggests that service prototyping should be considered from the perspectives of purpose, fidelity, audience, position in the process, technique, representation, validity and author. The second paper compares research about how humans use external representations to think, with reasons for using prototypes in service design and service design techniques. The third paper compares two versions of a service prototyping technique called service walkthrough; showing that walkthroughs with pauses provided both more comments in total and more detailed feedback. The fourth paper also contributes to our understanding of how prototypes aid in designing services, by connecting the surrogate situation with the future situation of service. The paper shows how the formative service evaluation technique (F-SET) uses the theory of planned behaviour to add knowledge to service prototype evaluations about the intention to use a service in the future. Taken together the research provides a deeper understanding of what prototypes are, and their roles in service prototyping. This understanding is further deepened by a discussion about service as a design material, suggesting that from a design perspective, a service consists of service concept, process and system. The service prototype acts as a surrogate for the future situation of service. The thesis describes what the benefits of using surrogates are, and shows how prototypes enhance the ability to gain knowledge about future situations. This leads to an understanding of prototyping as a way of thinking in design. 



\section{Acknowledgments}

There is a long list of people that I need to thank for all their support. First of all, Stefan Holmlid, my main supervisor, and Robert Ramberg and Daniel Kindström, my secondary supervisors. Early on, Arne Jönsson also helped me by pointing me in the right direction. Thank you all very much.

I would also like to thank all the teachers and fellow students at the cognitive science program in Linköping. You are the reason I ended up doing a PhD. All the members of IxS have also helped in various ways, most importantly through tisdagsfika!

The most important person for my work as a PhD student has been Fabian Segelström, with whom I have had countless discussions about service design theory, practice and teaching. Thank you very much Fabbe!

Of course, my co-authors have also been important, thank you to: Mattias Arvola, Stefan Holmlid, Johan Åberg, Fabian Segelström, Daniel Kindström, Angela Bode, Bosse Westerlund, Fredrik Sandberg, Daniel Anundi, and Amy Rankin among others.

I would also like to thank all the people who have read and commented on, parts or entire, versions of this thesis: Stefan Holmlid, Fabian Segelström, Nils Dahlbäck, Mattias Kristiansson, Mathias Nordvall, Daniel Kindström, Robert Ramberg, Amy Rankin, and Timothy Overkamp.

During my studies I have been part of two graduate schools, and I would like to thank the teachers, supervisors and $\mathrm{PhD}$ students of:

- SweCog - Swedish national graduate school in cognitive science.

http://gradschool.swecog.se/

and 
- D! - Swedish Faculty for Design Research and Research Education. www.designfakulteten.kth.se

A number of people who have helped keep me sane during these years should also be mentioned. Anna, Karin and Rolf, thank you. Sture, thank you for inviting me to the football team. A big thank you also to Sara, Maria, Sanna, Jody, Fabian, Amy, Lisa, Jonas, Mattias, Mathias, Kricke, Erik, Falkenskägg, Tim, Camilla, and Robin for all the fun discussions and doktorandpubs. Anne and Lise-Lott have helped greatly in navigating the administrative side of my studies. TUS has also helped with everything from extension cords and speaker systems to software updates. A special thank you to Jody for making lunch \#dagensbästastund, and to the Heroes of Golarion: Narssus, Helm, Dagg, Ulf, and almighty GM Jäger.

Finally, I would like to thank the best family anyone could ever wish for: Mamma, Leif, Micke, Frida, Danne, Johanna, Svante, Kajsa, Stina, Sven, Ulfhild, Lina, Pappa, and Anita. Most of all I would like to thank Anna, you mean everything to me! 


\section{Table of Contents}

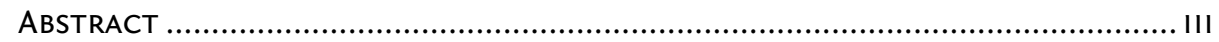

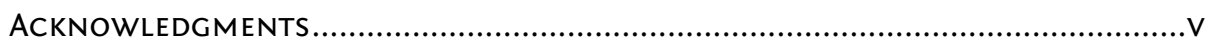

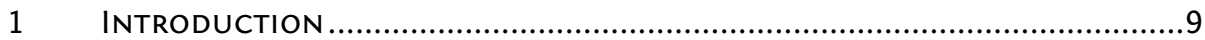

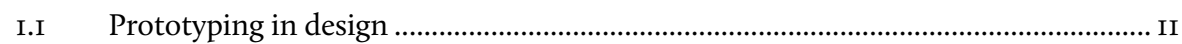

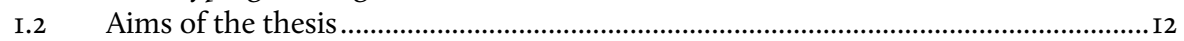

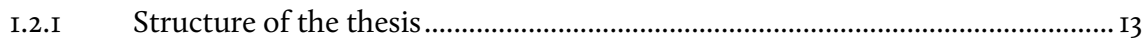

I.3 Reach and scope ......................................................................................................

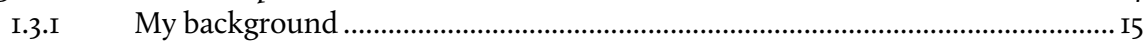

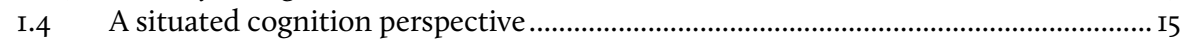

I.5 Vocabulary ..................................................................................................... I5

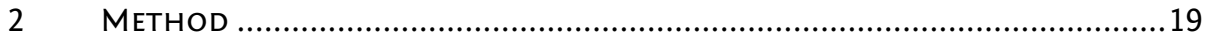

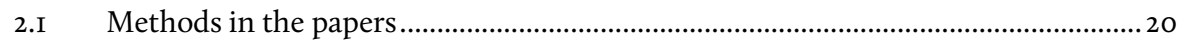

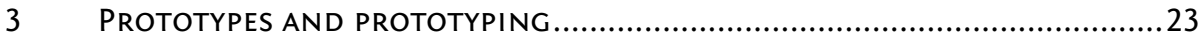

3.I Prototyping .................................................................................................................. 24

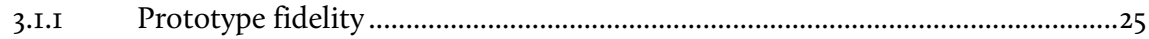

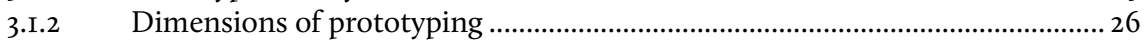

3.2 A broad view of prototyping ……………............................................................... 27

3.2.I Explorative and evaluative prototyping ............................................................... 28

3.2.2 Prototypes as surrogate situations.......................................................................... 29

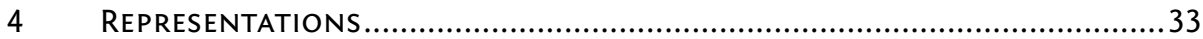

4.I Situated cognition and cognitive science..........................................................................3

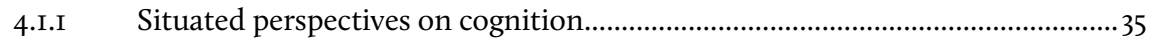

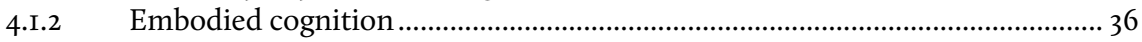

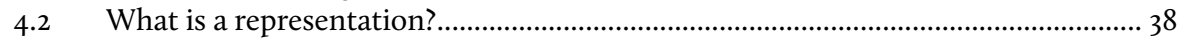

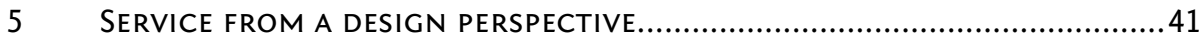

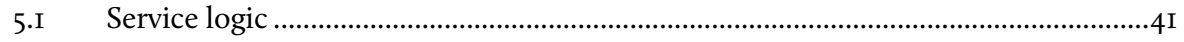

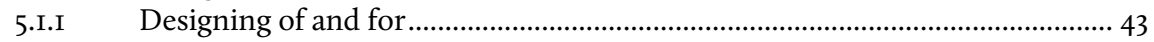

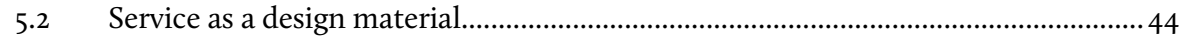

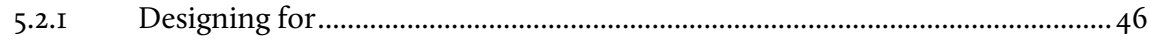

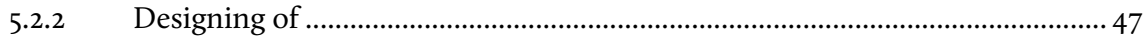

5.3 Summarising service as a design material........................................................... 49

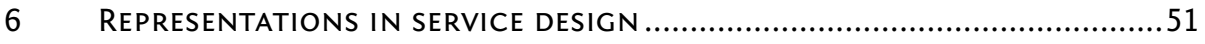

6.I External representations and design .........................................................................52

6.I.I Benefits of making representations................................................................ 54

6.I.2 Conversations with design representations ......................................................... 54

6.2 Representations of and for service..........................................................................5

6.3 The service walkthrough technique ......................................................................... 56

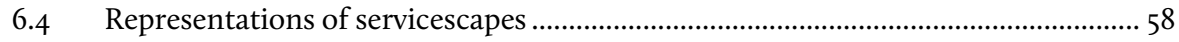

6.4.I Signifiers ...................................................................................................... 58

6.5 Representations and the future situation of service ..................................................60 


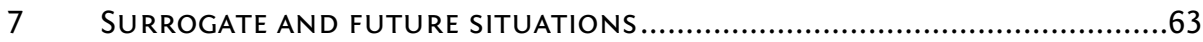

7.I The relationship between surrogate and future situations of service .........................63 63

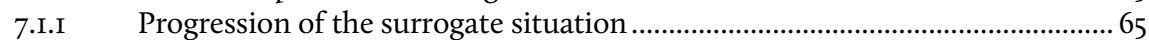

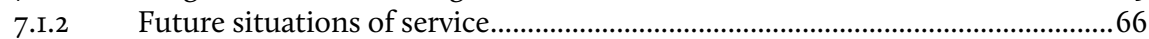

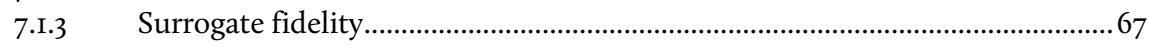

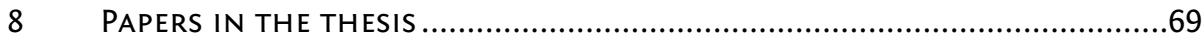

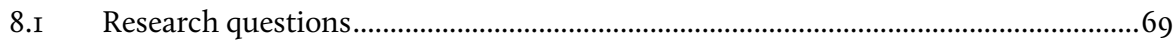

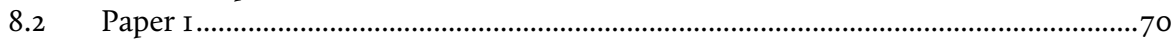

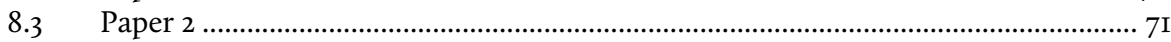

8.4 Paper 3

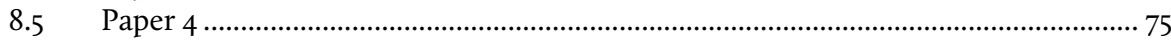

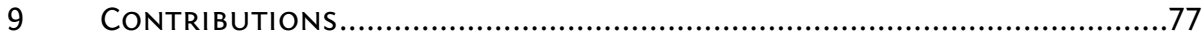

9.I Prototyping and situated cognition ............................................................................. 77

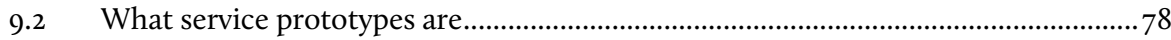

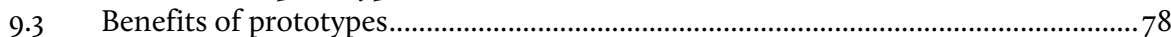

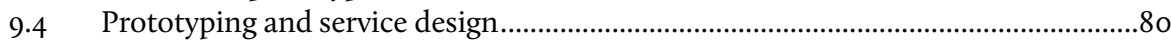

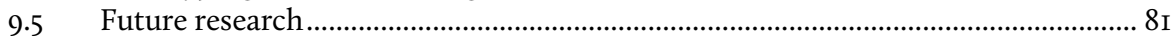

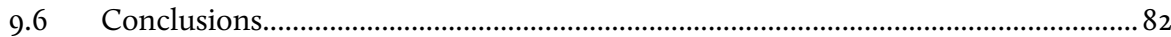

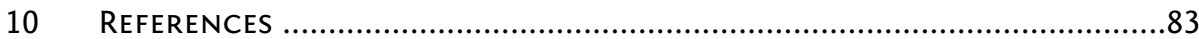




\section{Introduction}

Service is a relatively new domain of design ${ }^{1}$. Traditional materials or objects of design include buildings, products, and graphics. Interaction is also a design material, which has been a domain of design slightly longer than service. Regardless of what the material is, the domains of design share some attributes. For example, the intent to change a current situation into a preferred situation is shared by all design disciplines, whether it is by improving aesthetic experiences or by making it easier to pay taxes online. On a general level, the process of design also looks the same across domains. The process of design has been described and visualised numerous times from different perspectives and using different metaphors. One such visualisation is the double-diamond design process model (Design Council, 2007). Underlying the model is the assumption that design is concerned with a space within which relevant information in a design project is located. This design space specifies what knowledge and solutions are available and relevant, and it contains e.g. the possible solutions to a design problem.

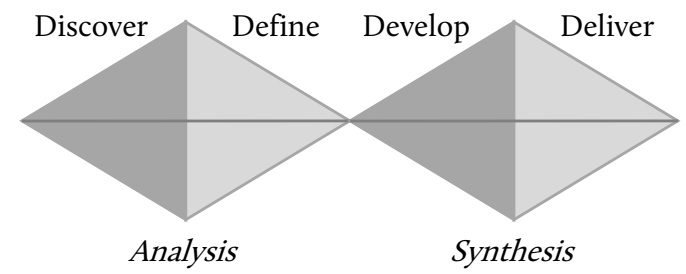

FIGURE 1: THE DOUBLE-DIAMOND MODEL (BASED ON DESIGN COUNCIL (2007)). DIVERGENT AREAS ARE DARKER THAN CONVERGENT.

\footnotetext{
${ }^{\text {I }}$ Designers started approaching service design in a structured way in the early I990s, based on research in services marketing. See Segelström (2013) for a comprehensive history of service design.
} 
On an abstract level, divergent and convergent approaches can be used to distinguish between different parts of a design process. Divergent activities open up the design space by e.g. adding knowledge or data to it. Convergent activities have the opposite effect. A divergent phase thus is generative and suggestive, while a convergent phase is discriminating and selective. The double-diamond model consists of two iterations of divergent and convergent processes; see Figure I. Divergent activities are indicated by a darker grey and convergent by a lighter grey colour. The left diamond represents analysis in design work (understanding the current situation, the context, people and problems) and the right represents synthesis (generating solutions, suggestions, ideas, and concepts). Dubberly, Evenson, \& Robinson (2008) have suggested that what support a transition from analysis to synthesis are the models that designers use. In this thesis such models will be called representations (see Chapter 4).

The left diamond in the model can be thought of as design research, and consists of discovery and define. Discovery means adding more knowledge about the target group and the context of design. The define phase organises and selects relevant aspects of the knowledge to make it manageable. The right diamond starts with a generative phase where alternative suggestions are developed. By choosing between the suggestions it is possible to come up with a final solution to be delivered in the second part of the right diamond. Hence, the right diamond includes idea generation, and idea evaluation. The representations used in the right diamond are sometimes called prototypes, and in this thesis, prototyping mainly means activities associated with the right diamond. Prototypes, and the activity of prototyping in the discipline of service design is the main focus of the thesis. Chapter 3 is dedicated to defining and describing prototypes and prototyping, but a brief introduction is provided in I.I, to frame the aims of the thesis.

Service design has been described as: "the use of a designerly way of working when improving or developing people-intensive service systems through the engagement of stakeholders" (Segelström, 2013, p. 27). Approaching services as "people-intensive service systems" implies a holistic approach, which is also explicitly stated in many definitions and conceptualisations of service design: "[s]ervices created in silos are experienced in bits" (Polaine, Løvlie, \& Reason, 2013, p. 22; see also Stickdorn, 2010; Kimbell, 2009; Service Design Network, n.d.).

The holistic scope means that service designers look at whole service systems and consider the people in them; their needs, intentions, expectations and so forth, as well as the context, resources, and the location where the service takes place. The holistic understanding that results from these investigations is then summarised and visualised to enable a transition to synthesis. The visualisation contains an understanding of what the solution should be and what it should do for people, and as such it decides the focus of the following design activities and prototyping. 
However, what prototyping looks like in service design, and how representations can be used to support the synthesis part of service design projects, are subjects for further investigation (Hollins \& Hollins, I99I; von Stamm, 2008; Holmlid \& Evenson, 2007; Ostrom et al., 20I0). The holistic approach in service design means that there should also be prototyping techniques that use representations of whole services (Blomkvist, 20II). Such techniques rest on a description and understanding of what service is as a design material, because that is how designers frame what should be designed.

Hence, some characteristics of service as a design material are needed. This will guide the process of representing services, which in turn requires some knowledge about what representations are and how they can be useful in design. Based on such representations, new services can be prototyped. A more explicit understanding about different perspectives on prototyping further improves the possibility and ability to prototype services. Some of the perspectives on prototyping can be adopted from other design disciplines, with longer prototyping traditions.

\subsection{Prototyping in design}

In most design domains, prototyping is an integral part of the design process. Prototyping practices have been developed and adapted to fit the specific design materials in the respective fields (Schrage, 1996), and the value of prototyping has been documented academically. It is important to note that when different design disciplines talk about prototypes, they rarely mean the same thing. In many design disciplines, prototypes are concentrated around a physical artefact or symbol that represents the future state.

In graphic design, pen and paper (or the software equivalents) are used to prototype. The quick and inexpensive approaches utilised in graphic design has influenced other disciplines. Wong (1992) suggested that graphic design could inform and enhance interface design, which used elaborate, detailed, and time consuming approaches to prototyping. Wong (1992) wrote that "[i]n contrast, graphic designers use a wide range of prototyping strategies to communicate ideas to others for discussion and feedback. For example, prototypes constructed early in the graphic design process rely on different techniques and rendering styles from those produced in the final stages" (Wong, I992, p. 83). Early in graphic design projects, "dummies" are sketched to make ideas open for critique and to focus attention to certain aspects of an idea.

Also in industrial design, sketching is important, but mainly as a vehicle to move to other representations of ideas. In I955, industrial designer Henry Dreyfuss described the work process of reaching a final product in industrial design. He did not mention the word prototype, but used the words model or mock-up, mainly to designate the 3-D versions of products. The process was described like this: 
"We go over countless rough sketches. Components are arranged and rearranged. Working drawings and blueprints are made, some by the client's engineers, some by us, and frequently exchanged. Our blueprints, by the way, have letters and numerals on the margins, like road maps, so that any point on them can be easily located and discussed by phone or referred to by wire or letter. Three-dimensional clay, plaster, wood or plastic models are developed, for we believe that three-dimensional objects should be designed in three dimensions.// as soon as possible, we get a form into clay and actually do our designing in this pliable material" (Dreyfuss, 2003, p. 46-47).

Perhaps what people generally associate with the word prototype (if they at all are familiar with it), is the product prototype. In the broadest sense of the word, prototypes are used, and have been used for a long time, in product design (Arnowitz et al. 2007), throughout the product development process. However, in product design, the term prototype is many times used for later representations that are "similar to the final product in terms of form, function and material” (Österlin, 2003, p. 68). Hence, while graphic designers talk about rough and early sketches as prototypes, product designers reserve the term for representations in later stages of development.

Also within other disciplines the term is used in many different ways. For instance, in interaction design there are many different ways to conceptualise prototypes (Floyd, 1984). The most diverse, and the broadest view of prototypes, can arguably be found in interaction design. A summarisation of perspectives on prototypes and prototyping from interaction design (and related fields such as software design and human-computer interaction), can be seen in Paper I.

While most techniques and approaches used in other design disciplines should be possible to transfer to service design, they are not specifically adapted to service as a design material. Hence, there is a need to adapt the knowledge and practice of prototyping to fit the design material and the aims of the service design discipline. For example, the issues of how to prototype whole services, what the benefits of such approaches could be, and how to understand the outcomes of service prototyping, need further examination. This thesis will provide examples and knowledge about those areas of research.

\subsection{Aims of the thesis}

The main audience of the thesis are design researchers, firstly those working with service design, secondly researchers in other design disciplines, and thirdly those in the borderlands between design and cognitive science. People in the intersection between design and cognitive science are probably working in areas such as distributed or situated cognition, and can be interested in how their perspectives are used in this thesis. In addition, the conceptualising parts of the thesis (mainly the kappa and in Paper I) should be useful in 
design education. The aim is to provide a theoretical lens for service prototyping. Using this lens, it should be possible to understand

- what a service prototype is,

- what the benefits of prototypes (mainly in service design) are, and

- how prototyping aids the design of services.

The theoretical lens will provide a way to understand what service prototypes are, and also a way to think about the relationship between prototypes and the future situation they represent. More specific questions will be answered by research papers included in the thesis. The questions can be found in Chapter 8.I.

\subsubsection{Structure of the thesis}

This is a compilation thesis. This means that the thesis consists of an initial summarising part, and a part consisting of research papers. The first part is referred to as the kappa. In this thesis, the kappa consists of Io chapters including the references. To understand how prototypes aid in designing services, it is important to understand what a service is from a design perspective. Hence, the kappa will provide the necessary background knowledge about service as a design material. This will also include a discussion about what the constituent parts of services are. Furthermore, the kappa will propose ways to approach service prototyping, given the provided understanding of service prototypes, and show ways in which service prototyping can generate knowledge about a future situation.

First, the Introduction (Chapter I, which you are reading now) introduces the aim of the thesis and the vocabulary used, as well as the reach and scope of the research. The used methods are presented in Chapter 2, and in Chapter 3 the concepts of prototype and prototyping are discussed. A broad view is suggested as a way to think about prototyping in the thesis. Prototypes are conceptualised as surrogate situations that stand in for the future situation where services will take place in Chapter 3.2.2. The next chapter (4), is focussed on a central concept in the thesis; representations. First, the chapter shows how situated cognition grew out of cognitive science, and examples of different interpretations of situated cognition are provided. It is from these perspectives that representations are described and understood in the thesis. Chapter 5 describes services from a design perspective, and talks about the service process and system as aspects of services that should be considered in service design.

In Chapter 6, the main theme is how services can be represented as prototypes. Different suggestions for why prototypes are beneficial for thinking in design are introduced, and how they support exploration in design projects. A technique for service prototyping called service walkthrough is introduced as a holistic approach to service prototyping. The relationship between representations of service and the future situation of service is then 
visualised in Chapter 6.5. Chapter 7 concludes the discussion about situated cognition as a theoretical lens for service prototyping and the relation between surrogate situations and future situations of service is further explored,. In Chapter 8, the papers in the thesis are presented, and followed by Chapter 9, which contains the conclusions and contributions of the thesis.

\subsection{Reach and scope}

There are many types of services, and perspectives on service: self-service, health service, public service, and so on. The typical type of service referred to in this thesis is the commercial service. More specifically, the typical case considered in the thesis is a service that is designed to make money for the client of a design agency. The reason for this focus is that most encountered examples during the doctoral studies have been of this type. The focus on commercial services does not necessarily mean that the findings only are relevant for this type of service, or that it implies that this is the most appropriate domain for service design.

The aim is to communicate mainly with a design research audience (see Aim of the thesis I.2). The techniques should be seen from a design perspective and service should be understood as a design "material". As a design material, services share a number of characteristics with most traditional design disciplines. Traditional design disciplines in the thesis, means mainly architecture, graphic design, interior design, fashion design, and product design.

Prototyping is an excellent way to include people in design. However, in this thesis this aspect will not be discussed in detail, and sometimes the issue of who is (or should or could be) involved is left out of discussions completely. This might cause some confusion because the thesis will interchangeably talk about designers working with prototypes, and designers working together with other stakeholders. However, the issue of inclusion is briefly discussed in Paper I. The reasons for not writing about inclusion and collaboration per se, is I) that the issue has been thoroughly discussed in previous research ${ }^{2}$, and 2) that who participates in prototyping is not as important for the thesis as how prototyping is conducted and how representations are, or can be, used in service prototyping.

Prototyping is intended to mean a specific stage of development or mind-set that designers can choose to adopt. Prototyping is preceded in service design by other design activities that usually result in an understanding of the presumptive customers, the involved stakeholders, and the context.

\footnotetext{
${ }^{2}$ See e.g. Mattelmäki (2006), Vaajakallio \& Mattelmäki (2007), Jégou \& Manzini (2008) Kaasinen, et al. (20Io), Han (2009; 2010), Andriof \& Waddock (2002), Kronqvist \& Korhonen (2008), Brandt (2006), Fullerton (2009), Keitsch et al. (2010), Tan \& Szebeko (2009), Vanstone \& Winhall (2006), Bødker (I996), and Bradwell \& Marr (2008).
} 
The thesis mentions three reasons for prototyping; exploration, evaluation, and communication (see also Chapter 3.2). Communication in this context means something more specific than the general idea that prototypes help facilitate collaboration and coordination of design activities. In this context, communication refers to prototypes designed to present a suggestion to (mainly) the client (the people, person or organisation that pay for the project). Prototypes built for presenting service ideas to external stakeholders is a quite specific type of prototypes that is not a primary concern for this thesis. In Paper 2, communication is mentioned as a reason for prototyping that refers to this limited meaning.

\subsubsection{My background}

I started my academic career quite late, when I was 25 years old. I had been working mostly with care for the elderly until then. I started studying at the cognitive science programme at Linköping university in 2004, and took out my bachelor degree in 2007. My interest was mainly in the design area and I continued by taking a master degree in design in 2009. The main focus during my master years was on the Scandinavian version of interaction design, influenced largely by Arvola (2005), Löwgren \& Stolterman (2004), and Holmlid (2002). My studies gradually changed from interaction design to service design, and my master thesis was about references to services in design communication (Blomkvist \& Holmlid, 2009). Shortly after my studies I started working as a PhD student, also at Linköping University. In parallel I supervised newly graduated design students in design projects provided by the industry. I also made a usability evaluation study of the university library's web pages. In 20II I presented my licentiate thesis with the title Conceptualising Prototypes in Service Design (Blomkvist, 20II).

\subsection{A situated cognition perspective}

The view of prototyping in service design presented in the thesis is influenced by cognitive science. More specifically, the understanding of prototypes and how they factor in as representations of ideas in prototyping is based on a situated cognition perspective. This is a perspective that claims that what is external to the mind and body plays an important role for how humans think and act. Design is full of external representations, things like sketches, models and prototypes that designers make and use partly to be able to move forward in projects. Situated cognition is used as a way of understanding why and how these representations support the design of services, not as a way to make claims about the nature or state of reality. The roots of situated cognition, and how representations can be understood from a situated cognition perspective, are discussed in Chapter 4.

\subsection{Vocabulary}

The central concepts for the thesis are introduced here. Some concepts are also defined to make it easier to understand the meaning in the following chapters. 
Cognition. Processes that depend upon the body and the environment and produce behaviour and thought.

Design. My aim is to be relevant mainly for a design audience. For this end it is important that I explain what I mean by design. There are many (unfortunate) connotations of design; one being that design is about superficial qualities. When I say design I do not mean decoration, fashion, or art; these are all elements of design but not the main focus. Design is about finding ways to customise products and services for humans, to understand deeply the wishes and hopes and lives of people and to enable them to go about their lives. This is done by mixing creative and rigid methods and approaches with the use of design techniques.

Externalisation. A physical representation of an internal (thought) or intangible event or structure. The word externalisation emphasises that something that would otherwise have been internal is represented. Externalisations are a sub-group of representations, see below.

Fidelity. The degree of detail in a prototype. A prototype's fidelity (sometimes called resolution or precision) can be thought of as how much of the final design the prototype represents.

Prototype. The definition of prototype in the thesis is: Any shared physical manifestation externalising an otherwise internal or unavailable vision of a future situation.

Definite prototype. A prototype that has a static state. That state is static and noninteractive. Examples include storyboards, service blueprints, and customer journeys.

Ongoing prototype. A prototype that is dynamic and does not have a static state. Examples include desktop walkthroughs and role-plays.

Prototyping. The definition of prototyping in the thesis is: Prototyping is the use of prototypes to explore, evaluate or communicate in design.

Representation. In the conceptualisation of prototypes used here, a prototype is a representation. Just like the term prototype is ambiguous, so is the term representation. In this context, I suggest that representations should be seen as: anything perceivable that is used or made for the purpose of representing something else.

A representation is always a substitute for something else, it is used or made in regard to something else. Sometimes representations represent real things in the world, and sometimes they represent ideas. When a representation represents an idea about the future, it is a prototype of that idea (see Chapter 4). 
Service touchpoint. Refers both to the places where customers and service providers interact, and the artefacts that mediate the interaction ${ }^{3}$.

Surrogate situation. A surrogate is "any kind of real-world structure that is used to stand in for, or take the place of, some aspect of a certain 'target situation"' (Clark, 20Io, p. 24). Here used as a way to think about prototypes in service design, that stand in for the future service.

The future situation of service. This is a way to refer to the abstract future, where a service that is being designed has been implemented.

\footnotetext{
${ }^{3}$ Service moments are sometimes used to refer to the situations where customers interact with service providers (Koivisto, 2009). According to this conceptualisation, service moments contain touchpoints.
} 



\section{Method}

The thesis has mainly been informed by studying and, either participating in, or taking part of, documentation or second hand sources about cases. The main contexts of data collection are the projects SERV, ICE, Food on Demand, DFL (an outdoor pedagogy project), PEMM, and VISUAL. In addition, teaching in the courses Service design studio for master students and Service design and innovation for design engineering students has informed the thesis greatly. A workshop held at the Participatory design conference has also influenced the knowledge presented in this thesis. The data sources are summarised in Table I.

A qualitative approach has been utilised and a mix of inductive and deductive inquiries and shifts have been made to adjust to specific research issues. The process has been guided largely by descriptive data however. The data has been analysed and sometimes resulted in hypotheses that have been explored, and sometimes the analysis has lead on to other questions. Overall, a pragmatist (Bernstein, 2010) approach has guided the research process. This means that what is considered 'true' or 'real' is decided by what works rather than by what type of inquiry is used, i.e. which epistemological assumptions are made. The thesis is mainly informed by qualitative research, but this does not mean that qualitative knowledge is considered more valuable, only that the aim of research has been more suited to qualitative inquiry. The pragmatic approach also fits well with situated cognition, which is used as a research lens, since it also has its roots in pragmatism (Clancey, 2008).

The initial phase, up until early 20II, was characterised by a descriptive and ethnographic approach. The intention was to follow this path by conducting ethnographic research at service deign consultancies. Instead, the approach changed to an empirically based prescriptive approach, where instances of specific service prototyping approaches informed 
suggestions for how to improve the practice. These suggestions have also been put to the test, most notably in Paper 3.

The first part of the PhD studies resulted in a licentiate thesis (Blomkvist, 20II), which was based largely on the interview study conducted during the SERV and ICE projects. The aim was to find an answer to the question of how prototyping could be conducted in an area where the object of design is so different from that in other design disciplines. The original plan was to find suitable entrances into the issue of service prototyping using the interviews, and then enrich the image by studying the work, and complementing the verbal accounts with observational data. Very few examples of specifically tailored service prototyping approaches were identified however, and the original plan for the next step had to be changed. The interview data showed that I) the work was mainly focussed on the early stages of the design process (before prototyping) and 2) that there was very little evidence of specifically adapted service prototyping approaches.

Instead, the few examples of a more consciously adapted approach to prototyping services were explored by talking informally to, and in some cases interviewing, design practitioners. In addition, the few cases available online on the web sites of the consultancies were analysed. The main ingredients of the identified prototyping approach was then summarised, and cases could be set up where the approach could be tested. It looked like a technique utilising a step-wise walkthrough process was most appropriate. The context of these walkthroughs was the projects Food on demand, DFL, and PEMM. Also, the approach could be incorporated in teaching, leading to some initial exploration of how to successfully prototype services from different perspectives.

\subsection{Methods in the papers}

The papers have used different methods. The first paper was a literature study conducted to arrive at a visualised framework of prototyping perspectives. The second was a theoretical paper combining different sources of knowledge. For instance, it uses theories from distributed cognition, service design techniques from previous interview studies (Segelström, 20I3; Blomkvist, 20II), and the book This is Service Design Thinking (Stickdorn \& Schneider, 20Io), and finally, purposes for making externalisations in service design are collected from the same two interview studies (Segelström, 2013; Blomkvist, 20II). The third paper was a case study. The result of the case study was analysed using a qualitative content analysis. The fourth and final paper was also a case study where an evaluation technique was used to generate formative knowledge about a service prototype. The procedures are more closely described in connection with the papers in Chapter 8.

The aim of the case studies has not been to arrive at generalizable facts. The results are specific and related to the contexts of the studied cases, even when hypotheses were tested. This is a deliberate consequence of how the case studies have been conducted. The service 
design discipline is changing rapidly, and design is by nature context dependent, making qualitative and specific knowledge contributions useful. The results of the cases should be understood as consequences of where and how they were conducted.

As the below table (Table I) shows, mainly case studies have informed the doctoral studies. The data sources are presented in chronological order, starting in 20Io. Cases here should be seen as instances where design activities have been conducted in specific contexts. In the cases I have been directly involved in, my role is marked as direct. One such case was conducted together with the Swedish service design consultancy Transformator, in the waiting room of an emergency ward. I helped plan the project and evaluate the impact of the prototype. Another case where I was involved concerned the design of a meal-planning and food delivery service. This was done in the Food on Demand project where I planned the prototyping activities, and then participated in prototyping, and later in Food on Demand 2 I conducted interviews and observed a later version of a prototype, called Service pilot in the table. The pilot was also the case described in Paper 4, but I did not collect data in that part of the project.

In the service design courses many of the early insights about prototyping services have been tested and further developed together with students mainly from the cognitive science and design and product development programs. The first variants of the service walkthrough technique (see 6.3) were tested in this context. In the PEMM project I helped plan the service walkthroughs, and participate and conduct 6 of the I2 walkthroughs. These walkthroughs also used a similar approach as the one described in Paper 4 . The other cases were carried out before I got involved, and I have relied on interviews or documentation from those cases. In these cases I refer to my role as indirect.

TABLE 1 SUMMARISES THE DATA SOURCES THAT HAS INFORMED THE THESIS.

\begin{tabular}{lllll}
\hline Type & Topic & Context & Role & Publication(s) \\
\hline Interviews & Prototyping services & SERV and ICE 4 & Direct & (Blomkvist, 20II) \\
Case I & Service prototyping & SERV and ICE 5 & Direct & $\begin{array}{l}\text { (Blomkvist \& } \\
\text { Holmlid, 2OIIb) }\end{array}$ \\
Case 2 & Service walkthrough & Food on Demand ${ }^{6}$ I & Direct & $\begin{array}{l}\text { (Blomkvist, Åberg, } \\
\text { \& Holmlid, 20I2) }\end{array}$ \\
Case 3 & Service walkthrough & DFL $^{7}$ & Indirect & (Arvola et al., 20I2) \\
Case 4 & Prototyping & DFL $^{4}$ & Indirect &
\end{tabular}

\footnotetext{
4 http://www.ida.liu.se/ steho/research/servindex.en.shtml 5 http://www.vinnova.se/sv/Resultat/Projekt/Effekta/ICE---Tjansteinnovation-for-vard-och-halsa-i-vardagen/ 6 http://www.vinnova.se/sv/Resultat/Projekt/Effekta/Mat-vid-behov/

7 Datorförstärkta landskap: https://www.liu.se/ikk/ncu/vimmerby/forskningsprojekt?l=sv, funded by Nationellt centrum för utomhuspedagogik: https://www.liu.se/ikk/ncu/vimmerby?l=sv
} 


\begin{tabular}{|c|c|c|c|c|}
\hline Type & Topic & Context & Role & Publication(s) \\
\hline Case 5 & Service pilot & Food on Demand 2 & $\begin{array}{l}\text { Direct/ } \\
\text { Indirect }\end{array}$ & (Paper 4) \\
\hline Case 6 & Service walkthrough & Design consultancy & Indirect & $\begin{array}{l}\text { (Blomkvist \& Bode, } \\
\text { 20I2) }\end{array}$ \\
\hline Case 7 & Prototyping & Master project & Indirect & (Paper 3) \\
\hline Teaching & Prototyping services & $\begin{array}{l}\text { Service design } \\
\text { courses }\end{array}$ & $\begin{array}{l}\text { Direct/ } \\
\text { Indirect }\end{array}$ & \\
\hline Case 8 & Service walkthrough & PEMM $^{8}$ & Direct & \\
\hline Workshop & Service prototypes & $\mathrm{PDC}^{9}$ & Direct & $\begin{array}{l}\text { (Blomkvist et al., } \\
\text { 20I2) }\end{array}$ \\
\hline Interviews 2 & Service design roles & VISUAL $^{10}$ & Indirect & \\
\hline
\end{tabular}

The research was made possible by: grants from VINNOVA, the Swedish Governmental Agency for Innovation Systems; the projects SERV (2007-03444), Service design, innovation and involvement 2008 - 2009; ICE (2007-02892), Service innovation for health and care 2008 - 20II; FoD (2010-02683), Food on Demand 20II-20I2. Also, the projects VISUAL (2012-2016), funded by The Research Council of Norway through the programme Userdriven Research Based Innovation (BIA), and Datorförstärkta landskap (DFL) have contributed.

8 https://www.acreo.se/projects/printed-electronics-meet-mobile 9 Participatory design conference 20I2: http://pdc20I2.org/

Io The Research Council of Norway: http://www.forskningsradet.no/en/Home_page/II77315753906, BIA: http://www.forskningsradet.no/prognett-bia/Home_page/I226993636038 


\section{Prototypes and prototyping}

There is a distinct difference between prototypes (representations of design ideas) and the activity of using prototypes to extract knowledge about design ideas: prototyping. Prototypes are always representations, but all representations are not prototypes. Prototypes are aimed towards the future (Mogensen, 1994) in the sense that they suggest what the future could be like. As such they manifest ideas about futures that would otherwise be incorporeal. These futures are here referred to as future situations of service, as a paraphrase of Henrik Gedenryd's future situation of use (Gedenryd, I998). The future situation of service is the understanding of the situation, including the location, where a new or improved service will take place. Future situations of service will be further discussed in section 7.I.2. Depending on what the object of design is, prototypes will look different.

Prototypes are used in prototyping activities and can be more or less consistent representations, meaning that they either have a stable, static state or perish after the prototyping activities end. The definition of prototype used here is:

Any shared physical manifestation externalising an otherwise internal or unavailable vision of a future situation.

Prototyping, on the other hand, is an activity where a future situation is explored or evaluated. Prototyping can also be the activity of showing a prototype, to communicate with people that are involved in design activities or people that will somehow be affected by the outcome of design activities. Activities such as role-playing and enactments are considered prototyping, when the activities are conducted to explore or evaluate a future situation. The definition of prototyping used in the thesis is:

Prototyping is the use of prototypes to explore, evaluate or communicate in design. 
This chapter presents a broad view of prototyping, starting by looking at the activity of prototyping and some common assumptions about e.g. the reasons for prototyping. This will provide a foundation for the rest of the thesis and aid the understanding of the following discussions. Prototype fidelity and some commonly mentioned dimensions of prototypes are also introduced, before the view on prototyping that will be used in the thesis is introduced in 3.2. The distinction between explorative and evaluative prototyping follows and then a concluding discussion, in section 3.2.2, about understanding prototypes in service design as surrogate situations. This concept will also be important for the later chapters.

\subsection{Prototyping}

The use of prototypes is considered one of the cornerstones of a designerly approach to development in many areas. Some disciplines cannot do without prototyping; it is intimately interwoven into the practice and conduct. Prototyping has been of special interest in fields where the inclusion of external stakeholders has been important (Ehn \& Kyng, I992), such as usability, participatory design, and interaction design. Many reasons for why prototyping is important in design have been put forth, some of which will be restated here.

Without the use of prototypes and prototyping it might be difficult to understand the concept that is being developed (Brandt \& Messeter, 2004; Buchenau \& Fulton Suri, 2000; Bødker, Kensing, \& Simonsen, 2004; Greenbaum \& Kyng, I99I). The externalisation of ideas about future concepts is a way to make the ideas shareable and open to communication, both externally with clients or users (Bryan-Kinns \& Hamilton, 2002; Erickson, I995; Schrage, 2004; Kelley, 200I; Wagner, I990), and internally within the design team (Segelström, 2009). This makes involvement of different stakeholders in the development process possible (Brandt \& Grunnet, 200o). Prototypes manifest concepts, ideas or hunches about what good solutions might be. This is a way to show the concept and make sure that everyone that is involved has a chance to understand the concept. In the long run this can save time because it can decrease the amount of misunderstandings.

Prototyping also benefits the process by saving resources such as time and money. Prototypes can identify problems early to save money (McCurdy, et al., 2006; Brand Flu, 2013). The logic is that it costs less to fail when the concept has not been fully developed (Zelkowitz, I980). Moreover, if a proper exploration of the design space is not performed, much can potentially be lost because the design isn't the right one (Buxton, 2007). Of course, the process of developing a prototype is also a cost, but many believe that "[t]he cost of a model is more than compensated for by future savings" (Dreyfuss 2003 p. 62).

A sometimes overlooked benefit is the effect prototyping has on the participants. Gerber \& Carroll (2012) found that prototyping is a way to manage uncertainty, and that it "I. reframes failure as an opportunity for learning 2 . supports a sense of forward progress, and 3. 
strengthens beliefs about creative ability" (Gerber \& Carroll, 2012, p. 70). Prototypes also increase the feeling of security, by showing that ideas are realisable and feasible as proofs of concepts (Jégou \& Manzini, 2008; Parker \& Heapy, 2006). Using multiple prototypes in parallel can also increase confidence in design ideas and diversity between suggestions (Dow, et al., 2009).

The reasons for prototyping mentioned above can be summarised in three categories:

- Prototyping supports communication. Both internal and external communication.

- Prototyping saves resources. Mainly in terms of time and money.

- Prototyping affects the mind-set of the participants.

The first two benefits are mentioned in almost every article about prototyping. The communication benefit can be divided into internal, pointing to how prototypes help the design team understand ideas and collaborate, and external communication, where design suggestions are showed to clients or other stakeholders for feedback. In some disciplines and traditions this is common practice, and in other the evaluation is carried out by the designer(s).

The purpose of evaluation can be to suggest a future direction of the design process, called formative evaluation, or it can be to understand the performance of the current prototype, summative evaluation. However, prototyping is often about understanding the prototype, and how well the prototype performs, rather than focussing on the activity and behaviour that the prototype is testing. More specifically, many times prototypes are evaluated by considering the performance of the prototype in itself rather than asking if and how people want the benefit that the prototype provides or their intention to use e.g. a service in the future. Paper 4 presents a way to address this issue, by focussing evaluations on the intentions to use a service in the future.

\subsubsection{Prototype fidelity}

A common assumption in interaction design ${ }^{11}$ is that there is a relation between resolution/fidelity and the target audience of a prototype (Bryan-Kinns \& Hamilton, 2002; Erickson, I995; Holmquist, 2005; McCurdy et al., 2006; Rudd, Stern, \& Isensee, I996; Schrage, 2004; Schneider, I996; Wong, 1992). For the most part, the opinion is that fidelity gives more detailed feedback, and lower fidelity provides more general feedback. The exact meaning of fidelity has however been discussed extensively in software development. One of the most ambitious attempts to disambiguate and detach the different types of fidelity has

\footnotetext{
11 The term interaction design is used as an umbrella for disciplines working with software design and interaction in different ways. An examination of the referenced literature in this chapter (Chapter 3 ) shows the variety of sources.
} 
been made by McCurdy et al. (2006). They showed that fidelity is not one thing, but prototypes rather display levels of fidelity along different dimensions of the representation.

There are some contradicting views when it comes to fidelity. For instance, Virzi, Sokolov, \& Karis (I996) looked closer at the relationship between fidelity and the stage of development, concluding that low-fidelity prototypes can be useful throughout the development process. Buxton (2007) and have expressed similar sentiments. Rettig (1994) argued that low-fidelity prototypes not only increased the number of times you could refine your prototype, they also emphasised the role of usability and formative evaluations. Holmquist (2005) however, has suggested that to generate reliable information the representation must give a realistic impression. In addition, keeping a similar level of fidelity across the dimensions of a prototype has been proposed as a way to improve prototyping results (Bryan-Kinns \& Hamilton, 2002). This view is however contradicted by many researchers (Lim, Stolterman, \& Tenenberg, 2008; Beaudouin-Lafon \& Mackay, 2007; Houde \& Hill, 1997) which can be seen as a result of different understandings of the design material.

An appealing version of the relation between fidelity and audience has been proposed by Lim, Stolterman, \& Tenenberg (2008), saying that if the purpose is to frame or explore a design space with a prototype, then prototyping is about "finding the manifestation that in its simplest form, filters the qualities in which designers are interested, without distorting the understanding of the whole." (Lim, Stolterman, \& Tenenberg, 2008, p. 7:2). They referred to this as the fundamental prototyping principle, which is supported by a conceptualisation framework that they call the anatomy of prototypes. Part of the conceptualisation is an idea that dimensions of a prototype can be filtered (filter dimensions), so that other aspects do not interfere. Filters become manifested in the material used, the resolution, and the scope of the prototype. According to Lim, Stolterman, \& Tenenberg (2008), the choice of which aspect or dimension to filter should be coupled with the purpose of prototyping. For instance, a prototype can be designed to investigate the interactivity in terms of feedback behaviour. It should then be designed to filter out all other aspects that are not currently being considered. This is the economic principle of

prototyping: "the best prototype is one that, in the simplest and most efficient way, makes the possibilities and limitations of a design idea visible and measurable." (Lim, Stolterman, \& Tenenberg, 2008, p. 7:3).

\subsubsection{Dimensions of prototyping}

In software prototyping particularly, a permeating idea has been that certain characteristics or dimensions of prototypes are coupled together. Many suggestions for what the best way is to make possibilities and limitations visible have been put forth. In recent research Sellen et al., (2009), found significant interaction between the format of a prototype and the target audience. They used video and storyboard as representation techniques of a concept system, and the audience groups of young and old persons. Thus, rather than associating the results 
of prototyping directly with the system, the influence of the format of representation should also be considered.

Understanding the dimensions of prototypes is a way to make them more useful. Johansson \& Arvola (2007) conducted a case study and found that the prototype representation, the composition of the group, and the desired focus of the meeting each influenced each other. Gutierrez (I989) coupled specific problem types with the roles of the user, the specialist (e.g. engineers) and the technology. To be successful in prototyping, it has been suggested that e.g. the purpose and role must be explicit, otherwise it is difficult for participants to understand the performance of the prototype (Schneider, 1996; Holmquist, 2005; Houde \& Hill, I997; Lim, Stolterman, \& Tenenberg, 2008). Along the same lines, Bryan-Kinns \& Hamilton (2002) suggested a coupling between a prototype's fidelity, the target audience, and the stage of development. For instance, it will be difficult to test the prototype if the fidelity is too low at the end of development, or if the audience do not understand the intended use of the prototype.

\subsection{A broad view of prototyping}

Both prototype and prototyping are considered in very broad terms here to include all the possible interpretations in service design. One reason for using this broad definition is because it reflects the understanding of prototyping expressed by many service design practitioners:

"[f]or me a prototype can be anything - anything that helps you learn about the thing you want to test /./ Prototypes for us are anything that can be used to test a certain part of a new concept" - informant \#4 in (Blomkvist \& Holmlid, 20Io)

Prototypes can be anything from early drafts to very detailed representations intended for implementation of new designs. Because of the previously mentioned holistic approach in service design, many different types of representations can, and are, used (see e.g. Stickdorn \& Schneider (20I0)). In service design, prototypes range from sketches and wireframes to role-playing and envisioning exercises (Blomkvist \& Holmlid, 20IIc). This means that a prototype in service design is not only a thing, like a storyboard, a product, or a user interface; it can also be a meeting of people, or an assemblage as it has been called (Wilkie, 20I0). Hence, a prototype is any representation of a future situation.

This is why the definition of prototype includes 'any shared physical manifestation'. Sitting down on a meeting and talking about a future situation does not qualify as prototyping because there is no representation of the future situation. But having a meeting where people enact that same future situation is considered prototyping because the communication is facilitated and/or mediated by a representation, a prototype. Note that 
this definition also includes a sketch of a service or other future situation, as long as it is 'shared' with others for the purpose of prototyping.

Similar to other disciplines, service designers use prototyping to explore, evaluate, and communicate Blomkvist \& Holmlid (2010). Explorative prototyping includes the search for ideas and possible solutions using (predominantly) quick and rough prototypes. Explorative prototypes ${ }^{12}$ help suggest different potential futures. Evaluative prototyping, on the other hand, is used to understand how people experience the future that prototyping suggests. Evaluation can be formal or informal. Formal evaluation is used to test more or less explicit hypotheses or assumptions, while informal evaluation is more context-specific and less defined. When the purpose is to communicate, a prototype is built to show or present a solution to someone external, most likely a client. Prototypes used to communicate to external stakeholders are a special kind of prototyping that is outside of the scope of this thesis.

\subsubsection{Explorative and evaluative prototyping}

To some, the broad definition used here can be problematic, since it can include things like storyboards and sketches. Bill Buxton, for instance, has emphatically argued that a sketch is not a prototype (Buxton, 2007). The difference, according to Buxton, lies in the purpose.

Buxton argued that sketches are used to play, explore, learn and try to gain a deeper understanding in design. However, the purpose of prototypes was not explicitly mentioned by Buxton (2007). What seems to be the difference is at what time in a project - the position in the process - the techniques are used. Sketching occurs early and prototyping later in projects according to Buxton, but no clear boundary is defined. Instead differences are explained along a continuum of purposes or intentions behind the sketches or prototypes.

TABLE 2: SUGGESTED DIFFERENCES BETWEEN A

SKETCH AND A PROTOTYPE. (BUXTON, 2007, P. 140)

\begin{tabular}{lll}
\hline Sketch & & Prototype \\
\hline Evocative & $\rightarrow$ & Didactic \\
Suggest & $\rightarrow$ & Describe \\
Explore & $\rightarrow$ & Refine \\
Question & $\rightarrow$ & Answer \\
Propose & $\rightarrow$ & Test \\
Provoke & $\rightarrow$ & Resolve \\
Tentative & $\rightarrow$ & Specific \\
Noncommittal & $\rightarrow$ & Depiction \\
\hline
\end{tabular}

12 The term explorative prototypes was used as far back as 1984 , when Floyd summarised the findings from the Working Conference on Prototyping. Prototyping for exploration was described as situations where "the emphasis is on clarifying requirements and desirable features of the target system and where alternative possibilities for solutions are discussed" (Floyd, I984, p. 6). 
However, I argue that prototyping can be driven by either of the sketch or prototype motivations in Table 2. In fact, the table illustrates the differences between, and characteristics of, explorative and evaluative prototyping approaches. There are many examples of prototypes that fit the sketch description, such as work in critical design by Anthony Dunne, Fiona Raby, and William Gaver (Dunne \& Fiona , 2002; Dunne, I999; Gaver, Beaver, \& Benford, 2003). Their prototypes are designed to suggest, provoke, question, explore and so on, but they can hardly be thought of as sketches. The same goes for provotypes, initially termed by (Mogensen, 1994), that serve to challenge existing practices. In the case described by Boer (20II) a provotype was designed in the shape of a lamp and five boxes to make people experience and relate to, in new ways, the concept of indoor climate. Yet another example can be found in the playful triggers, used by (Akama et al., 2007; Rettig, 2007) that support both collaboration and create meaningful dialogue.

Conceptualising prototypes as learning vehicles (Floyd, I984; Coughlan, Fulton Suri, \& Canales, 2007), or as tools for knowledge creation (Lawson, I997) also indicates a broad understanding. Also, Kurvinen, Koskinen, \& Battarbee (2008) suggested that new domains of design mean that we must understand design in new ways. Put in their words a prototype "is not a piece of technology, constructed to see whether technology works, nor is it something that is 'tested' on humans. Instead, the prototype - or a series of prototypes - is a 'pair': there is a representation /./ and several people using it in /./ social situations." (Kurvinen, Koskinen, \& Battarbee, 2008, p. 49). Their research paper mainly focused on ways to extract ethnographic knowledge about social interactions, i.e. to use prototypes to question and propose, rather than answer or resolve.

The distinction made by Buxton (2007) between the right design, and getting the design right is also helpful in this context. The words listed under Sketch in Table 2 are related to the process of finding the right design (exploration), while the questions on the right side help designers get the design right (evaluation). A similar thought can be found in (Arvola \& Artman, 2007). They used five elements of design; I) concept, 2) function and content, 3) structure, 4)interaction, and 5) presentation, to make sense of expressions and enactments performed by designers. In their conceptualisation, the elements of concept, function and content, were associated with the what of the design. While structure, interaction, and presentation were associated with the how. However, there is no clear distinction between these types, as exploration is part of evaluation, and evaluation also leads to new ideas. Arvola \& Artman's (2007) elements of design are used in Paper 3.

\subsubsection{Prototypes as surrogate situations}

This thesis proposes a new way to think about services, which can be applied regardless of whether the purpose of prototyping is to explore or to evaluate. This way of thinking is 
more in line with the broad view presented in the previous section, and it has been inspired by Andy Clark's idea of a surrogate situation (Clark, 2005; 20I0). "By surrogate situation I mean any kind of real-world structure that is used to stand in for, or take the place of, some aspect of a certain 'target situation"' (Clark, 2010, p. 24). These situations are constructed when the actual thing we are investigating or trying to understand is not physically present or accessible. One can think of a prototype as the surrogate for a future service. The situated cognition perspective says that cognitive activities, such as thinking and acting, depend on what is represented of the future situation of service ${ }^{13}$.

Clark has connected the concept of surrogate situations to design by reference to Gedenryd (1998). Here, Gedenryd, based on his examination of several diverse design cases, details many different uses of surrogate situations, such as "sketches, prototypes, thumbnails, storyboards, and scenarios, to name but a few. What these all have in common, of course, is that they allow human reason to be disengaged (to reach out to that which is absent or distant or otherwise unavailable) while at the same time providing a concrete arena in which to deploy perceptuo-motor routines of a fundamentally world-engaging kind" (Clark, 2005, p. 236). This will be a useful metaphor for thinking about prototyping as it is described in this thesis.

A surrogate has properties that allow you to better understand another situation, or to relieve cognitive resources that are occupied in "real" situations (Clark, 2005). An advantage of the surrogate situation then, is that the normal constraints on e.g. time can be put aside. Events in real life unfold continuously and unhindered, but by using a surrogate it is possible to slow, or even stop time and rewind events to explore them more thoroughly. The point is that the surrogate is not a real situation, and you are in control of what the surrogate represents and the events that unfold.

When a prototype is used, a temporary, liminal state (Dyrssen, 20Io), occurs. In this state, designers try to understand what the surrogate situation means for the future situation of service. The surrogate is located in the real world, but in a liminal state. Calling it a liminal state emphasises that this is a space where the surrogate can be tested and experimented with. In the liminal state, the temporal constraints of the real world are thus relaxed, and the surrogate can be tested without regarding actual time limits (Clark, 2010). For instance, if you are prototyping the check-in process at an airport by simulating all the interactions that take place, you can stop the simulation after each interaction (or touchpoint) to evaluate or comment. You can also divide the simulation into parts and run a much slower version, with time to prepare the next part in between.

To summarise this chapter, prototypes and prototyping can facilitate communication, save resources and influence the mind-set in a design process. To be useful, different dimensions

\footnotetext{
${ }^{13}$ Clark (2005) used the term normal situation for what is called the future situation of service in the thesis.
} 
of prototypes, and how they influence each other, need to be understood. One dimension that is often discussed is the fidelity of prototypes. How this relates to service prototyping, and the conceptualisation used in this thesis, will be discussed in section 7.I.3, as well as in Paper I. Prototypes have been described as representations of otherwise internal or unavailable ideas of what the future should or could look like. These representations are considered as surrogate situations that allow designers to break off a piece of a situation and examine it in a controlled way. The next chapter will introduce representations from a situated cognition perspective, and show examples of how they are said to support cognition. 



\section{Representations}

This chapter delves deeper into the issue of what representations are and why they are important in design. The first Chapter 4.I, is about cognitive science, which ends with an introduction of situated cognition that grew out of cognitive science. After discussing the related concepts of embodied and distributed cognition, the next Chapter 4.2, focuses on describing what representations can be.

\subsection{Situated cognition and cognitive science}

The story of cognitive science can be introduced by a short and severely over-simplified story about action and reaction. Much research in the end of the $19^{\text {th }}$ and beginning of the $2 \mathrm{O}^{\text {th }}$ centuries in psychology and philosophy was conducted through introspection. As a reaction, behaviourism disregarded any processes within the heads of individuals and focussed on observable and measurable behaviours for their studies. Behaviourism influenced a lot of other disciplines as well, but cognitive science took shape in the early I950s, partly as a reaction to behaviourism ${ }^{14}$. The reasons were many, but one was the advances being made in the new discipline of artificial intelligence, where aspects of human cognition could be modelled. This research put emphasis on knowledge, and processes operating on that knowledge, within the heads of humans. A typical area of interest was problem solving and what knowledge and operations that needed to be virtually represented to solve problems. For instance, how could the knowledge of chess and its' allowed moves be represented by a machine in a way that simulated human cognition well enough to challenge human players?

\footnotetext{
${ }^{14}$ This is mainly a North American view on the events leading up to cognitive science.
} 
The focus on the mind and cognition and on what went on internally spurred another reaction. This was due, in part, to the observation that cognitive tasks, such as problem solving, were not performed the same way by humans and problem solving machines. While humans were better at real-world, or ill-defined problems, computers were soon beating humans in well-defined problems where computers could represent whole problems simultaneously and quickly find the correct solutions. For well-defined problems, more knowledge made the machines better and more accurate, while the performance of humans showed the opposite effect due to e.g. limitations of human memory capacity.

Machines represent problems internally, and solve them internally by symbol-manipulation. As humans, it seems like we rely on the external world to offload memory load; a glance at the chessboard informs us about the current situation. This prompted scholars to investigate the influence of external representations on cognition in different ways, e.g. so called distributed cognitive tasks, on problem solving (Zhang \& Norman, I994) and "the cognitive processing involved when interacting with graphical representations, the properties of the internal and external structures and the cognitive benefits of different graphical representations." (Scaife \& Rogers, I996, p. I88).

Up until the early I990s, the definition of cognition was processing of information in the head (Bechtel, Abrahamsen, \& Graham, 1999). However, the importance of external representations for the ability to solve cognitive tasks was becoming more and more prevalent in the late I980s and early I990s. This prompted a need to understand the role of the interplay between internal and external representations in cognitive tasks (Scaife \& Rogers, I996), and in cognition in general. "A fundamental problem for cognitive modellers is to interleave internal and external states in order to achieve naturalistic behaviour" (Vera \& Simon, 1993, p. I2). This made scholars reconsider their view of cognition as located (exclusively or predominantly) within the brain, and some argued that external representations should be given "a more central functional role in relation to internal cognitive mechanisms.” (Scaife \& Rogers, I996, p. I88).

An early proponent of this perspective was Jean Lave. In I988, Lave wrote from a cognitive anthropology perspective, that cognition "in everyday practice is distributed - stretched over, not divided among - mind, body, activity and culturally organized settings (which include other actors)." (Lave, I988, p. I). This view of cognition was proposed under a number of different names, e.g. situated action (Suchman, 1987), external cognition (Scaife \& Rogers, I996), situativity theory (Greeno \& Moore, I993), distributed cognition (Rogers \& Ellis, I994; Holland, Hutchins, \& Kirsh, 2000), and extended mind (Clark \& Chalmers, I998). As research from a situated and distributed perspective accumulated, it led to some controversy in the field (Vera \& Simon, I993). This controversy was caricatured by Donald Norman: 
"The proponents of situated action - at least in caricature - tend to emphasize the importance of historical influences, social interaction, culture, and the environment, and to minimize the importance of internal cognition. Proponents of the traditional symbolic approach - at least in caricature - tend to downplay the importance of these external, social, and historical factors, and to emphasize the importance of internal cognition. Each group, however, raises the hackles of the other: 'Behaviorist,' cries the symbolic proponent, 'you think that everything is controlled by the environment, independent of internal processing.' 'Disembodied intelligence' cry the situated action folks, 'you tend to have a person lost in thought, planning all future actions regardless of the fact that the situations in the world will change faster than thought can keep up, so your approach is idealistic, overly simple, and doomed to failure'." (Norman, I993, p. 3)

\subsubsection{Situated perspectives on cognition}

Situated cognition will be used as an umbrella term here, including the distributed and embodied perspective on cognition. This approach is similar to Robbins \& Aydede (2009), who included an embodied, embedded, and extended perspective in their description of situated cognition. The embodied perspective adds a body to the mind. It is the body that perceives and acts, and researchers have imagined various degrees of interaction from the mind to the body and vice versa. The role of the body in cognition is highlighted briefly in the next section, and the view on how the body matters in cognition with relevance for design is also discussed.

The embedded perspective places the mind in a context. Robbins \& Aydede (2009), provide numerous examples of how this process can be observed. For instance, Kirsh \& Maglio (I994) described the concept of epistemic actions. These are actions that influence the world so that the new state, which could also have been calculated mentally, reveals a solution. Kirsh \& Maglio (I994) used the video game Tetris to illustrate how expert users, when they were short on time, moved the pieces physically to calculate distances rather than solving the task in the head and then executing the solution. This is also where distributed cognition enters the picture. This perspective will be discussed further below.

The extended perspective finally, moves cognition out in the world. According to Robbins \& Aydede (2009), this view is the hardest to reconcile with "traditional" cognitive science. However, Clark \& Chalmers (I998) claims that there is no difference e.g. between using a notebook to remember and using the mind to remember the same information. Also Wilson (2002) considers cognition as part of a cognitive system (see also 4.I.2).

The root of situated cognition can be traced to systems thinking which permeated a diverse group of fields such as philosophy, artificial intelligence, pedagogy, and sociology. Situated cognition has philosophical heritages from e.g. American pragmatism and constructivism (Clancey, 2008). It is difficult to accurately pinpoint what situated cognition means. 
However, (Clancey, 2008) has provided an appealing characterisation that fits well with how cognition is understood in this thesis:

"As stated, an all-encompassing generalization is the perspective of complex systems. From an investigative standpoint, the one essential theoretical move is contextualization (perhaps stated as 'antilocalization,' in terms of what must be rooted out): we cannot locate meaning in the text, life in the cell, the person in the body, knowledge in the brain, a memory in a neuron. Rather, these are all active, dynamic processes, existing only in interactive behaviors of cultural, social, biological, and physical environment systems.” (Clancey, 2008, p. 33).

Edwin Hutchins proposed the theory of distributed cognition (Hutchins, I990; 1995), with the idea that the environment (physical, cultural and social) is essential for thinking and acting. Hutchins' cognitive ethnography showed how the navigation of a ship can be seen as a cognitively distributed task (Hutchins, I995). In this view, cognition is carried out in systems, consisting of humans and artefacts, and distributed across time and space.

Hutchins (1995) saw that no single element of the system, consisting of the people and the artefacts on the bridge of a ship, had all the knowledge concerning ship navigation. Hutchins suggested that what made the task possible was the coordination of the states of the system, over which cognition was distributed.

Andy Clark and David Chalmers (1998) introduced the extended mind theory, emphasising the role of the environment as a driver (and co-location) for (some) cognitive processes. While similar to distributed cognition, extended mind theory differs in two essential assumptions; I) that there are different kinds of thinking - thinking without the environment and thinking with the environment, and 2) that there is a border between the mind and the environment that cognition can extend across ${ }^{15}$. Both distributed cognition and extended mind emphasise the role of the external world for thinking, but in distributed cognition, the role of the external world can be seen as a necessary condition for thinking. In extended mind theory however, the internal processes can temporarily extend out into the world. This distinction is not pivotal for the thesis, and support from both research areas will be used, since they both emphasise, and provide examples of, the role of external representations for cognition.

\subsubsection{Embodied cognition}

Embodied cognition emphasises the role of the body in thinking, by arguing that the primary function of the brain is not to calculate, but to control and coordinate the body. Our bodies are used to relate to situations and the fact that we have bodies significantly influence how and what we think. An example is using our fingers to count. A process described like this: "the function of these sensorimotor resources is to run a simulation of

\footnotetext{
${ }^{15}$ This is only part of the story. For a more in-depth comparison, see (Hutchins, 2013; I995; Clark, I999).
} 
some aspect of the physical world, as a means of representing information or drawing inferences." (Wilson, 2002, p. 633).

Wilson (2002) puts embodied cognition at the core of a distributed and situated perspective. Hence, his characterisation encompasses arguments for both situated and distributed cognition. He has described the basic assumptions of embodied cognition like this:

- cognition is situated

- cognition is time-pressured

- we off-load cognitive work onto the environment

- the environment is part of the cognitive system

- cognition is for action

- off-line cognition is body based

Wilson (2002) critically discussed the claims and the existing evidence for each argument. The last claim, off-line cognition is body based, is based purely on an embodied view of cognition and relates to the ability to use our bodies to solve tasks that are unrelated to the actual properties of the task, i.e. we use our bodies not only to reach specific goals in the physical environment, but also to aid in other, more reflective tasks. There is evidence that sensorimotor simulations are involved in manipulating mental imagery, working memory, episodic and implicit memory, and in reasoning and problem-solving (Wilson, 2002).

An example of such a process is marking, a practice used by dancers to represent a stance or move by using body gestures (Kirsh, 20IOb). This practice is described by Kirsh (20IOb) as a way to augment cognition. The hand gesture scaffolds mental projection and allows for a more detailed understanding than would otherwise be possible to achieve using only internal simulation. Some gestures are taught in dance schools as appropriate for specific dance moves, while others are indicative of specific aspects (such as tempo, sequence, or spatial position) and improvised ways of marking (Kirsh, 20Iob).

A similar pattern can be seen in downhill skiers who memorise and rehearse the way down to the finish line. Instead of relying solely on internal rehearsal of the way down, skiers mover their bodies, and sometimes their hands as they go down the hill in their minds. This can be interpreted as the skiers using their bodies as anchors for thinking and memorising.

The idea that engaging the body can simplify, or support, mental processes underlies a movement towards more tactile user interfaces (Antle, Droumeva, \& Ha, 2009), where engaging with artefacts in new ways is believed to make e.g. abstract concepts more accessible. This is important for design, since it means that there is a distinct difference between e.g. seeing a representation of something and physically engaging with it. The body can also be viewed as a link between the outer world and the mental world. This view claims that the body allows us to ground concepts from the world by adding perceptive links to 
them (Robbins \& Aydede, 2009). This implicates an important role of the body also in acquiring knowledge and learning, which are important aspects of prototyping where the aim is to learn about the future situation.

\subsection{What is a representation?}

If cognition is situated, then the physical environment plays an important role for the ability to think. From the previous sections, it should be clear that this thesis argues that all humans, more or less consciously, use the external environment, informed by the body, to think and act. However, the concept of representation and how it is used in the thesis will need to be clarified. Billman (I999) has argued that there are at least five realms of representation;

- external, representations in the world such as maps, models, writing,

- mental, internal representations of knowledge used in cognitive processes such as reasoning, perception, language, problem solving and so on,

- computational, representations used by a computer to perform similar tasks as mental representations,

- theoretical, abstract models representing a theory of something, and

- physiological, areas of the brain where things are materially represented.

The two most interesting types for this thesis are external and mental (or internal) representations. One type resides in the external world; external representations, and the other is located in the mind of individuals; internal representations. In cognitive science, the focus has long been on internal representations, since much research was aimed at understanding what goes on in the mind. For instance, how are visual stimuli represented in the brain, are there innate representations that aid in language acquisition and if so, what are they, how can we represent objects in the memory and processing of computers, how is knowledge about logic represented in the mind, etcetera, are questions that cognitive scientists have grappled with.

These questions relate to how external entities can be transferred (or grounded) into the brain of individuals. For this thesis, it is interesting to also consider this relation, and to look at transitions from ideas inside the head to representations in the world. This is a central concern for using situated cognition to explore design work. In this thesis, when nothing else is mentioned, a representation or externalisation is an external representation.

The distinction between internal and external representations is important. Internal representations are different from their counterparts in the world. When you see something in the real world (or a virtual object), your internal representation of it has properties, and offer different actions, than the object in the world. For instance, our "mental representation of some event does not contain the same information as did the event itself." 
(Billman, I999, p. 650). Similarly, two people observing the same object will perceive it differently and use their knowledge, their understanding of the cultural role of the object, their memories of previous similar objects and how they were used, to create an interconnected understanding of the object.

A prototype is a type of representation that is directed towards the future. What prototypes generally represent are ideas about future situations. The perception of prototypes will be influenced by who perceives it, and the activity surrounding the prototype will influence the type of knowledge that can be generated by a prototype. The often mentioned benefit of coordinating ideas or visions using prototypes is a result of externalising otherwise internal representations, located within the heads of individual designers, and making them shareable. The knowledge this externalisation of internal ideas and visions can generate, depending on the type of representation that is used, will be discussed further in the following chapters. 



\section{Service from a design perspective}

There are many ways to conceptualise service. One aspect of trying to pin down the meaning of service is to focus on the different kinds of services that exist. Such attempts to categorise services have been made within the service marketing and management fields (Cowell, I980; Lovelock, I983; Patterson \& Cicic, I995; Hipp \& Grupp, 2005). This chapter takes a slightly different approach to understanding what a service is, by looking at the constituent parts of services. This approach: considering what the constituent parts of service are, is a way to understand what can and should be designed and represented in prototyping. To do so, the discussion takes a detour through a recent and on-going paradigm shift in service research towards a service logic. The chapter than continues by discussing the difference between design of (static "things") and designing for (interaction). Examples of what, more specifically, it is that can be designed in services is also provided by discussing service as a design material. A distinction is made between the concept, process, and system of services.

\subsection{Service logic}

In recent years there has been a turn from what has been called the IHIP conceptualisation of services, towards what will be referred to here as a service logic ${ }^{16}$. IHIP stands for what was considered the defining characteristics of service: Intangibility, Heterogeneity, Inseparability and Perishability (Lovelock \& Gummesson, 2004). Underlying this characterisation is an assumption that services are what products are not. The intangibility

\footnotetext{
I6 Service logic is mainly associated with Grönroos (2006, 2008). A similar logic is used by Vargo \& Lusch (2004; 2008) under the name Service-dominant logic. A third example of similar thoughts is represented by Heinonen et al. (20I0) using the name Customer-dominant logic. The term service logic is used as a way to describe the shared sentiments of all these movements. The discussion will use mainly Vargo \& Lusch (2004; 2008) to exemplify the core ideas. The other authors' conceptualisations partially overlap with this view.
} 
characteristic is central to the difference between products and services, and the other characteristics are all related to- or a result of, the intangibility characteristic. While manufacturing focuses on the creation of tangible products, services were seen as intangible add-ons to products. Heterogeneity, or perhaps a better word is variability (Lovelock \& Gummesson, 2004), refers to the vast differences in the way services are delivered depending on the individuals that partake (e.g. front-line staff, customers), the physical location, the weather, and other factors. In comparison, products and their manufacturing process can be standardised and all products given the same appearance and quality.

Inseparability of production and consumption of services was also a commonly mentioned characteristic, following the idea that services are produced and consumed at the same time when a customer interacts with a service provider. Unlike products, services were also considered perishable in the sense that services cannot be put on a shelf and stored, resold or returned. This focus on the dichotomy of products and services was pointed out as unproductive already in 1977 (Solomon et al., 1985), but still remained as the dominating logic for many years.

A service-dominant logic was suggested and described by Vargo \& Lusch (2004; 2008) as an alternative to the prevailing goods-dominant logic. Using a service logic put less focus on the differences between products and services and more on value creating activities, regardless of whether they are mediated by products or not. Edvardsson, Gustafsson, \& Roos (2005) summarised the new perspective on service like this: "it is suggested that service is a perspective on value creation and that value creation is best understood from the lens of the customer based on value in use" (ibid., p. I07). Vargo \& Lusch (2004) suggested 8 foundational premises of service logic. These were later updated and two additional premises were added (Vargo \& Lusch, 2008). The complete list of premises reads as follows:

- FPr: Service is the fundamental basis of exchange

- FP2: Indirect exchange masks the fundamental basis of exchange

- FP3: Goods are a distribution mechanism for service provision

- FP4: Operant resources are the fundamental source of competitive advantage

- FP5: All economies are service economies

- FP6: The customer is always a cocreator of value

- FP7: The enterprise cannot deliver value, but only offer value propositions

- FP8: A service-centered view is inherently customer oriented and relational

- FP9: All social and economic actors are resource integrators

- FPıo: Value is always uniquely and phenomenologically determined by the beneficiary

The first and fifth premises establish why it is called a service-dominant logic, and FP3 further explains why the product/service dichotomy is less interesting from this perspective. Products serve the purpose of providing or 'distributing' value for customers. FP6 and 7 says 
that value is co-created, meaning that it emerges from the interactions between a customer and the resources that an organisation provide. The value of such interactions is decided by the beneficiary, according to FPIo, and this means that most times the customer decides the value (FP8). The resources in a company that are active (often the human employees) are considered the fundamental resources ( $\left.\mathrm{FP}_{4}\right)$. Finally, the premise saying that social and economic actors integrate resources (FP9) means that organisations, or individuals within them, use knowledge and other resources to meet the demand of service.

The service logic can influence how service is understood as a design material, and affects the discussion about what is represented in service prototypes. A goods-dominant view means that services are what products are not. The design material is then the processes that can be added to products, or processes without products. A service logic is more inclusive and expands the understanding of service as a design material. However, a point is made here, that there is also a limit to how far the service logic can be applied or directly transferred to service design.

New perspectives, such as service logic and service design, are always contrasted with existing perspectives and paradigms. Sometimes these contrasts can lead to overly emphatic generalisations about the existing or old perspective. In the case of service logic, the denial of the existence of a dichotomy between products and services can be seen as one such overambitious polarisation ${ }^{17}$. Using a service logic, value is the result of interactions, which is the basis for all business. The view that service is the basis for all business deemphasises the difference between tangible and intangible resources in a service. At least from a design perspective it is not necessarily helpful to consider tangible and intangible resources as the same, because from a design perspective they must be approached in different ways. The different approaches to design can be thought of as designing of and designing for.

\subsubsection{Designing of and for}

There is an ongoing discussion about the words of and for in service design. At the surface, this discussion is about whether it is possible to design a service (design of service), or if it is the preconditions for service that is designed (design for service) (Kimbell, 2oII; Sangiorgi, 20I2; Wetter-Edman, 20I4). Underlying the surface of the discussion is the intention to push service design in the direction of service (dominant) logic (Segelström, 2013). Combining service logic and service design has also been identified as a research trend in service design (Blomkvist, Holmlid, \& Segelström, 20Iob).

The idea of focussing on the value that emerges in interaction is easily combined with current thinking in some design disciplines. In interaction design e.g. Dan Saffer (2007) has released a book called designing for interaction, thereby implying that interaction designers

I7 A middle ground was suggested in 1977 by Shostack (1977), saying that services and goods can be either tangible or intangible-dominant. 
design for the possibility of interaction between people, or between people and interfaces. The actual interaction is unique and happens in those exchanges. Similarly, the concept of use qualities (Ehn \& Löwgren, I997; Holmlid, 2002; Arvola, 2005; Arvola, 2010; Löwgren \& Stolterman, 2004), means that what is important in interaction design is understanding the qualities people experience in use. Use qualities as a theoretical stance thus contains elements of service logic where qualities can be thought of as value.

However, the push towards integrating service logic in design has so far had very little practical implications for how to design services or how to approach service as a design material. The problem is that service logic does not provide any hints about how to design services, or more importantly in context of this thesis, what to represent during the design of services. The discussion in this chapter will instead focus on the distinction between designing tangible and intangible aspects of services.

The discussion starts with the simple statement that service design is concerned with the design of tangible "things" and design for service processes (the intangible aspects). However, as the following discussions in this chapter will show, the different constituents and perspectives used in service design complicate this basic assumption. An example is Polaine, Løvlie, \& Reason (2013) who, from a design perspective, have described the difference of working with products and services like this: "services are entirely different animals than products. Applying the same mindset to designing a service as to the design of a product can lead to customer-hostile rather than user-friendly results." (Polaine, Løvlie, \& Reason, 20I3, p. I9). Hence, regardless of whether the material is intangible or tangible, service design needs a specific approach, and to be able to work with a material designers need to know what the material consists of. "To make /./ cognition work well, the designer has to create her own working materials; before the world can become a part of cognition, the designer has to create it" (Gedenryd, I998, p. 157).

\subsection{Service as a design material}

The introduction of a service logic ${ }^{18}$ meant that scholars in the management and marketing fields needed to shift their understanding of service, as well as reconsider some of the research conducted within the fields. Gummesson, Lusch, \& Vargo (20I0) suggested implications for research, education, and practice within the management field. They proposed that the main questions that needed to be answered for the transition was: "How much of the heritage should be carried forward and how much should be left behind? How fast should it move? How quickly can it inform practice?" (ibid., pI3). Similar questions can be asked about the transition from traditional design disciplines to service design, or how to incorporate service design into existing fields (see e.g. Forlizzi \& Zimmerman (2013)).

\footnotetext{
${ }^{18}$ This move to a service logic was supported by various theoretical developments over many years. Some notable examples include Grönroos (2006; 2008) and Heinonen et al. (2010).
} 
The issue of how to approach service as a design material has not been a priority in service design research, but an attempt to unfold the issue has been made by (Secomandi \& Snelders, 20II), who conducted an overview of research concerning the constituent parts of services. The most notable aspect of service, according to the overview, is the exchange relations between mainly the service providers and the customers. Secomandi \& Snelders (20II) also identified a distinction between the interface; resources supporting exchanges between stakeholders, and infrastructure; consisting of resources that are not immediately present during the exchanges. Secomandi \& Snelders (20II) discussed the content and nature of the service interface extensively, describing it as I) highly material, 2) highly heterogenic, and 3) that the interface actualises the interactivity of services. Hence, the intangible aspects of a service are the result of designing the (tangible) interface. They claimed that "the design of the service interface, perhaps more than anything else, is the design of the service itself"(Secomandi \& Snelders, 20II, p. 33). The view expressed by Secomandi \& Snelders (20II) places the available resources, for customers to interact with, at the centre of service design.

Another and similar conceptualisation of service, has been provided by Edvardsson \& Olsson (I996). Edvardsson \& Olsson (I996) divided the concept of service into customer outcome, customer process, and prerequisites of the service. The customer outcome is the value of the interaction between a customer and a service provider. The customer process is the way the service actually plays out for customers: the process of co-producing the service using the available resources. The service prerequisites are the resources available for the customer processes. Hence, much in line with a service logic, the service provider does not actually provide the service: the service provider provides the prerequisites for a service to take place, or the value propositions. According to Edvardsson \& Olsson (1996), what is designed is thus the service prerequisites. They further explain that the constituent parts of the prerequisites are the service concept, service process, and service system.

The service concept (Goldstein et al., 2002; Edvardsson \& Olsson, I996) is an abstract version of the service, including the customer's needs and how they are met by the service. Goldstein et al. (2002) suggested that the service concept has been overlooked by service research. In their view, the service concept is the service in the mind of the customer: what a customer remembers or thinks about when talking about a service. According to Edvardsson \& Olsson (I996): "[t]he service concept specifies the domain of needs with respect to extent and nature (=both primary and secondary customer needs) and the service offer (=both core service and supporting services) to meet this domain" (Edvardsson \& Olsson, I996, p. I49). From a design perspective it is helpful to think about the service concept as a design idea that concern what the service is, what it does for someone, and what the benefits are. As such, the service concept does not specify what the processes are or what the service consists of. This is specified in the service process, and the service system. The process can be 
approached with more of a designing for mind-set, while the system can be seen more as designing of.

\subsubsection{Designing for}

The service process is the idealised version of the service: the way the customer is intended to interact with the service provider. Unlike the customer process, this is a description of what should take place in the service while the customer process is what actually happens, which cannot be designed beforehand. The service process specifies how the interaction with the customers is supposed to work and how the exchange is meant to play out. A bit broader view was presented by Gallouj \& Weinstein (1997), they suggested that this is the 'what' of the service, such as "interface, interaction, co-production, 'servuction', socially regulated service relationship, service relationship” (Gallouj \& Weinstein, I997, p. 54I). The service process should be designed to achieve the correct 'outputs' from the service interactions (Edvardsson \& Olsson, I996). The outputs are in turn defined by the service concept, which guides the development of processes. Sub-processes then define the actual events, and by extension the individual actions of the participants in the service.

With more focus on the interactions between customers and service providers, and less on the infrastructure, the approach suggested by Secomandi \& Snelders (20II) can also be characterised as designing for service. Secomandi \& Snelders (20II) argued for a material heterogeneity of the interface, and suggested that service evidence (introduced by Shostack (I977)) comes closest to their view of what the service material is. Service evidence has been described by Shostack as consisting of objects that "play the critical role of verifying either the existence or the completion of a service" (Shostack, I982, p. 5I), and Shostack also distinguished such service-related objects from other objects in services: "A true product element, of course, never requires evidence. It is its own evidence.” (ibid.). Shostack (I982) proposed two types of evidence: peripheral and essential. Peripheral evidence is either something that confirms a purchase, e.g. a hotel voucher, or it represents a service that you are using, like a membership magazine. Essential evidence cannot be possessed by (what was then called) the consumer, but they are imperative for the delivery of a service. Going to the movies for instance, requires a movie theatre but is not the purpose of the purchase. To Shostack (1982), managing service evidence, meant to control and design all objects, people and service location included, that a customer encounters in a service.

If the interface consists of the resources that support exchanges between stakeholders, the design of the interface is inevitably the design of touchpoints. Using the term interface also emphasises the material aspects of touchpoints. A touchpoint is described as the contact point between customers and organisations (Saffer, 2007; Clatworthy, 20II; Secomandi \& Snelders, 20II). A related term in service research is service encounter (Bitner, Booms, \& Tetreault, I990; Bitner, I990; Solomon et al., I985), which is another way to understand the service interface. The service enconters are the moments when a customer interacts with a 
service provider. Many times "those discrete encounters are the service from the customer's point of view" (Bitner, I990, p. 69). From a design practice perspective, touchpoints have been called "the places and spaces where people experience services" (Parker \& Heapy, 2006, p. 26).

Many touchpoints together form a journey through the interface, i.e. a customer journey (Parker \& Heapy, 2006). The touchpoint focus is convenient for many designers, since this is where the existing design tools and techniques are helpful, for e.g. visualising and modelling the material aspects of touchpoints. The journey metaphor is one of the most important theoretical concepts in service design, since it offers a way to describe and summarise services. A customer journey is both a metaphor for how a customer navigates the touchpoints of a services, and a service design technique. As a technique, the customer journey (or customer journey map) is generally a description from the customer's point of view that specify the service process, and it describes services as interaction between customers and service providers.

Designing touchpoints can include the design of: channels, objects, processes, and people (Koivisto, 2009), meaning that this is what a designing for-approach can consist of.

Channels are the locations or environments where services take place (see servicescapes below). Parker \& Heapy (2006) have referred to this as the forgotten touchpoint, and stressed that the environments need to be seen as architectures (as opposed to architechture); "the complex and dynamic arrangements of objects, dialogues, information, content, processes and navigation" (Parker \& Heapy, 2006, p. 30). Objects roughly correspond to service evidence, but more limited to things and excluding environments. Processes and procedures are essentially scripts for the delivery of the service. People include roles and responsibilities, and can concern the "social skills, the way of dressing and the manner of speaking" (Koivisto, 2009, p. I48). This description is partially overlapping with the focus of a designing of-approach can look like.

\subsubsection{Designing of}

For the service processes to take place in a service, a certain infrastructure needs to be available. This is the service system. Edvardsson \& Olsson (I996) described the service system as a resource structure "made up of the service company's staff, the customers, the physical/technical environment and organisation and control" (Edvardsson \& Olsson, I996, p. I5I). Edvardsson \& Olsson (I996) even talk about how these elements of the service should be developed. The company's (front-line) employees are important because they impact the perception of the quality of the service to a large extent. In service development, the roles and actions of the staff cannot simply be designed and scripted, we "must also understand how individuals and groups of staff can be encouraged to work in the best manner. We must take their special needs, demands and wishes into account - not just 
those of the customers" (Edvardsson \& Olsson, I996, p. 15I). Knowledge and experience is important, but also the motivation and enjoyment of work influence service interactions.

Customers are also part of the service system, and they must be understood in order to design services. The knowledge and equipment used by the customer can influence the system. Managing the relation with the customer through service marketing is part of designing the system. This is also the way to manage the expectations of customers. Customers should be seen as active co-producers of the service. This means that the service provider must manage "firstly, interaction between customers, e.g. a queue system when the service is overloaded; secondly, the customer's relationship whit the company's organisation as regards routines; thirdly, the interaction between customers and staff; and fourthly, the interaction with the physical/technical environment" (Edvardsson \& Olsson, 1996, p. 152). The physical and technical environment includes things like technological systems and locations. Technology should be seen as a means to an end (see the previous discussion on use-qualities and values in 5.I.I). Development of a new service can include changes to technical and physical elements, but it can also be designed to fit in the organisation, the staff, ways of working in the company, and so on.

In terms of organisation and control there are four aspects to consider (Edvardsson \& Olsson, 1996). The first one is the organisational structure which defines authority and responsibility of different parts of the service providing organisation. The organisational structure should be organised to be centred on the customers. The second one concerns administrative support systems that control e.g. the planning, finance, and wage systems. The third one includes stakeholder dialogues and defines how feedback can be given, complaints handling and ways to respond to customer dissatisfaction, i.e. the channels and how they are communicated, and the possible responses. The fourth aspect includes marketing activities, which is aimed at understanding the customers, create expectations, and 'teach' customers how they can co-produce the service. This has to be done in accordance with the internal potential to meet customer needs (Edvardsson \& Olsson, I996). This account of the content and development of services is appealing, and easily adaptable by a design approach. Also, in addition to the process/interface and system/infrastructure it adds the development of the service concept: the wholeness of the services seen from a topdown perspective.

\subsubsection{Servicescapes - physical and technical environment}

A way of expanding the concept of physical and technical environment is to look at the concept of servicescapes (Bitner, 1992). According to Bitner (1992), the servicescape is the built environment where a service takes place, which influences the behaviours of both customers and employees. Service environments range from very simple, called lean, to very complex, called elaborate, depending on the number of elements, spaces and forms (Bitner, I992). The dimensions suggested as comprising the service environment are: 
- the ambient conditions: generally those things in a service that can be perceived with the five senses, such as weather, lighting, smells, music and so on,

- spatial layout and function: the arrangement of the things that are needed for the service to be produced such as furniture, machines, equipment and their interrelations, and the

- signs, symbols and artefacts: cues (or signifiers) in the service such as signage, and the messages conveyed by explicit symbols or the design of artefacts.

Hence, in service design there are a large number of potentially important factors to consider when making representations of services. This will be discussed further in 6.4, along with the question of how these representations influence cognition in design. An important deliberation is always what the relation between such representation of locations and the actual future situation looks like; this issue will be further discussed in Chapter 7. Next, the chapter will be concluded by summarising service as a design material.

\subsection{Summarising service as a design material}

Service as a design material has three manifestations; a concept, a process, and a system. Edvardsson \& Olsson (I996) conceptualised services from the perspective of new service development, and provided useful suggestions for what elements that need to be designed in a service. In short; the staff, customers, the physical/technical environment, and organisation and control need to be designed. These elements should be designed to support the processes that need to take place in the service for the service concept to be realised.

It is important that designers are aware of the difference between designing of and for service. Designing the service process is mainly designing for, but designing the service system is, in a way, designing of. Deliberately shaping the interactions that should take place, to fulfil the intended service concept, requires thinking that is different than that of designing static products: different than designing of. In service design, both designing of and for will take place, using the current terminology. Interaction is not the result of materials, you cannot predict what will happen based on properties of products. A way to get access to potential interactions is to prototype. To build something and see what happens, see what interactions take place and how things play out. Doing it several times gives an idea about the variations of interactions, and introducing obstacles such as errors reveals even more of the interactions that might take place (Blomkvist \& Bode, 20I2). In a way this is both designing of and for. Possible service and customer processes can be designed using representations of the service system.

Using the journey metaphor is one way to make service as a design material manageable. Customer journeys provide overview and define what the touchpoints are. Touchpoints are however complex in themselves and can be almost arbitrarily complex in terms of technical 
and physical environments. The challenge becomes understanding what the important aspects of the touchpoint are, how to represent them in an economical yet useful way, and what the contribution of the individual touchpoint is to the overall service experience. It should be noted also, that the role of a touchpoint for the experience of a service cannot be understood in isolation. Because of this, it is suggested here that service design should not consider the design of the interface to be the design of touchpoints, it should be the design of the relationship between the touchpoints.

Another important aspect of the touchpoint is that it describes services from the customer's point of view. Secomandi \& Snelders (20II) describe the main focus as the design of the service interface, where the customer interacts with the available resources. Edvardsson \& Olsson (I996) also focus on the customer in their conceptualisations of service. Service designers should be aware that this represents a limited view of services. Service design does not have to focus on the customer perspective, it can be a matter of finding the best possible service from the perspectives of multiple stakeholders. Different representations put more or less focus on touchpoints, and ideally complementing representation techniques should be used. The discussion about how to represent services is continued in the following chapter. 


\section{Representations in service design}

In I955, Dreyfuss said "I have often thought that one of the industrial designer's most valuable contributions to his client's product is his ability to visualize" (Dreyfuss, 2003, p 57). The external representations used in design take many shapes and are often described as vital for the process. In the previous chapter, service was discussed from a design perspective, and in Chapter 3, we saw that thinking with or in surrogate situations is influenced by what is represented of the future situation of service. This chapter continues that discussion, and deepens it, in regard to representations of services. With the discussion in the previous chapter in mind, this chapter looks at how representations can support service designers and how the interplay between designers and representations works.

This chapter also emphasises that making external representations is central to design in general, and in service design in particular (Segelström, 2010). Some more specific ways in which representations aid designers are discussed here. A representation is anything perceivable that is used or made for the purpose of representing something else. Something else in the context of prototyping often means some idea, concept, or image of the future. So what are the benefits of using external representations?

David Kirsh has dedicated much research to external representations, and to understanding the benefits externalisations provide in different contexts. Kirsh suggested seven ways in which external representations support and benefit cognition (Kirsh, 2oroa; Blomkvist \& Segelström, 2013), see Paper 2. Additional suggested benefits can be found in Gärdenfors (I999), who pointed out that externalising is a way to off-load cognitive resources. Also, Zhang \& Patel (2006) have provided a list, summarising what they called "properties of external representation: 
- Provide short-term or long-term memory aids so that memory load can be reduced.

- Provide information that can be directly perceived and used such that little effortful processing is needed to interpret and formulate the information explicitly.

- Provide knowledge and skills that are unavailable from internal representations.

- Support perceptual operators that can recognize features easily and make inferences directly.

- Anchor and structure cognitive behaviour without conscious awareness.

- Change the nature of a task by generating more efficient action sequences.

- Stop time and support perceptual rehearsal to make invisible and transient information visible and sustainable.

- Aid processibility by limiting abstraction.

- Determine decision making strategies through accuracy maximization and effort minimization." (Zhang \& Patel, 2006, p. 335, citing Zhang, I997b)

Besides from showing the many ways externalisations support cognition, lists like this also show how intimately our cognition is tied to the external world. People are always cognitively situated: our thoughts are influenced by previous thoughts and experiences, and situated in a cultural context. These aspects influence how and what we think, along with the sensory information our bodies provide and the physical environment surrounding us. Based on this idea, cognition is seen in this thesis as constantly situated and distributed, meaning that there is no ability to "extend" the mind at will, and consequently, no ability to disconnect from the world. It should be noted that using the situated perspective as described above, means that rather than supporting or influencing, representations actually become part of thinking; part of the cognitive process. Hence, once a representation has been built, it becomes part of how we think. In Chapter 6.I.I the process of creating representations and the role it plays for cognition in design is discussed.

\subsection{External representations and design}

The discussion here, about the role of externalisations in design from a situated cognition perspective has two sides: how representations influence cognition and how the surrounding environment influence cognition. The main focus is on representations. Based on the situated cognition perspective, it follows that the materiality of prototypes gives rise to certain behaviours, they; "structure cognitive behavior without conscious awareness" (Zhang \& Patel, 2006, p.335). Kirsh (2010a), working in the distributed cognition branch of cognitive science, has specifically talked about the role of externalisations for architects and designers, and focussed on how they are helped by "tangible representations of an intended design" (ibid., p.448).

Kirsh (20IOa) used the term models, saying that they I) are shared objects of thought that are not tied to the author or designer of the model. Hence, they can be manipulated and used independently from how the author might have imagined they should be used. This makes 
them valuable when designers relate to each other and external clients. 2) models show that a concept is realisable by enforcing consistency. If you can build a model of something there are no logical inconsistencies that make the model impossible to build. This is unlike internal representations that do not have an in-built reality check. 3) Related to the first point, models also reveal unanticipated consequences when different people perceive and interact with models. Peoples' individual frame of reference will make them approach a model in their own specific way, which might reveal new and unintentional uses or interpretations. This is an important part of creativity in design Oxman (I997) ${ }^{19}$. There is evidence that suggests that some types of innovation or creativity is not possible at all until a form has been externalised and explicated (Oxman, 1997).

If you imagine a new look for a bicycle, there is a limit to e.g. the degree of detail and complexity that the image in the head can have (Kirsh, 2oroa). This is due to limitations in representational power of the brain. Similarly, if you imagine a bicycle that you have seen, perhaps your own bicycle, it will be a less natural representation than the actual bike (Kirsh, 2oroa), meaning that the image in the head might not be proportional, lack certain parts and functions, be of the wrong colour and so on. If you externalise your vision of a bike you can make it arbitrarily complex and detailed. If you wanted, you could also make an exact replica of the bicycle, perhaps one with the appearance but not the function of your own bicycle. In addition, externalising your bicycle makes it shareable with others, unlike an internal idea of a bicycle, which is impossible to convey to others.

When it comes to the issue of how the surrounding environment influences cognition, it is often in a less conscious way. People are not as aware that where they are changes their cognition as they are about the fact that different things can be used to facilitate thinking e.g. using a calculator or drawing a sketch. Nonetheless, a situation's characteristics are tightly coupled with our ability to perform tasks within it. Lave (I988) has provided evidence from difference sources about this issue. An illustrative example is taken from Herndon (I97I, in Lave I988), who wrote about a student who worked as a scorer in a bowling league. This was a very demanding arithmetic task, but when Herndon used similar problems as the one's encountered in the bowling alley in the classroom, the student failed to solve them. Similarly, students who were used to buying shoes at discount prices had problems solving shopping problems in the classroom. Hence, what surrounds us is also part of how and what we think. For this reason, visual designers like to surround themselves with inspirational material and inspirational environments (Binder et al., 20II).

\footnotetext{
${ }^{19}$ Oxman (1997) has looked at the process of description and re-description in architecture and visual design, and noted that the process is important for creativity.
} 


\subsubsection{Benefits of making representations}

When something is externalised in service design, it describes or manifests the internal idea about the service. This description can then be re-described in a new version that talks back to the designer. This process is highly informative and central for prototyping and creativity. Gedenryd (1998) talked about how designers and architects depend on making sketches as part of the cognitive process. Also, in the situated cognition tradition scholars have pointed out that "making and experimenting with physical objects (including drawings and notations) facilitates the learning of abstract concepts, as well as the generation of new insights that promote abstract thinking" (Clancey, 2008, p. 27). In this way, the situated perspective on cognition helps us understand certain aspects of representations in design and how they help designers, not just that they help.

In their work on understanding the ways that cognition was supported during the building of externalisations, Chandrasekharan \& Nersessian (20II) looked at a computational modelling lab trying to understand and simulate biochemical pathways. In that context, they found a number of cognitive roles played by the externalisation. It provided saliency, facilitated integration and linking of sources related to biochemical pathways, it worked as a growing shared collaboration and representation space (the "mangrove function"), it allowed researchers to stop-and-poke, a coagulation of initially fluid structures and parameters towards more constrained and solid state could be used, and externalisation allowed for a more natural and variable way of thinking, similar to how mutations provide variability.

This means that materialising (externalising) something is a way of learning in itself. This issue is rarely mentioned in prototyping literature. Even in the situated and distributed cognition research literature, very little has been said about how the building of external representations facilitate cognition (Chandrasekharan \& Nersessian, 20II). Benefits of designing the external representations that are used in prototyping is the start of learning from prototypes.

\subsubsection{Conversations with design representations}

An example of how the process of making representations supports cognition in design can be found in the writings of Donald Schön (Schön \& Wiggins, I992; Schön, I983; Schön \& Bennett, I996). Schön has suggested that design is a conversation with design materials, where the material talks back to the designer ${ }^{20}$. Schön \& Wiggins has described the process like this:

"She [the designer] discovers features and relations that cumulatively generate a fuller understanding or 'feel for', the configuration with which she is working. Her ability to

\footnotetext{
${ }^{20}$ The component parts of conversations with materials have been described as seeing-moving-seeing (Schön \& Wiggins, 1992).
} 
recognize qualities she has not anticipated, or may not even be able to describe, gives her increased access to her appreciative system. Her repeated move experiments can yield an understanding of relationships, in the context of a given configuration, among moves, consequences, and qualities in multiple domains - in short, an understanding of the problem of the design situation." (Schön \& Wiggins, 1992, p. I55).

This is a well-known example, often mentioned in relation to the process of sketching. The way materials talk back to designer(s) is interpreted literally in this thesis, as a way of having an actual conversation with a situation, or representation. The material says something, much like a person could complain about bad solutions or suggest new venues that can be explored, a sketch or a more elaborate representation can do the same. This can be thought of as what Dearden (2006) has called a speech genre: a specific type of communication. Conversations are made possible through their materiality (see material utterance in Dearden (2006, p. 40I)). The material says something that a designer can (learn to) interpret in relation to a specific context or situation, and change as a way to communicate back to the situation, that in turn talks back to the designer(s). Each answer opens up a field of answerability (Bakhtin, 1994 in Dearden, 2006). Depending on what material is used, and the properties and use of that material, different types of knowledge will be attainable.

\subsection{Representations of and for service}

Different service design techniques represent different aspects of services. A blueprint focusses on the processes, a customer journey describes the journey that the customer makes through touchpoints, and a role-play describes a version of an interaction in a touchpoint. What techniques represent also depends on how they are used, but generally the techniques have all been developed to address a certain facet or aspect of a service. Some of these techniques are better to use for representations of service, and some for representations for service.

Two types of representations used for prototyping in service design are: definite and ongoing (see also Paper 2). Definite prototypes are representations that, when they have been created, reach a stable state and do not change in response to actions. As such definite representations are persistent and constant prototypes. Ongoing representations are interactive and dynamic in the sense that they respond to actions, many times because humans are part of the actual representation. Ongoing techniques can also be described as instantaneous, extemporaneous, and evanescent, in the sense that they exist only in the moment, and then perish. Techniques like this have been referred to as enactive techniques (Holmlid, 2007).

Definite representation techniques can, for example, represent the service process (service blueprinting: Bitner, Ostrom, \& Morgan, 2008; Shostack, I982; I984), the customer journey (customer journey maps: Parker \& Heapy, 2006), the service concept (storyboards: Carroll, 
I999) and value networks and systems (system maps: Segelström, 20Io). Ongoing techniques tend to lean more towards representations of locations and social relations (desktop walkthrough, role-play, enactments: Stickdorn \& Schneider, 20I0). Note that most definite techniques describe all relevant aspects of services from their respective perspectives. The service blueprint describes all the processes, the customer journey describes all touchpoints and system maps describe all relevant connections between e.g. stakeholders. Ongoing techniques on the other hand seem to focus on one location, tochpoint or interaction. Service design still to a large extent lack ongoing techniques with a broader scope, that e.g. represent all interactions of a service.

Returning to the discussion about design of and for service, we cannot assume directly from this discussion that techniques that use definite representations are more suitable for design of service, and ongoing are more suited to design for service. Both types of representations can depict service interactions, but the only way to access knowledge about how services will actually play out when people take part in them is to use ongoing representations. Representations used in ongoing prototyping are designed for interaction, for the actions and activities that are played out using ongoing techniques.

The reason why ongoing representations are better for understanding interactions is that interactions are felt and experienced (McCarthy \& Wright, 2005). This does not mean that only ongoing representations should be used for service prototyping. Service design projects also need to describe services from different perspectives, since all representations allow different insights and 'thinking'. One ongoing service prototyping technique is the service walkthrough where designers represent whole services and use embodied interactions to explore or evaluate services.

\subsection{The service walkthrough technique}

Walkthroughs are promising as a service design prototyping technique. In a service walkthrough, participants walk through, using their bodies, a more or less realistic representation of a service. The technique has been identified by observations and interviews, and further exploration and previous literature have further developed the technique during the $\mathrm{PhD}$ project. The service walkthrough technique can be seen as an experience prototyping (Buchenau \& Fulton Suri, 2000) technique for service design. It also uses elements from bodystorming (Oulasvirta, Kurvinen, \& Kankainen, 2003) and the pluralistic walkthrough technique (Lewis et al., I990).

There are now a number of documented uses of service walkthroughs (Arvola et al., 2012; Blomkvist, Åberg, \& Holmlid, 20I2; Blomkvist \& Bode, 20I2). Advantages of using the service walkthrough technique include that it is an embodied approach, where people literally walk through a whole service journey from start to finish, and that it can be conducted in quick and inexpensive ways. Exploring whole services means that a holistic perspective on the 
service can be maintained, while most other techniques focus on parts or fragments of services. Walkthroughs can thus support embodied and situated learning in interactive and social settings.

Walkthroughs have also been used in other design disciplines such as in software and interaction design, where the material (like in service design) has a temporal aspect, i.e. it unfolds over time. One early type of walkthrough was the pluralistic usability walkthrough (Bias, I994; I99I), which can increase empathy for the involved stakeholders in software development. Pluralistic walkthrough is partially based on the cognitive walkthrough method (Lewis et al., I990; Wharton et al., I994; Rieman et al., I99I; Polson et al., I992), which in turn are based on the theory of exploratory learning (Polson \& Lewis, I990) and the more general design walkthrough approach (Polson et al., I992).

The cognitive walkthrough method was developed to be used early in development processes (Polson et al., I992) as an alternative to other usability methods which were too ambitious and formal to be practically feasible (Lewis et al., 1990). The cognitive walkthrough was conducted by experts. One designer showed other designers an idea, which was then walked through by talking about each individual step, using a predefined list of criteria. The focus of the evaluation was on the cognitive processes required to complete tasks.

While cognitive walkthrough focused on experts, pluralistic walkthrough was developed to involve different roles, e.g. users, developers, usability experts (Bias, I994). The pluralistic walkthrough was conducted using hardcopy panels, representing the intended interface contents, to walk through the steps. After each task had been introduced the participants (all pretending to be users), wrote down the actions they would take to perform the task. An administrator then provided the correct answer for how to perform the task, followed by a discussion where the task was further inspected. The experts and developers were only allowed to speak after the users had exhausted their comments about the task. A later adaption of the method put less focus on inspection, and more on the test of the interface from the users' perspective (Riihiaho, 2002). Hence, walkthroughs in design are based on theories about learning and have been used to make quick evaluations using low-fidelity representations and for involving different stakeholders in the design process.

There seems to be something quite innate in humans that we enact or walk things through. Walking through tasks has cognitive benefits also in the way that it helps temporally organise knowledge. Another advantage is that anyone can use the technique because it uses what people already do every day: embodied interactions with their environments and each other. An example of this is the improvised enactments that always occur in design collaboration. Arvola \& Artman (2007) have provided an account of how improvised enactments occur in design meetings. These enactments support the collective 
understanding of the system that is being developed, by providing behavioural elements. Being a natural way of expression also favours inclusion in design, as shown by (Vaajakallio, 2009; Vaajakallio \& Mattelmäki, 2007). In a study looking at how generically shaped products could be used in different scenarios, users enacted future situation to inform the development process (Vaajakallio \& Mattelmäki, 2007).

Interaction has also been seen as performance in the field of interaction design (lacucci, lacucci, \& Kuutti, 2002). In service design, walking through a service can be seen as a way of performing the service. This performance can have dramatic elements, and by using a holistic approach, it can inform designers about experiences of going through the service. In a recent dissertation, Goodman (2013) reflected on the types of performance that occur in interaction design. She showed how walkthroughs supported system representations in different ways, including how humans complement static material, like presentation slides or hardcopy, with a behaviour that it cannot provide itself since it is not interactive. This is a way of including things like ticket machines, computers and other technology interfaces, by enacting also the interaction between humans and artefacts. A specific look at the feedback generated from two walkthroughs provides insights about the different dimensions of the technique in Paper 3.

\subsection{Representations of servicescapes}

Designers have become increasingly skilled at representing dynamic sequences and time, using e.g. ongoing prototyping, in inexpensive and quick ways. However, representing elements in the environment, in a similarly quick and easy way is less evolved. Interesting work with technical solutions, where images or videos of physical locations are projected, and other elements of the physical environment are simulated digitally (to some extent) has been conducted (Rontti et al., 2012). This is a way of approximating the experience of being in the location of a future service, and the representation can be coupled with role-plays or enactments of service processes. An important part of servicescapes is the information, explicit and implicit, that it conveys to the people that populate them. This can be done using signifiers.

\subsubsection{Signifiers}

The way designers can directly influence the ability to act and think in environments is through signifiers. These can be described by looking at two related concepts from cognitive psychology; schemas and scripts. Schemas are frameworks of collections of concepts in the head (Brewer, 1999, in Sternberg, 2003) that allow organisation of knowledge and creation of meaningful structures of related concepts. For instance, new situations are always compared with your current knowledge of other, similar situations. A new restaurant is compared to other restaurants, and organised as a new instance of a restaurant in a framework. 
A related aspect is the script, described in 1977 by Schank \& Abelson (in Sternberg 2003, p.264) as "/.../ a structure that describes appropriate sequences of events in a particular context." Much like schemas, scripts are semantically organised concepts, but in the case of scripts, the concepts are also organised as sequences. This means that when a sequence is activated, the next concept in the sequence get activated, and so on. Scripts are used in everyday life to guide behaviour and inform us about available actions. Scripts can be social or more general behavioural sequences. When you enter a restaurant, a set of available actions are triggered based on cues about what type of restaurant you are in. This will inform you about whether to sit down or to wait for someone to take you to a table for instance.

When designing service environments, these cues can be deliberately designed to help customers behave in the expected way. One tool designers have to inform customers with is affordances. The term affordance was coined by James J. Gibson, and refers to "an action possibility available in the environment to an individual, independent of the individual's ability to perceive this possibility" (McGrenere \& Ho, 2000, p. 179). Norman (2008) has suggested that there is a difference between the actual affordances and the perceived affordances, which he has called signifiers. Signifiers are physically available cues, described like this:

"People need some way of understanding the product or service-some sign of what it is for, what is happening, and what the alternative actions are. People search for clues, for any sign that might help them cope and understand. It is the sign that is important, anything that might signify meaningful information. Designers need to provide these clues. Forget affordances: What people need, and what design must provide, are signifiers. Because most actions we do are social, the most important class of these are social signifiers." (Norman, 2008, p. 19)

Further research about the role of signifiers, and what their role in service design is, can potentially lead to a better understanding of how they can be incorporated in prototyping techniques. It is not realistic to assume that designers create representations of ambient conditions, spacial layout and functions, and signs, symbols and artefacts, for each service they work with, but perhaps a more conscious effort to incorporate signifiers in representations can lead service prototypes that are more realistically representing the service journey. Signifiers guide choices, by paying attention to the schemas and scripts associated with a service, and thus be the 'signs' that customers use to navigate e.g. an enactment of a future service process. 


\subsection{Representations and the future situation of service}

To conclude this chapter we now look at a way to relate prototypes to what they represent. It has been suggested in previous chapters that a prototype can be understood as a surrogate situation, and that prototyping is the activity of using prototypes to increase knowledge about a future situation. That means that there is a relation between the current situation the surrogate (see 3.2.2) - and the future situation.

Calling the situation where the new service will exist the future situation of service, is based on Gedenryd's (1998) concept of future situation of use. This situation is described as the conditions that designers need to understand about where an artefact will be used in the future. Gedenryd talked about what it means that the situation that designers aim for is not present during design activities: "Not only are the designer's concerns remote from her; the functional situation is located in the future, and hence does not even exist yet. Therefore, the given basic provisions do not enable the designer to nurture a healthy, interactive cognitive process: she will have to settle for something less" (Gedenryd, I998, p. 157).

Using Gedenryd's vocabulary, designers use prototypes and other representations to make inquiries about the future situation. Using prototypes and other externalisations are what Gedenryd (1998) called situating strategies. For Gedenryd, this mainly meant thinking about what future situations would mean for the use of artefacts, but in service design, the material is also part of the future situation. A service, as we saw in the previous chapter, consists of both processes and system, and a part of the system is the servicescape. Hence, the future situation of service is both what the actual service does as well as the situation where the service will exist. This means that the future situation is never available in service design, only the imagined future situation can be used when designers make inquiries about the future situation. The imagined future service is a mix of the understanding of the future situation and the idea about what the service should do in the future. Let's consider the relation between the surrogate situation and the future situation of service. 


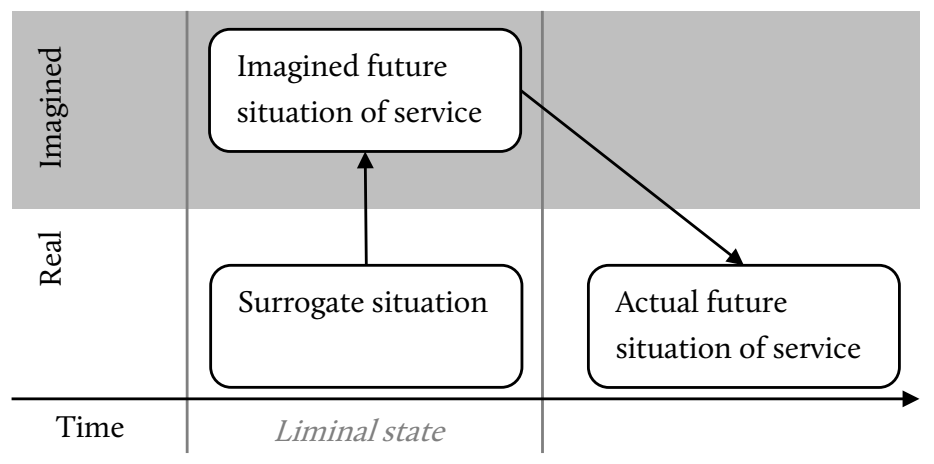

FIGURE 2 VISUALISES THE RELATION BETWEEN THE SURROGATE SITUATION AND THE FUTURE SITUATION OF SERVICE. THE SURROGATE SITUATION EXISTS IN A LIMINAL STATE WHERE INQUIRIES CAN BE MADE ABOUT DESIGN OPTIONS. THE IMAGINED FUTURE SITUATION IS USED TO EVALUATE AND UNDERSTAND THE TALK-BACK FROM THE SURROGATE.

In Figure 2 there is an area above the real world representing the world of ideas and thoughts (mental representations), and a timeline. The imagined future situation of service exists as ideas about what the future situation will look like, and the surrogate situation is designed to replicate aspects of this situation. The future situation can be visualised, as e.g. the outcome of a future workshop, or held in the minds of the designers. However, as mentioned above, the future situation is not the actual future situation of service; it is in turn an approximation of what the future situation might look like. The approximation is based on design research and the visualisations and prototypes that describe the future situation and the future service. Each member of the design team creates their own imagined future situation, partially overlapping with other member's understanding.

As representations of services, the suggested externalisation benefits (Chandrasekharan \& Nersessian, 20II; Kirsh, 20Ioa; Zhang \& Patel, 2006; Clark, 20I0; 2005) apply to surrogate situations (see Chapter 4 also). Some techniques in service design are better suited to prototype for exploration of a design space, and some are better at evaluation. Also, some service design techniques are better suited to provide a certain type of externalisation benefits. These last two issues are addressed in Paper 3. The next chapter will take a closer look at the relationship between the surrogate situation and the future situation of service. 



\section{Surrogate and future situations}

The previous chapters converge in this chapter. The focus is on the relationship between surrogate situations and future situations of service. Both the surrogate and the future situation of service are further examined individually. The focus is shifted slightly towards evaluation of prototypes, and fidelity in the context of service prototyping concludes the chapter.

\subsection{The relationship between surrogate and future situations of service}

A surrogate here is a prototype. And a service prototype represents a service, or aspects of a service. When ongoing prototypes have some elements of the service system present, they are sometimes referred to as props. For example when a role-play or enactment is used to prototype, quick mock-ups of interfaces, important documents, artefacts that influence the interaction, and so on, can be used. These props are in themselves also prototypes that are part of the larger surrogate for the future situation.

Only the aspects of the service that is represented in the prototype is part of the surrogate, meaning that designers choose what the surrogate will inform the designers about. The aim of prototyping is not to replicate the future situation of service. Replicating the future situation is what you do when implementing a service. Instead, the aim is to find ways to represent (to construct surrogates of) aspects of services that allow designers to generate knowledge or ideas about those aspects. This is in line with the economical principle of prototyping: "the best prototype is one that, in the simplest and most efficient way, makes the possibilities and limitations of a design idea visible and measurable." (Lim, Stolterman, \& Tenenberg, 2008, p. 7:3). 
Sometimes designers are interested in large portions of the future situation, and thus make elaborate representations, usually in the later stages of design when evaluation is more in focus than exploration, see Paper I about the importance of position in process, and Paper 4 for an example where two consecutive versions of a service was used. Regardless of the scope of the surrogate, one important task for the designer is to understand the relation between the surrogate and the future situation of service. Part of the problem is that the future situation is not available (see 6.5), making evaluations problematic for three reasons, I) the future situation is imagined by the designers, 2) designers must transfer the knowledge from the surrogate to the imagined future situation (based on partial representations) and 3) evaluations can become focussed on the surrogate itself rather than the future situation.

The first problem means that designers try to understand how the surrogate would fit in the future situation of service by comparing it to an imagined version of the future situation. This imagined future situation can be more or less well-described and shared, using e.g. customer journeys or service blueprints, or partially overlapping individual ideas about what the service should do in the future. Regardless, there is a risk that the imagined future situation is not well founded or that it simply does not reflect the actual future conditions. More on this in 7.I.3.

The second problem: designers make representations of parts of services and observe what happens. Based on their observations or understanding of the partial representation they must then translate and transfer the findings to their understanding of the future situation of service. This ability to understand a prototype in relation to the future situation is improved with experience and can be learned, but the understanding will always be partial. Also, each situation is unique and each future situation will have specific criteria for good solutions. This means that criteria for choosing solutions is closely tied to the specific (surrogate) situation, and cannot be generalised.

The third problem concerns the risk that designers focus on the surrogate, and evaluate the surrogate in itself rather than its relation to the future situation. This problem has been described as a focus on the action context rather (surrogate) than the target context (future situation of service) (Artman et al., 2005; Ramberg et al., 2004), and can be the result of unclear understanding of the target context (Artman et al., 2005).

A rarely addressed question, related to the third problem, is what if the people who evaluate or use a prototype are not really interested in the future service? Evaluations usually concern the 'performance' of the suggested prototype in itself, not whether the future where the design will be implemented is a preferred one, or even desired. There's usually pretty good grounds to assume that people in the future situation will prefer the suggested solution before the existing situation, especially if the designers have done their homework. 
However, even if designers know that a solution is wanted, evaluation techniques usually do not provide information about what influences peoples' willingness to use the design. In, Paper 4, a prototype evaluation technique is presented that allows designers to better understand which factors influence peoples' intention to use a service in the future.

\subsubsection{Progression of the surrogate situation}

Making and/or using surrogates to generate knowledge about a future service leads to changes both in the understanding of the future situation of service, and in how the surrogate is designed. Figure 3 illustrates the feedback loops involved in the progression of surrogate representations. When a surrogate is used in prototyping, it will influence details about the understanding of the future situation. For example, answers about how an interaction between a customer and a service provider should play out, or how a website should be structured, lead to adjustments to the understanding of the future situation. This in turn feeds back to the surrogate that is changed to suggest a solution or improve another, much like a conversation with the design situation in 6.I.2. During design projects, different surrogates are usually used. Each surrogate also influences the next one through the kinds of insights that have been generated.

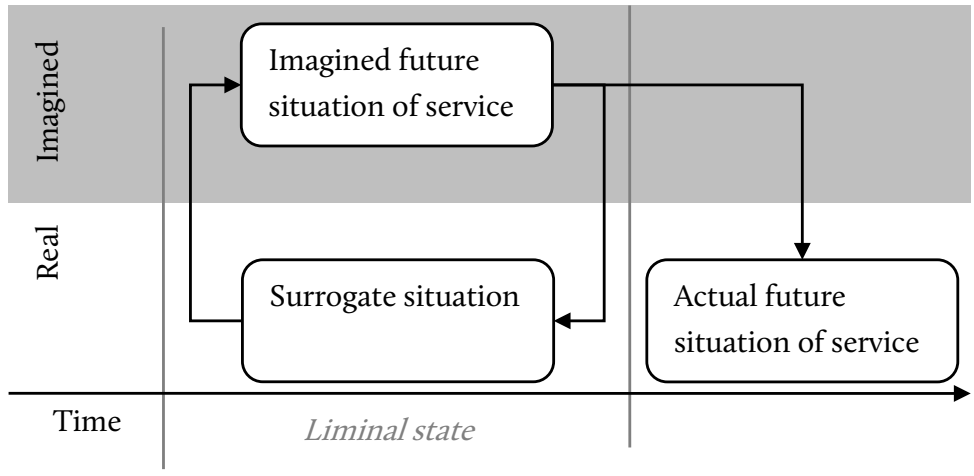

FIGURE 3: ILLUSTRATION OF THE INTERPLAY BETWEEN THE SURROGATE SITUATION AND THE FUTURE SITUATION IN PROTOTYPING.

As projects progress, more and more gets known about appropriate solutions, and more decisions can be made. This is the process of going from a fluid to a more coagulated state (Chandrasekharan \& Nersessian, 20II). More knowledge means that surrogates can become more elaborate, as more and more is known about what works in the imagined future situation of service. Being in a liminal state is what allows designers to test different ideas and versions, because changes and mistakes do not have ramifications outside of the temporary situation that has been created. In one project, a service walkthrough was used to iteratively develop a bank service (Blomkvist \& Bode, 20I2). To test different scenarios, delays, mistakes and failures were added. The liminal state allowed knowledge to be generated about extreme or unfortunate situations that would otherwise be difficult to 
generate. This also allowed the designers to make plans and design solutions and routines for service failures.

An ongoing surrogate situation, like a role-play or a service walkthrough, is continuously changing. This makes techniques that use ongoing representations good for exploring and evaluating different behaviours, and finding the most appropriate behaviour from the viewpoints of different stakeholders. A definite representation on the other hand has the benefit of being constant, but it does not allow exploration of e.g. behaviours or interaction in the same way. Definite surrogate situations have the character of descriptions that specify what the future situation should look like. It is a version of the imagined future situation. A definite prototype can thus work as a target for other prototypes. When a service walkthrough (ongoing technique) was conducted to try a service that delivered food from the grocery store and from restaurants (Blomkvist, Åberg, \& Holmlid, 20I2), a customer journey (definite technique) was used to introduce the touchpoints, information flow, and goals of the service.

\subsubsection{Future situations of service}

The accuracy of the imagined future situation is decided by the quality and extent of design research, and the availability of the actual future situation. In service design, it is impossible to know exactly what the future situation is going to look like. When you are designing a graphical user interface, it is possible to predict many things, because many of the variables will be in the hands of the designer. The surrogate situation that is created can approximate the finished result relatively well. The prototype can even evolve into the actual future situation. But when services are being developed, there are many unknown variables. You cannot be sure what will happen when other people enter the service. This is why Edvardsson \& Olsson (1996) distinguished between the customer and service processes.

The designers might have a vague idea about the situation, where it will take place and some of the people that will be present. Some types of customers and roles of the service provider are probably also known. Each individual designer will have a unique idea of what the situation might be. Without a shared representation, each designer will also act according to his or her understanding of the future situation. A surrogate representation can be a way to align each participant's understanding of the future situation. This has been described as "a transaction between conceptual knowledge structures and design representation through a visual representational medium" (Oxman, I997, p. 33I). The ideas will not be exactly the same, but they will be more alike.

The surrogate situation - the prototype - is not a representation of the servicescape. A service consists of a process, system and a service concept, but the location (servicescape) where the service will take place is not represented by the surrogate. Not unless there is something in the servicescape that enables the service process to take place. Then that 
something can be incorporated in the surrogate. However, the future situation of service includes the servicescape. And the servicescape, consisting of ambient conditions, spatial layout and form, and signs, symbols and artefacts is important also for how well a new service will be received. The servicescape influence the service experience and how people behave and perceive elements of the service. Usually however, prototypes are not tested or used in the same location as the future service. Prototypes can be tested or used in different places, like the design studio, an office somewhere, or in the actual future service location. Depending on where the service is tested, more or less is known about how well the service works in context. More on this relation below.

\subsubsection{Surrogate fidelity}

The relation between the 'likeness' of the surrogate and the service in the future situation can be thought of as the fidelity, where higher likeness means higher fidelity. However, fidelity is a blunt instrument to apply to services. A service consists of a process (the interactions) and a system consisting of staff, the customers, the physical/technical environment (ambient conditions, spatial layout, function, signs, symbols, and artefacts) and organisation and control. Fidelity can be high in regard to e.g. layout or interaction, but no other aspect; does that make the fidelity of the representation high or low?

The surrogate in this thesis is seen as separate from the location where it is tested ${ }^{21}$. This is a way of separating the fidelity of the representation, from the validity ${ }^{22}$ of the location where it is used. The knowledge that can be transferred (transferability) from a surrogate situation to a future situation of service depends on: the fidelity, the validity, the people that participate, and the accuracy of the imagined future situation, see Figure 4. If the understanding of e.g. the presumptive customers in the future situation of service is wrong, the criteria used to select appropriate solutions will be wrong because the knowledge generated by the surrogate situation is based on an inaccurate assumption. Transferability is also affected by the people that participate in the prototype, in terms of how closely they imitate the motivations, expectations, and so on of the people in the future situation of service. An interesting question is how these emotional aspects can be triggered or simulated in participants as part of prototyping.

2I The situation where the service is tested has been referred to as a liminal state.

22 See also paper I and Blomkvist \& Holmlid (2010). 


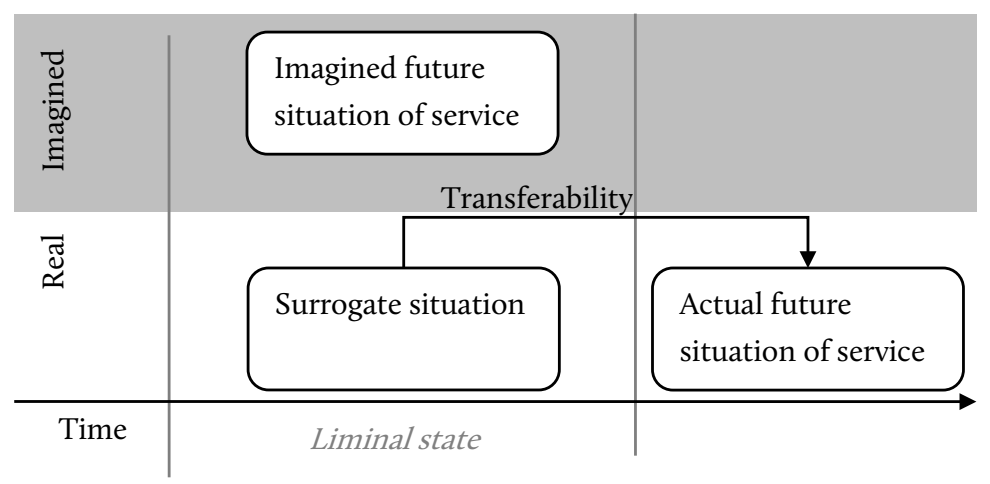

FIGURE 4: TRANSFERABILITY IS THE AMOUNT OF KNOWLEDGE THAT CAN BE TRANSFERRED FROM THE SURROGATE TO THE FUTURE SITUATION OF SERVICE.

When examined further in the light of previous chapters, fidelity of service prototypes can be seen as the degree to which the surrogate resembles the imagined future service. While it is generally assumed that higher fidelity gives more useful feedback (lacucci \& Kuutti, 2002; Pedersen \& Buur 200o), keeping representations quite crude might have advantages. When an experience is central to prototyping, according to (Odom et al., 20I2), it is enough fidelity if the experience is evocative enough to get the participants to buy in to the scenario.

Perhaps creativity is also helped by not aiming for too much realism. Brodersen, Dindler, \& Iversen (2008) use what they call "imaginative places" that are significantly different from the actual place where the activity takes place to activate creativity. The idea is that such places can help creativity and expand the design space. Some evidence also suggests that too much detail can limit the ability to think. Clark has provided support for this assumption; "the surrogates profit from idealization, abstraction, and the omission of much concrete detail" (Clark, 2005, p. 238). Too much detail can get in the way of thinking, and put added focus on details. The situated cognition literature also suggests that shifting, in our mind, between what is present and what is not is done quickly and seamlessly, adding to the idea that fidelity should be kept low.

The next chapter will introduce the papers in the thesis. The papers can be seen both as complementing the theoretical discussions of the kappa (mainly Paper i \& 2), as well as instances where surrogates are used to generate knowledge about future services (Paper 3 \& 4). 


\section{Papers in the thesis}

This chapter presents the specific research questions and introduces the articles in the thesis. Then, it briefly outlines the content and the findings of each paper, and explains where and how the papers have been submitted. The main contributions to the aim of the thesis, and answers to the research questions are also provided for each paper.

\subsection{Research questions}

The thesis ends with four research papers. The papers all add to the aims of the thesis (Chapter I.2) in various ways, and the questions the papers answer range from high-level concerns to specific issues. The aims of the thesis are to use a situated cognition perspective to inform service design about I) what service prototypes are, 2) what the benefits of using prototypes, mainly in service design are, and 3) how prototyping aids service design.

The first two papers concern more theoretical aspects of service design and prototyping. In papers 3 and 4 , versions of the service walkthrough technique have been used to prototype services. The questions are:

I. what are the existing perspectives on prototyping in design?

a. what, if any, additional perspectives are relevant for service prototyping?

2. what are the benefits of using external representations in service design?

a. what techniques are associated with the different benefits?

3. how can we understand the knowledge generated by service prototypes?

a. what is the difference between pausing or not pausing during service walkthroughs?

4. how can information about customers' intention to use a service be included in evaluations of service prototypes? 
The first question will support the aim of understanding what a service prototype is and inform choices about how to conduct prototyping activities. The second question will suggest what the benefits are with using external representations, and connect the externalisations with techniques used in service design, and thus inform the second aim of the thesis. The third and fourth questions contribute to the third aim of the thesis by showing how prototypes, in the form of service walkthroughs, can be used. It also shows how knowledge about different techniques and variations can be generated by looking at feedback from service prototype evaluations.

\subsection{Paper 1}

\section{Existing Prototyping Perspectives: Considerations for Service Design}

Authors: Johan Blomkvist \& Stefan Holmlid

This paper presents a literature study that examined existing knowledge about prototyping, mainly by looking at literature in software development and interaction design. In total, 30 papers about prototyping were chosen as the basis for a framework of perspectives on prototyping. The perspectives were intended to summarise the important aspects considered so far academically, and consider them in relation to prototyping in service design. A previous interview study with service design practitioners (Blomkvist \& Holmlid, 20I0) mentioned 5 challenges for service prototyping. The challenges were compared with the prototyping perspectives, after the framework had been constructed and visualised.

\section{Contributions to the thesis}

The questions that this research answers are:

I. what are the existing perspectives on prototyping in design?

a. what, if any, additional perspectives are relevant for service prototyping?

The perspectives purpose, fidelity, audience, position in the process, technique, and representation were discussed in the paper. These perspectives and their relation to each other was explained and summarised. When comparing the perspectives with the challenges mentioned by service design practitioners, two additional perspectives; validity and author were suggested. The paper suggested that validity concerns how similar the test and implementation contexts are, and uses servicescapes to indicate the importance of the context for service prototyping.

The author of prototypes was also proposed as a new important perspective for service prototyping, and concerned who is involved in creating the prototypes and the relation between the creators (or authors) and the audience of the prototype. The final framework was then visualised and explained, thus contributing knowledge about what prototypes are. 
The most fundamental issues concerning prototyping according to the framework, is the position in process and the purpose of prototyping. Then, the stakeholder level of the framework contains the author and audience perspectives. The next level is the activity level where the perspectives technique and validity is placed, and on the top level is the prototype itself with the perspectives of fidelity and representation.

Paper accepted to and presented at the 20II Nordic Design Research Conference, NorDes: Making Design Matter. Double blind review process, Acceptance rate $\approx 20 \%$ (Koskinen, 20I4).

\section{Reference:}

Blomkvist, J., Holmlid, S., (20Ira). Existing Prototyping Perspectives: Considerations for Service Design. Proceedings of the Nordes'II: The $4{ }^{T H}$ Nordic Design Research Conference: Making Design Matter, (pp. 3I-40). Helsinki, Finland.

Link to the online version of the paper:

http://ocs.sfu.ca/nordes/index.php/nordes/20II/paper/view/40I/232

\subsection{Paper 2}

\section{External Representations in Service Design: a Distributed Cognition Perspective}

Authors: Johan Blomkvist \& Fabian Segelström

This is a theoretical paper comparing different sources of knowledge to better understand the role of external representations for service designers. Three main sources were used in the paper, I) benefits of using external representation found in distributed cognition research (Kirsh, 2010a), 2) reasons for making externalisations in service design found in two interview studies (Segelström, 20I0; Blomkvist, 20II), and 3) techniques used to externally represent services, found in the interview studies and in Stickdorn \& Schneider (20I0). The benefits were:

I. They ease the processing in inferential reasoning

2. External representations can serve as a shareable object of thought

3. They make persistent points of reference

4. They facilitate re-representations

5. External representations are often more natural representations of structure

6. They make it easier to deal with complex information by using multiple representations

7. They make it possible to create arbitrarily complex structures

The interview studies showed that external representations were used in service design for the purposes of articulating insights, learning, communicating, collaborating, and 
maintaining empathy. The techniques used for the analysis were roleplaying, customer journey maps, blueprints, design scenarios, storyboards, desktop walkthrough, and staging. The authors then proceeded by comparing the benefits with the reasons for externalising. This analysis was conducted by carefully examining each benefit and reason, and then mapping them to each other. A second analysis was conducted in a similar manner, but this time with the benefits and the service design externalisation techniques.

\section{Contributions to the thesis}

The questions that this research answers are:

2. what are the benefits of using external representations in service design?

a. what techniques are associated with the different benefits?

This research complements existing research that says that externalisations are helpful in design, and what they are helpful for, with knowledge about how externalisations support design activities. The first analysis showed which benefits each reason for making external representations had. Interestingly, reasons mentioned in the interviews about both the early and the later stages had similar benefits. The second analysis showed the relationship between the benefits and the techniques used in service design to represent services. The second analysis also led to a classification of techniques into definite and ongoing, because of the very clear pattern that emerged during the analysis. The definite techniques were Customer journey maps, Blueprints, Design scenarios, and Storyboards, and the ongoing techniques Roleplay, Desktop walkthrough, and Service staging. The analysis also showed that no technique supported the use of multiple simultaneous representations (benefit 6).

The result in Paper 2 have been summarised in Table 3. This table shows the connection between the benefits of using externalisations, compared with the reasons for using external representations in service design and techniques that use external representations of services. This table was not included in Paper 2, but it makes the three data types easier to compare.

Paper awaiting publication in The Design JournaP ${ }^{3}$.

\section{Reference:}

Blomkvist, J. Segelström, F., (20I4). External Representations in Service Design: a

Distributed Cognition Perspective. The design journal, I丸(3). New York, NY: Bloomsbury.

Link to a previous version accepted to European Academy of Design Conference 2013:

http://ocs.sfu.ca/nordes/index.php/nordes/20II/paper/view/40I/232

23 The Journal can be found at: http://www.bloomsbury.com/us/journal/the-design-journal/ 
TABLE 3: BENEFITS OF EXTERNAL REPRESENTATIONS MATCHED WITH THE REASONS FOR USING THEM IN SERVICE DESIGN AND THE TECHNIQUES USED TO MAKE EXTERNALISATIONS. BENEFITS FROM KIRSH (2010A), REASONS LISTED IN BLOMKVIST \& HOLMLID (2010) AND SEGELSTRÖM (2009), AND TECHNIQUES FROM STICKDORN \& SCHNEIDER (2010).

$\begin{array}{lll}\begin{array}{l}\text { Benefit of external } \\ \text { representation }\end{array} & \begin{array}{l}\text { Reason for using } \\ \text { external representation }\end{array} & \begin{array}{l}\text { Techniques using external } \\ \text { representations }\end{array}\end{array}$

\begin{tabular}{|c|c|c|}
\hline $\begin{array}{l}\text { I. Eased processing in } \\
\text { inferential reasoning }\end{array}$ & $\begin{array}{l}\text { Articulation } \\
\text { Learning }\end{array}$ & $\begin{array}{l}\text { Roleplay, Desktop walkthrough, } \\
\text { Service staging }\end{array}$ \\
\hline $\begin{array}{l}\text { 2. External } \\
\text { representations can } \\
\text { serve as a shareable } \\
\text { object of thought }\end{array}$ & $\begin{array}{l}\text { Communication } \\
\text { Collaboration } \\
\text { Maintaining empathy }\end{array}$ & $\begin{array}{l}\text { Roleplay, Customer journey } \\
\text { maps,Blueprints, Design scenarios, } \\
\text { Storyboards, Desktop walkthrough, } \\
\text { Service Staging }\end{array}$ \\
\hline $\begin{array}{l}\text { 3. External } \\
\text { representations make } \\
\text { persistent points of } \\
\text { reference }\end{array}$ & $\begin{array}{l}\text { Learning } \\
\text { Collaboration } \\
\text { Maintaining empathy }\end{array}$ & $\begin{array}{l}\text { Customer Journey maps, Blueprints, } \\
\text { Design scenarios, Storyboards }\end{array}$ \\
\hline $\begin{array}{l}\text { 4. Facilitation of re- } \\
\text { representation }\end{array}$ & $\begin{array}{l}\text { Articulation } \\
\text { Learning }\end{array}$ & $\begin{array}{l}\text { Roleplay, Customer journey maps, } \\
\text { Blueprints, Design scenarios, } \\
\text { Storyboards, Desktop walkthrough, } \\
\text { Service Staging }\end{array}$ \\
\hline $\begin{array}{l}\text { 5. External } \\
\text { representations are } \\
\text { often more natural } \\
\text { representations of } \\
\text { structure than internal } \\
\text { representations }\end{array}$ & Communication & $\begin{array}{l}\text { Roleplay, Desktop walkthrough, } \\
\text { Service staging }\end{array}$ \\
\hline $\begin{array}{l}\text { 6. Easier to deal with } \\
\text { complex information } \\
\text { by using multiple } \\
\text { representations }\end{array}$ & $\begin{array}{l}\text { Articulation } \\
\text { Learning }\end{array}$ & \\
\hline $\begin{array}{l}\text { 7. Possibility to create } \\
\text { arbitrarily complex } \\
\text { structures }\end{array}$ & $\begin{array}{l}\text { Articulation } \\
\text { Learning }\end{array}$ & Blueprints \\
\hline
\end{tabular}




\subsection{Paper 3}

\section{Pausing or not? Examining the Service Walkthrough Technique}

Johan Blomkvist \& Mattias Arvola

This is a case study where one aspect of the service walkthrough technique was explored: what is the difference between pausing after each touchpoint and walking through the whole service without pauses? Three more specific questions were posed: I) what types of feedback were there in the service walkthroughs with pauses compared to the service walkthroughs without pauses, 2) was there more detailed feedback in any kind of walkthrough, and 3) was there more feedback about whole service experiences in any kind of walkthrough? To find out the study was conducted by analysing transcribed feedback from audio recordings taken during the two types of service walkthroughs.

The first question was answered by using a qualitative content analysis. This resulted in both the types of feedback, as well as the number of mentions about each topic. The result was then checked by three researchers (the two authors and Stefan Holmlid). Both the second and third questions were addressed by using a quantitative content analysis, each using a separate framework and associated coding scheme. The first framework concerned the degree of detail in feedback, and the second concerned long-term and momentary user experience.

The first analysis required a joint coding session after two failed attempts to reach a satisfactory inter-rater agreement. The problems with coding degree of detail were then discussed leading to improvements to the coding scheme. The second coding was easier and a substantial agreement was met.

\section{Contributions to the thesis}

The questions that this research answers are:

3. how can we understand the knowledge generated by service prototypes?

a. what is the difference between pausing or not pausing during service walkthroughs?

This paper showed an interesting way to analyse the knowledge that a prototyping technique generates. By examining the feedback using content analysis it is possible to find ways to evaluate prototyping techniques and compare them to each other. In this case, the same technique with different conditions were tested which is a useful way of examining different dimensions of prototyping techniques. The approach can also be used to compare different techniques with each other. The paper suggested ways in which the coding scheme concerning the degree of detail in feedback could be improved. 
When it comes to the more specific results, the paused condition provided both more comments in total and more detailed feedback, but in regard to content of feedback, no qualitative difference was found. Some comments referred to the whole service experience, but no difference between the conditions was found.

Paper submitted to The $28^{\text {th }}$ British HCI Conference, $20 I 4$.

\section{Reference:}

Blomkvist, J., Arvola, M., (2014). Pausing or not? Examining the Service Walkthrough Technique. Proceedings of the $28^{\text {th }}$ British HCI Conference. (SUBMITTED). BCS Learning and Development Ltd, UK.

\subsection{Paper 4}

\section{Formative Evaluation of IT-based Services: A Case Study of a Meal Planning Service}

Johan Blomkvist, Johan Åberg, and Stefan Holmlid

In Chapter 7, the problem of finding ways to evaluate prototypes based on the intention to use a service in the future was discussed. This paper suggested that the theory of planned behaviour (TPB) could be used to generate formative knowledge in service development projects. The paper is based on a case study where two consecutive service representations were used. First a low-fidelity representation was used in a pre-study that generated salient factors which influence the target group's intention to use the service in the future. Then a high-fidelity service representation was evaluated using the result from the pre-study to gain in-depth feedback about how the prototype related to the factors. This approach of using TPB to generate feedback related to intentions to use a service in the future was named the formative service evaluation technique (F-SET).

Part of the F-SET is using content analysis to abstract the knowledge it generates. The three authors examined the feedback from both the pre-study and the following prototype, with the aim of finding out if the technique had generated formative knowledge, and if useful comments had been made concerning the different constructs of TPB. This would indicate that the feedback is useful in iterative prototyping and that the feedback is relevant for the intention to use the service in the future.

\section{Contributions to the thesis}

The questions that this research answers are:

4. how can information about customers' intention to use a service be included in evaluations of service prototypes? 
The paper listed many alternative ways to understand customers' intention to use a service in the future. However, after comparing the alternatives, TPB stood out, especially when formative knowledge is wanted in a design project. The feedback did clearly suggest fruitful directions of the project by informing the process about good and bad solutions and through TPB it was possible to understand what specific design solutions might mean for the intention of the target group to use the service in the future. Stated clearly, the feedback could be used to gather specific knowledge about what influenced the participants' intentions to use the service in the future. This knowledge could also be transformed into design goals, and suggestions for features and functions.

This research also provides more knowledge about the third research question: how can we understand the knowledge generated by service prototypes? Also in this case a content analysis is used and the feedback analysed with regard to types and content of feedback. The generated knowledge is based on surrogates for the future situation of service, and hence the results can be understood as informing the idea about the future situation.

Paper published in Interacting with Computers ${ }^{24}$.

\section{Reference:}

Blomkvist, J., Åberg, J., Holmlid, S. (2013) Formative Evaluation of IT-based Services: A Case Study of a Meal Planning Service. Interacting with Computers. doi: I0.I093/iwc/iwto52. Oxford Journals.

Link to the online version of the paper: http://iwc.oxfordjournals.org/cgi/reprint/iwto52?ijkey=FaSkflgl8A8Cvl4\&keytype=ref

24 The Journal can be found at: http://iwc.oxfordjournals.org/ 


\section{Contributions}

This thesis used the theoretical lens of situated cognition through which service prototyping has been understood. The concluding chapter starts with a discussion about the contribution of the situated perspective for service prototyping. The rest of the chapter is dedicated to the aims of the thesis, and they will structure the discussion about what the contributions are. The research aims were to provide knowledge about what service prototypes are, what the benefits of using prototypes are, and the role of prototyping in service design. The chapter ends with suggested directions for future research and conclusions.

\subsection{Prototyping and situated cognition}

Using the situated cognition lens, two main concepts were identified. One was the surrogate situation, which is a way to understand service representations. The surrogate situation is used to stand in for a real situation that is not physically present or accessible. The future situation of service is the second concept that came out of the situated cognition perspective, and represents the inaccessible situation in the future where and when the new service will take place. The future situation of service includes the service processes and resources, as well as the context where the service takes place. The connection between the surrogate (and the liminal state) and the future situation of service has been discussed in the thesis.

Research from the field of situated cognition has also enriched the understanding about external representations in design. Many benefits of prototyping are tied to the representation; what it is and what it represents. The thesis also makes minor contributions back to cognitive science in general. Mainly, the thesis shows how concepts, primarily from situated cognition, can be applied to specific real-world situations. An important contribution of the situated perspective should be noted: following the situated cognition 
perspective, prototyping is not something that merely supports thinking in design. Rather, it is a way to think, or a mode of thinking. Without the activity of prototyping, there is no 'prototyping thinking', and no other way of thinking can substitute the knowledge generated using external representations in design.

\subsection{What service prototypes are}

The thesis informs service design with suggestions about what prototypes are on three different levels: I) it suggests what the material in service design consists of, 2) it introduces perspectives on both the material and how it can be used for service prototyping, and 3) it suggests how the prototyping situation can be understood, and how it relates to the future situation of service.

Knowledge has been provided through the discussion about service as a design material, suggesting that from a design perspective, a service consists of a service concept, process and system. The thesis has proposed mainly what the process and the system consist of. Additionally, the servicescape has been discussed, and suggestions for how to approach this aspect of prototyping in service design.

On a more abstract level, the thesis has provided knowledge about what a prototype is by summarising the perspectives from which service prototypes and prototyping can be considered. The relevant perspectives are purpose, fidelity, audience, position in the process, technique, representation, validity and author, and can be further explored by reading Paper I. Some of these perspectives have been further explored. Based on using the situated cognition lens, and other research about fidelity (see 7.I.3), the thesis has proposed that low fidelity does not necessarily mean lower transferability of knowledge from a surrogate to a future situation of service.

Understanding prototypes as surrogate situations (Clark, 2005) is a way to conceptualise services on an abstract level. The surrogate is described as a structure or representation that is used to stand in for something else that is not present or accessible. In the surrogate situation, the normal, real-world constraints are relaxed and lacking the distant situation (the future situation of service), the surrogate provides a concrete arena where interactions and exploration can take place. The ramifications of actions in the surrogate are limited to the liminal state in which the surrogate exists, making it a safe place to explore even extreme behaviours. Time can also be slowed or stopped (or sped up) in the liminal state. The surrogate should be understood as representing aspects of the future situation of service.

\subsection{Benefits of prototypes}

Most of the benefits mentioned in situated and distributed cognition relates to the representations used in prototyping. The representations, i.e. the prototypes, are physical 
and possible to share, making collaboration within design teams and externally with other stakeholders possible. Prototypes can show that something is possible to build, or reveal what is otherwise unknown or inaccessible without an external representation. In this sense, a prototype coordinates the idea about a future situation at the same time as it can drive development forward. According to the situated cognition perspective the insights that prototyping generates are specific outcomes of thinking with externalisations, and as such they are not possible to generate without external representations. Also, the types and contents of externalisations change the types and contents of thinking.

Two main types of prototypes were suggested in the thesis: definite and ongoing. Definite prototypes are representations that reach a stable state, a state where they do not change as a consequence of external actions. Ongoing prototypes on the other hand do change and do not have a stable state. Both kinds of prototypes can be used to explore or evaluate, and they can be used to prototype service processes and systems. However, some aspects cannot be understood without using ongoing prototypes. Mainly these aspects relate to the service process, to interactions and, more or less, social situations. The advantage of some ongoing prototypes is that they can represent time. They can also engage whole bodies in the representations, such as in role-playing or service walkthroughs. The situated cognition perspective implies that the knowledge generated by such embodied approaches is qualitatively different than their counter-parts. What designers can learn and do with ongoing prototypes is tied to the situation and context where they take place. Most techniques in service design that use ongoing prototypes focus on one touchpoint, rather than representing whole service journeys.

The reason for using prototypes from a situated cognition perspective can be traced to the idea that not using externalisations would be too cognitively demanding (Zhang \& Patel, 2006). Having a physical reference point allocates resources that would otherwise be occupied with internally representing and remembering an idea. When service processes are simulated in prototypes, they help designers instinctively and immediately perceive the situation. This is qualitatively different than imagining it happening or playing out, and it makes the process of understanding good and bad solutions more intuitive and less cognitively demanding.

The understanding of the benefits of prototyping in design was further deepened in Paper 2 This paper showed the relation between benefits of externalising suggested in distributed cognition with both techniques in service design and purposes reported by service designer for making externalisations. In relation to the types of research that have been conducted earlier, this research is interesting because it focusses not only on the types of benefits or for what external representations are used but how they aid service designers: what their cognitive roles are. 


\subsection{Prototyping and service design}

The service walkthrough is a technique that allows designers to explore whole service journeys using ongoing representations. It shows an example of how prototyping can be adapted specifically to service as a design material and reflect aspects of a future service. Using the service walkthrough technique puts explicit focus on the service as a journey and allows exploration of several consecutive touchpoints or service moments. Knowlegde about how prototypes, like service walkthroughs, aid the design of services can be found in the last two research papers of the thesis. Both papers show examples of the kinds of feedback that service prototyping has generated. In addition, the papers examine the feedback and discuss its usefulness in service design. The examination of the feedback in the papers also shows how techniques and variants of techniques can be compared.

Feedback generated during prototyping is a way of connecting the surrogate with the future situation of service. Paper 4 provides a useful evaluation technique (the F-SET) that can be used in service design to make predictions about how the service will be received more reliable. By using the F-SET, formative knowledge related to peoples' intention to use a service in the future can be generated. This technique then, directly informs the understanding of the future situation of service during prototyping. The F-SET can provide knowledge both about what a surrogate should represent and how the surrogate relates to and interacts with the future situation of service.

On a more abstract level, the thesis has suggested that service prototyping should focus not only on touchpoints, but also on the relation between touchpoints. The service walkthrough uses the journey through touchpoints as a metaphor, and is also made up of touchpoints, but by representing several consecutive touchpoints it can also inform design about the relation between them. However, using a single representation of service to prototype will only generate knowledge related to that specific representation, since thinking with one prototype is different than thinking with another prototype. As the material representation or manifestation changes, so does the thinking. This is also why it is important to use multiple representations that describe services from different perspectives.

Another aspect considered in the thesis concerned what it is that service designers prototype, and by extension what they design. It has been argued that service design should be seen both as design of and for service. This includes designing static 'things' (the way things look, feel, communicate), as well as 'things' that support interaction (products, interfaces) and designing for interactions without 'things'. The way designers can know beforehand what those interactions will be, and what they will feel like, is by representing them and acting them out by using service prototyping. 


\subsection{Future research}

While the focus of the thesis has been on externalisations and representations of services, research on how other theories in situated cognition, concerning e.g. how the interplay between humans and their context and culture influence service prototyping, can provide additional insights that benefit research on prototyping in service design. In addition, the embodied cognition perspective, and what it means for prototyping and other design activities is an interesting future research area.

One issue related to prototyping in service design that has only been partially touched on in the thesis is the kinds of learning that occur during prototyping. The process of creating prototypes is briefly discussed in 6.I.I, but a deeper investigation of how, when and why designers learn from prototypes can greatly contribute to research about prototyping. For example, the issue of how the process of learning looks like before the prototype is finished, e.g. before a definite prototype reaches its final state, or the process of making the props for an ongoing prototype, what types of knowledge, and how, do these activities generate?

Services have been described from a design perspective in this thesis using literature from outside of design. This approach is based on a theoretical discussion, but can be more firmly grounded in practice. For instance, what are designers actually proposing at the end of service design projects? What are the effects on the organisations: does the design concern the concept, process or system mainly and what are the competences needed to implement the suggestions? These issues are interesting to explore further.

The service walkthrough technique is an important technique that fills a gap in service prototyping. It is a way to explore whole services using ongoing techniques. The types of knowledge that this can generate are important for service design. However, little is still known about what designers can learn from different types and variations of walkthroughs. More research into variations and the dimensions of service walkthroughs will make support choices about how to conduct service prototyping.

Two gaps in the research about service prototyping techniques can be identified in the thesis. One concerns the use of multiple representations in prototyping to support the design of services, and the other concerns techniques that explore the relationship between touchpoints. The situated perspective indicates that services should be described from a multitude of perspectives, and techniques could be developed that support simultaneous use of multiple representations during prototyping. Research that suggests such techniques, or more research like the one presented in this thesis that show the value and benefits of different representations are useful contributions to the field of service design. The same goes for techniques that explore the relationship between touchpoints more explicitly. 


\subsection{Conclusions}

Using a broad definition of prototyping, this thesis shows that a prototype can be seen as a surrogate for the future situation of service. Using a surrogate (i.e. prototyping) is a way of thinking and acting with externalisations. These externalisations not only enhance the ability to gain knowledge about future situations, it also offers a distinct way of thinking. From a situated cognition perspective, a surrogate changes the material preconditions to think. Using prototypes allows for certain thoughts and behaviours and without prototyping there is no 'prototyping thinking'.

A surrogate for a whole future service consists of a service concept, process and system. The surrogate can be seen and considered from the perspectives of purpose, fidelity, audience, position in the process, technique, representation, validity and author in service design. The surrogate has several benefits. One benefit is that it relaxes the real-world constraints and allows designers to experiment and test their ideas in what has been called a liminal state. Surrogates also provide a shared reference point in design, show that a concept is realisable, show unanticipated consequences of design decisions, and act as a counterpart in a conversation with the designers.

Some conclusions about the scope of service design can be made. Service design should look at what happens in the transitions between touchpoints, not only what happens in the touchpoints by themselves. The thesis has distinguished between designing of and for service, claiming that both are important in service design. Two techniques support different needs in prototyping, definite and ongoing. Definite techniques coagulate representations of future services in permanent states while ongoing techniques allow exploration of dynamic events and social aspects of services. Finally, the service walkthrough technique is suggested as a way of making ongoing representations of whole service journeys, and as a way of connecting the surrogate with the future situation of service. 


\section{References}

Akama, Y., Cooper, R., Vaughan, L., Viller, S., Simpson, M., \& Yuille, J. (2007). Show and Tell: Accessing and Communicating Implicit Knowledge Through Artefacts. Artifact, I(3), I72-I8I.

Andriof, J., \& Waddock, S. (2002). Unfolding stakeholder engagement. In J. Andriof, S. Waddock, B. Husted, \& S. Sutherland Rahman (Eds.), Unfolding Stakeholder Thinking: Theory, Responsibility and Engagement (pp. 19-42). Greenleaf, Sheffield.

Antle, A. N., Droumeva, M., \& Ha, D. (2009). Thinking with Hands: An Embodied Approach to the Analysis of Children's Interaction with Computational Objects. CHIzoog (pp. 4027-4032). Boston, Massachusetts, USA: ACM.

Arnowitz, J., Arent, M., \& Berger, N. (2007). Effective Prototyping for Software Makers. San Francisco, CA: Morgan Kaufmann.

Artman, H., Ramberg, R., Sundholm, H., \& Cerratto-Pargman, T. (2005). Action context and target context representations: A case study on collaborative design learning. In T. Koschman, D. Suthers, \& T. W. Chan (Eds.), Proceedings of the 2005 conference on Computer support for collaborative learning: learning 2005: the next Io years! (pp. I7). Mahwah, NJ: ACM Digital Library.

Arvola, M. (2005). Shades of Use: The Dynamics of Interaction Design for Sociable Use. Linköping Studies in Science and Technology, Dissertation No. 90o. Linköping, Sweden: Linköpings universitet.

Arvola, M. (2010). Interaction Design Qualities: Theory and Practice. Proceedings of the 6th Nordic Conference on Human-Computer Interaction (NordiCHI 2OIO). Reykjavik, Iceland: ACM. 
Arvola, M., \& Artman, H. (2007). Enactments in Interaction Design: How Designers Make Sketches Behave. Artifact, I(2), Io6-II9.

Arvola, M., Blomkvist, J., Holmlid, S., \& Pezone, G. (20I2). A Service Walkthrough in Astrid Lindgren's Footsteps. Service design and service innovation conference, ServDes 20I2. Espoo, Finland: Linköping University Electronic Press.

Beaudouin-Lafon, M., \& Mackay, W. E. (2007). Prototyping tools and techniques. In A. Sears, \& J. A. Jacko (Eds.), Human-Computer Interaction Handbook: Fundamentals, Evolving Technologies, and Emerging Applications (2nd ed., pp. IoI7-I039). Boca Raton, FL, USA: CRC Press.

Bechtel, W., Abrahamsen, A., \& Graham, G. (1999). The Life of Cognitive Science. In W. Bechtel, \& G. Graham (Eds.), A Companion to Cognitive Science (Paperback ed., pp. I-I04). Oxford, UK: Blackwell Publishing.

Bernstein, R. J. (2010). The Pragmatic Turn. Cambridge, UK: Polity Press.

Bias, R. G. (I99I). Interface-Walkthroughs: Efficient Collaborative Testing. Software, 8(5), 94-95.

Bias, R. G. (1994). The Pluralistic Usability Walkthrough: Coordinated Empathies. In J. Nielsen, \& R. Mack, Usability Inspection Methods (pp. 63-76). New York, NY: Wiley and Sons.

Billman, D. (1999). Representations. In W. Bechtel, \& G. Graham (Eds.), A Companion to Cognitive Science (pp. 649-659). Oxford, UK: Blackwell Publishing.

Binder, T., De Michelis, G., Ehn, P., Jacucci, G., Linde, P., \& Wagner, I. (201I). Design Things. (K. Friedman, \& E. Stolterman, Red.) Cambridge, Massachusetts, USA: The MIT press.

Bitner, M. J. (1990). Evaluating Service Encounters: The Effects of Physical Surroundings and Employee Responses. The Journal of Marketing, 54(2), 69-82.

Bitner, M. J. (1992). Servicescapes: The Impact of Physical Surroundings on Customers and Employees. Journal of Marketing, 56(2), 56-7I.

Bitner, M. J., Booms, B. H., \& Tetreault, M. S. (I990). The Service Encounter: Diagnosing Favorable and Unfavorable Incidents. Journal of Marketing, 54, 7I-83.

Bitner, M. J., Ostrom, A. L., \& Morgan, F. N. (2008). Service Blueprinting: A practical Technique for Service Innovation. California Management Review, 50(3), 66-94.

Blomkvist, J. (20II). Conceptualising Prototypes in Service Design. Linköping Studies in Arts and Science, Licentiate Thesis No. Ior. Linköping, Sweden: Linköping University Electronic Press. 
Blomkvist, J. (2012). Conceptualisations of Service Prototyping: Service Sketches, Walkthroughs and Live Service Prototypes. In S. Miettinen, \& A. Valtonen (Eds.), Service Design with Theory (pp. I77-I88). Vantaa, Finland: Lapland University Press.

Blomkvist, J., \& Bode, A. (2012). Using Service Walkthroughs to Co-Create Whole Service Experiences: A Prototyping Technique for Service Design. Proceedings of ISIDC 20I2. Tainan, Taiwan.

Blomkvist, J., \& Holmlid, S. (2009). Examplars in Service Design. Proceedings of DeThinking Service, ReThinking Design: The First Nordic Conference on Service Design and Service Innovation 2009. Oslo, Norway.

Blomkvist, J., \& Holmlid, S. (20I0). Service prototyping according to service design practitioners. Proceedings of Service Design and Innovation Conference, ServDes.20Io. Linköping, Sweden: Linköping University Electronic Press.

Blomkvist, J., \& Holmlid, S. (20IIa). Existing Prototyping Perspectives: Considerations for Service Design. Proceedings of Nordic Design Research Conference, NORDES $20 I I$. Helsinki, Finland.

Blomkvist, J., \& Holmlid, S. (20Irb). Prototype Evaluation in Service Design: A Case Study at an Emergency Ward. In N. M. Roozenburg, L. L. Chen, \& P. J. Stappers (Ed.), Proceedings of IASDR2oII, the 4th World Conference on Design Research, (p. II). Delft, the Netherlands.

Blomkvist, J., \& Holmlid, S. (20IIc). Service designers on including stakeholders in service prototyping. Proceedings of Include 2oII. London, UK.

Blomkvist, J., \& Segelström, F. (2013). External Representations in Service Design: a Distributed Cognition Perspective. Proceedings of European Academy of Design Conference 2013. Gothenburg, Sweden.

Blomkvist, J., Åberg, J., \& Holmlid, S. (2012). Service walkthroughs to support service development. Proceedings of Service design and service innnovation conference, ServDes 20I2. Espoo, Finland: Linköping University Electronic Press.

Blomkvist, J., Holmlid, S., \& Segelström, F. (20I0a). Service Design Research: which direction do we want it to take? Proceedings of Service Design and Innovation Conference, ServDes.2oIo. Linköping, Sweden: Linköping University Electronic Press.

Blomkvist, J., Holmlid, S., \& Segelström, F. (20Iob). Service Design Research: Yesterday, Today and Tomorrow. In M. Stickdorn, \& J. Schneider (Eds.), This is Service Design Thinking (pp. 308-315). Amsterdam, The Netherlands: BIS Publishers.

Blomkvist, J., Holmlid, S., \& Segelström, F. (20II). Prototyping a Service Design Curriculum. Touchpoint, 3(I), 52-55. 
Blomkvist, J., Holmlid, S., Sandberg, F., \& Westerlund, B. (2012). Exploring Participatory Prototyping of Services. Proceedings of the I2th Participatory Design Conference: Exploratory Papers, Workshop Descriptions, Industry Cases (pp. 15I-152). New York, NY, USA: ACM.

Blomkvist, J., Segelström, F., \& Holmlid, S. (20II). Investigating Prototyping Practices of Service Designers from a Service Logic Perspective. Nordic Academy of Management conference, NFF. Stockholm, Sweden.

Bødker, S. (I996). Creating Conditions for Participation: Conflicts and Resources in Systems Development. Human-Computer Interaction, II(3), 215-236.

Bødker, K., Kensing, F., \& Simonsen, J. (2004). Participatory IT Design: Designing for Business and Workplace Realities. Cambridge, MA. USA: MIT Press.

Boer, L. (20II). Participatory Provocation? Proceedings of the Participatory Innovation Conference (pp. I8-24). Sønderborg, Denmark: University of Southern Denmark.

Bradwell, P., \& Marr, S. (2008). Making the most of collaboration: an international survey of public service co-design. London, UK: Demos.

Brand Flu, M. (2013, 06 04). Pilot or Perish. Retrieved o8 08, 2013, from live|work: http://liveworkstudio.com/the-customer-blah/pilot-or-perish/

Brandt, E. (2006). Designing Exploratory Design Games: A Framework for Participation in Participatory Design? Proceedings of the ninth Participatory Design Conference 2006 (pp. 57-66). Trento, Italy: ACM.

Brandt, E., \& Grunnet, C. (200o). Evoking the future: Drama and props in user centered design. Participatory Design Conference 20oo. CPSR.

Brandt, E., \& Messeter, J. (2004). Facilitating collaboration through design games. Proceedings of the eighth conference on Participatory design (pp. I2I - I3I ). New York, NY, USA: ACM.

Brodersen, C., Dindler, C., \& Iversen, O. S. (2008). Staging imaginative places for participatory prototyping. CoDesign, 4(I), I9-30.

Bryan-Kinns, N., \& Hamilton, F. (2002). One for all and all for one? Case studies of using prototypes in commercial projects. NordiCHI(pp. I9-23). Århus, Denmark: ACM.

Buchenau, M., \& Fulton Suri, J. (2000). Experience Prototyping. Proceedings of the 3rd conference on Designing interactive systems: processes, practices, methods, and techniques (pp. 424-433). New York: ACM.

Buxton, W. (2007). Sketching User Experiences: getting the design right and the right design. San Francisco, CA: Morgan Kaufmann. 
Carroll, J. M. (1999). Scenario-Based Design: Envisioning Work adn Technology in System Development. New York, NY: John Wiley \& Sons.

Chandrasekharan, S., \& Nersessian, N. J. (20II). Building Cognition: The Construction of External Representations for Discovery. 33, 264-273.

Clancey, W. J. (2008). Scientific Antecedents of Situated Cognition. In P. Robbins, \& M. Aydede (Eds.), Cambridge Handbook of Situated Cognition (pp. II-34). New York, NY, USA: Cambridge University Press.

Clark, A. (I999). Embodied, situated and distributed cognition. In W. Bechtel, \& G. Graham (Eds.), A Companion to Cognitive Science (Paperback ed., pp. 206-517). Oxford, UK: Blackwell Publishing.

Clark, A. (2005). Beyond the Flesh: Some Lessons from a Mole Cricket. Artificial Life, II, 233244.

Clark, A. (2010). Material Surrogacy and the Supernatural: Reflections on the Role of Artefacts in 'Off-line' Cognition. In L. Malafouris, \& C. Renfrew (Eds.), The Cognitive Life of Things: Recasting the Boundaries of the Mind (pp. 23-28). Cambridge, UK: McDonald Institute for Archaeological Research.

Clark, A., \& Chalmers, D. (I998). The Extended Mind. Analysis, 58(I), 7-I9.

Clatworthy, S. (20II). Service Innovation Through Touch-points: Development of an Innovation Toolkit for the First Stages of New Service Development. Interantional Journal of Design, 5(2), 15-28.

Coughlan, P., Fulton Suri, J., \& Canales, K. (2007). Prototypes as (Design) Tools for Behavioral and Organizational Change. The Journal of Applied Behavioral Science, 43(I), I22-I34.

Cowell, D. W. (1980). The marketing of services. Managerial Finance, 5, 223-23I.

Dearden, A. (2006). Designing as a conversation with digital materials. Design Studies, 27(3), 399-42I.

Design Council. (2007). II lessons: managing design in global brands. Downloaded from Design Council's web page: http://www.designcouncil.org.uk/knowledgeresources/II-lessons-managing-design-global-brands. Retrieved 03 03, 2014.

Dow, S. P., Glassco, A., Kass, J., Schwarz, M., \& Klemmer, S. R. (2009, September). The Effect of Parallel Prototyping on Design Performance, Learning, and Self-Efficacy. Stanford Tech Report, Io. Stanford, CA, USA.

Dreyfuss, H. (2003). Designing for People. New York, NY, USA: Allworth Press. 
Dubberly, H., Evenson, S., \& Robinson, R. (2008, March + April). The Analysis-Synthesis Bridge Model. interactions, 57-6I.

Dunne, A. (1999). Hertzian tales. London, UK: Royal College of Art Related Design Research.

Dunne, A., \& Fiona , R. (2002). The Placebo Project. DIS 2002 (pp. II-I4). London, UK: ACM.

Dyrssen, C. (2010). Navigating in Heterogeneity: Architectural Thinking and Art-Based Research. In M. Biggs, \& H. Karlsson, The Routledge Companion to Research in the Arts (pp. 223-234). London, UK: Routledge.

Edvardsson, B., \& Olsson, J. (1996). Key Concepts for New Service Development. The Service Industries Journal, I6(2), I40-164.

Edvardsson, B., Gustafsson, A., \& Roos, I. (2005). Service portraits in service research: a critical review. International Journal of Service Industry Management, IG(I), I07-I20.

Ehn, P., \& Kyng, M. (1992). Cardboard computers: mocking-it-up or hands-on the future. In J. Greenbaum, \& M. Kyng (Eds.), Design at work: cooperative design of computer systems (pp. I69-I96). Hillsdale, NJ, USA: L. Erlbaum Associates Inc.

Ehn, P., \& Löwgren, J. (1997). Design for quality-in-use: Human computer interaction meets systems development. In M. Helander, T. Landauer, \& P. Prabhu, Handbook of human-computer interaction. Second, completely revised edition. (pp. 299-313). Amsterdam, The Netherlands: Elsevier.

Erickson, T. (1995). Notes on Design Practice: Stories and Prototypes as Catalysts for Communication. In J. Carroll (Ed.), Scenario-Based Design: Envisioning Work and Technology in System Development (pp. 37-58). New York, NY: Wiley \& Sons.

Floyd, C. (1984). A systematic look at prototyping. In Budde, R., Kuhlenkamp, K., Mathiassen, L., and Zullighoven, H. (Eds.), Approaches to Prototyping (pp. I-I8). Berlin, Germany: Springer-Verlag.

Forlizzi, J., \& Zimmerman, J. (2013). Promoting Service Design as a Core Practice in Interaction Design. The 5th IASDR World Conference on Design Research 2013. Tokyo, Japan.

Fullerton, B. (2009). Co-Creation in Service Design. interactions, I6(2), 6-9.

Gallouj, F., \& Weinstein, O. (I997). Innovation in Services. Research Policy, 26, 537-556.

Gärdenfors, P. (1999). From Computers to Anthills as Models of Human Thought. Human IT: Tidsskrift för studiet av IT ur ett humanvetenskapligt perspektiv [Humane IT: Journal of Studies of IT from a Human Science Perspective], 2.

Gaver, W. W., Beaver, J., \& Benford, S. (2003). Ambiguity as a Resource for Design. CHI'20o3 (pp. 233-240). NY, USA: ACM Press. 
Gedenryd, H. (1998). How Designers Work - making sense of authentic cognitive activities. Lund, Sweden: Lund University Cognitive Studies 75.

Gerber, E., \& Carroll, M. (2012). The psychological experience of prototyping. Design Studies, 33(I), 64-84.

Goldstein, S. M., Johnston, R., Duffy, J., \& Rao, J. (2002). The service concept: the missing link in service design research? Journal of Operations Management, 20, I2I-I34.

Goodman, E. S. (2013, September). Delivering Design: Performance and Materiality in Professional Interaction Design. Dissertation. Retrieved 03 30, 2014, from Confectious: http://www.confectious.net/wordpress/wpcontent/uploads/2013/o9/egoodman-dissertation-online.pdf

Greenbaum, J. \& Kyng, M. (199I). Design at Work: Cooperative Design of Computer Systems. New Jersey, USA: Lawrence Erlbaum Associates.

Greeno, J. G., \& Moore, J. L. (1993). Situativity and Symbols: Response to Vera and Simon. Cognitive Science, 17, 49-59.

Grönroos, C. (2006). Adopting a service logic for marketing. Marketing Theory, 6(3), 317-333.

Grönroos, C. (2008). Service logic revisited: who creates value? And who co-creates? European Business Review, 20(4), 298-3I4.

Gummesson, E. (2007). Exit Services Marketing - Enter Service Marketing. Journal of Customer Behaviour, G(2), II3-I4I.

Gummesson, E., Lusch, R. F., \& Vargo, S. L. (2010). Transitioning from Service Management to Service-Dominant Logic. International Journal of Quality and Service Sciences, 2(I), 8-22.

Gutierrez, O. (I989). Prototyping Techniques for Different Problem Contexts. CHI ' 89 Proceedings (pp. 259-264). ACM.

Han, Q. (2009). Managing Stakeholder Involvement in Service Design: Insights from British service designers. Proceedings of the Nordic Conference on Service Design and Service Innovation 2009. Oslo, Norway: Linköping University Electronic Press.

Han, Q. (20I0). Practices and principles in Service Design: stakeholders, knowledge and Community of Service. Dundee, Scotland: University of Dundee.

Heinonen, K., Strandvik, T., Mickelsson, K.-J., Edvardsson, B., Sundström, E., \& Andersson, P. (20I0). A Customer-Dominant Logic of Service. Journal of Service Management, 2I(4), 53I-548. 
Hipp, C., \& Grupp, H. (2005). Innovation in the Service Sector: The Demand for ServiceSpecific Innovation Measurement Concepts and Typologies. Research Policy, 34, $5 \mathrm{I} 7-535$.

Holland, J., Hutchins, E., \& Kirsh, D. (200o). Distributed Cognition: towards a New Foundation for Human-Computer Interaction Research. ACM transactions on Computer-Human interaction, 7, I74-196.

Hollins, G., \& Hollins, B. (199I). Total Design: Managing the Design Process in the Service Sector. London, UK: Pitman.

Holmlid, S. (2002). Adapting users: Towards a theory of use quality. Linköping Studies in Scicence and Technology, Dissertation No. 765. Linköping, Sweden: UniTryck.

Holmlid, S. (2007). Interaction design and service design: Expanding a comparison of design disciplines. Nordes 2007. Stockholm.

Holmlid, S. (2009). Participative, co-operative, emancipatory: From participatory design to service design. Proceedings of the Nordic Conference on Service Design and Service Innovation 2009. Oslo, Norway: Linköping University Electronic Press.

Holmlid, S., \& Evenson, S. (2006). Bringing design to services. Invited to IBM Service Sciences, Management and Engineering Summit: Education for the 2Ist century. New York: October.

Holmlid, S., \& Evenson, S. (2007). Prototyping and enacting services: Lessons learned from human-centered methods. Proceedings from the Ioth Quality in Services conference, QUIS Io. Orlando, Florida.

Holmquist, L. E. (2005). Prototyping: Generating Ideas or Cargo Cult Designs? interactions I2(2), 48-54.

Houde, S., \& Hill, C. (1997). What do Prototypes Prototype? In M. Helander, T. Landauer, \& P. Prabhu (Eds.), Handbook or Human-Computer Interaction (2nd Edition ed.). Amsterdam, The Netherlands: Elsevier Science B. V.

Hutchins, E. (I990). The Technology of Team Navigation. In J. Galegher, R. E. Kraut, \& C. Egido, Intellectual Teamwork: Social and Technological Foundations of Cooperative Work (pp. I9I-220). Hillsdale, NJ: Erlbaum.

Hutchins, E. (1995). Cognition in the Wild. Cambridge, MA: MIT Press.

lacucci, G., Iacucci, C., \& Kuutti, K. (2002). Imagining and experiencing in design, the role of performances. NordiCHI(pp. I67-I76). Århus, Denmark: ACM.

lacucci, G., Kuutti, K., \& Ranta, M. (2000). On the Move with a Magic Thing: Role Playing in Concept Design of Mobile Services and Devices. Designing interactive systems: 
processes, practices, methods, and techniques (pp. 193-202). New York, NY, USA: ACM.

Ilvari, J., \& Karjalainen, M. (I989). Impact of Prototypingon on User Information Satisfaction During the IS Specification Phase. Information and Management, I7, 3I-45.

Jégou, F., \& Manzini, E. (2008). Collaborative service: Social innovation and design for sustainability. Milano: Edizioni POLI.design.

Johansson, M., \& Arvola, M. (2007). A case study of how user interface sketches, scenarios and computer prototypes structure stakeholder meetings. In L. J. Ball, M. A. Sasse, C. Sas, T. C. Ormerod, A. Dix, P. Bagnall, et al. (Ed.), People and Computers XXI: HCI... but not as we know it, Proceedings of HCI 2007. The 2Ist British HCI Group Annual Conference. I, pp. I77-I84. Swindon, UK: The British Computer Society.

Kaasinen, E., Ainasoja, M., Vulli, E., Paavola, H., Hautala, R., Lehtonen, P., et al. (20I0). User Involvement in Service Innovations. Espoo, Finland: VTT Technical Research Centre of Finland.

Keitsch, M., Vavik, T., Morelli, N., Poulsen, S. B., Koskinen, I., Holmlid, S., et al. (2010). LUDINNO - Learning-Labs for User-Driven Innovation. Oslo, Norway: Nordic Innovation Centre.

Kelley, T. (200I). Prototyping is the shorthand of Design. Design Management Journal, I2(3), $35-42$.

Kimbell, L. (2009). The turn to service design. In G. Julier, \& L. Moor, Design and Creativity: Policy, Management and Practice (pp. I57-I73). Oxford: Berg.

Kimbell, L. (20II). Designing for Service as One Way of Designing Services. International Journal of Design, 5(2), 4I-52.

Kirsh, D. (20I0a). Thinking with external representations. AI and Society, 25(4), 44I-454.

Kirsh, D. (20Iob). Thinking with the Body. The 32 Meeting of the Cognitive Science Society. In S. Ohlsson \& R. Catrambone (Eds.), Proceedings of the 32nd Annual Conference of the Cognitive Science Society (pp. 2864-2869) Austin, TX: Cognitive Science Society.

Kirsh, D., \& Maglio, P. (1994). On Distinguishing Epistemic from Pragmatic Action. Cognitive Science, 18 , 513-549.

Koivisto, M. (2009). Frameworks for structuring services and customer experiences. In S. Miettinen, \& M. Koivisto, Designing Services with Innovative Methods (pp. I36-I49). Keuruu, Finland: Kuopio Academy of Design.

Koskinen, I. (20I4, February I2). Personal communication. 
Kronqvist, J., \& Korhonen, S.-M. (2008). Co-Designing Sustainable Solutions - Combining Service Design and Change Laboratory. Proceedings of the First Nordic Conference on Service Design and Service Innovation 2009. Oslo, Norway: Linköping University Electronic Press.

Kurvinen, E., Koskinen, I., \& Battarbee, K. (2008). Prototyping Social Interaction. Design Issues, 24(3), 46-57.

Lave, J. (1988). Cognition in Practice: Mind, Mathematics and Culture in Everyday Life. New York, NY: Cambridge University Press.

Lawson, B. (1997). How designers think: The design process demystified (3rd ed.). Oxford, UK: Architechtural Press.

Lewis, C. H., Polson, P. G., Wharton, C., \& Rieman, J. (I990). Testing a Walkthrough Methodology for Theory-Based Design of Walk-Up-and-Use Interfaces. Proceedings of the SIGCHI Conference on Human Factors in Computing Systems (pp. 235-242). New York, NY: ACM.

Lim, Y.-K., Stolterman, E., \& Tenenberg, J. (2008). The Anatomy of Prototypes: Prototypes as Filters, Prototypes as Manifestations of Design Ideas. ACM Trans. Comput.-Hum. Interact, I5(2).

Lovelock, C. H. (1983). Classifying Services to Gain Strategic Marketing Insights. Journal of Marketing, 4入(Summer), 9-20.

Lovelock, C. H., \& Gummesson, E. (2004). Whither Services Marketing? In Search of a New Paradigm and Fresh Perspectives. Journal of Service Research, خ(I), 20-4I.

Löwgren, J., \& Stolterman, E. (2004). Design av informationsteknik: materialet utan egenskaper (2:a upplagan ed.). Lund, Sweden: Studentlitteratur.

Mattelmäki, T. (2006). Design Probes. Helsinki, Finland: University of Art and Design.

McCarthy, J., \& Wright, P. (2005). Putting 'Felt-Life' at the Centre of Human-Computer Interaction (HCl). Cogn Tech Work, 7, 262-271.

McCurdy, M., Connors, C., Pyrzak, G., Kanefsky, B., \& Vera, A. (2006). Breaking the Fidelity Barrier: An Examination of our Current Characterization of Prototypes and an Examples of a Mixed-Fidelity Success. CHI 2006 Proceedings (pp. I233-I242). Montréal, Canada: ACM.

McGrenere, J., \& Ho, W. (200o). Affordances: Clarifying and Evolving a Concept. Proceedings of the Graphcis Interface (pp. 179-186). Toronto, Canada: Canadian Human-Computer Communications Society.

Mogensen, P. H. (1994). Challenging Practice - an approach to Cooperative Analysing . [PhD Thesis]. Aarhus, Denmark: University of Aarhus. 
Norman, D. A. (1993). Cognition in the Head and in the World: An Introduction to the Special Issue on Situated Action. Cognitive Science, I7, I-6.

Norman, D. A. (2008). Signifiers, not affordances. interactions, I5(6), I8-I9.

Odom, W., Zimmerman, J., Davidoff, S., Forlizzi, J., Dey, A. K., \& Lee, M. K. (2012). A Fieldwork of the Future with User Enactments. DIS. Newcastle, UK.

Österlin, K. (2003). Design i fokus för produktutveckling [Design in focus for product development]. Malmö, Sweden: Deleke Grafiska AB.

Ostrom, A. L., Bitner, M. J., Brown, S. W., Burkhard, K. A., Goul, M., Smith-Daniels, V., et al. (20I0). Moving Forward and Making a Difference: Research Priorities for the Science of Service. Journal of Service Research, I3(I), 4-36.

Oulasvirta, A., Kurvinen, E., \& Kankainen, T. (2003). Understanding contexts by being there: case studies in bodystorming. Personal and Ubiquitous Computing, 7, I25-I34.

Oxman, R. (1997). Design by Re-Representation: A model of Visual Reasoning in Design. Design Studies, I8, 329-347.

Parker, S., \& Heapy, J. (2006). The Journey to the Interface. London, UK: Demos.

Patterson, P. G., \& Cicic, M. (1995). A Typology of Service Firms in International Markets: An Empirical Investigation. Journal of International Marketing, 3(4), 57-83.

Pedersen, J., \& Buur, J. (2000). Games and Moves: Towards Innovative Codesign with Users. Proceedings of CoDesigning 20oo. London, UK: Springer.

Polaine, A., Løvlie, L., \& Reason, B. (2013). Service Design: From Insights to Implementation. Brooklyn, New York, USA: Rosenfeld Media, LLC.

Polson, P. G., \& Lewis, C. H. (I990). Theory-Based Design for Easily Learned Interfaces. Human-Computer Interaction, 5, I9I-220.

Polson, P. G., Lewis, C., Rieman , J., \& Wharton, C. (I992). Cognitive Walkthroughs: A Method for Theory-Based Evaluation of User Interfaces. International Journal of Man-Machine Studies, 36, 74I-773.

Ramberg, R., Artman, H., Sundholm, H., \& Cerratto-Pargman, T. (2004). Creative collaboration with representations: A case study of interaction design in an interactive space. Proceedings of Kaleidoscope (NoE) CSCL-SIG symposium. Laussanne, Switzerland.

Rettig, M. (I994). Prototyping for tiny fingers. Communications of the ACM, 374), 2I-27. 
Rieman, J., Davies, S., Hair, D. C., Esemplare, M., Polson, P., \& Lewis, C. (I99I). An Automated Cognitive Walkthrough. Proceedings of the SIGCHI Conference on Human Factors in Computing Systems (pp. 427-428). New York, NY, USA: ACM.

Riihiaho, S. (2002). The pluralistic usability walk-through method. Ergonomics in Design, IO(3), 23-27.

Robbins, P., \& Aydede, M. (2009). A Short Primer on Situated Cognition. In P. Robbins, \& M. Aydede (Eds.), The Cambridge Handbook of Situated Cognition (pp. 3-ıo). Cambridge: Cambridge University Press.

Rogers, Y., \& Ellis, J. (1994). Distributed Cognition: an alternative framework for analysing and explaining collaborative working. Journal of Information Technology, 9(2), II9I28.

Rontti, S., Miettinen, S., Kuure, E., \& Lindström, A. (2012). A Laboratory Concept for Service Prototyping - Service Innovation Corner (SINCO). Proceedings of Service Design and Innvoation Conference ServDes 20I2. Espoo, Finland: Linköping University Electronic Press.

Rudd, J., Stern, K., \& Isensee, S. (I996). Low vs. High- Fidelity Prototyping Debate. interactions $3(\mathrm{I}), 77-85$.

Saffer, D. (2007). Designing for Interaction: Creating Smart Applications and Clever Devices. Berkeley, CA, USA: New Riders.

Sangiorgi, D. (2012). Value Co-Creation in Design for Services. In S. Miettinen, \& A. Valtonen (Eds.), Service Design with Theory (pp. 95-I04). Vantaa, Finland: Lapland University Press.

Sato, S., \& Salvador, T. (I999). Methods \& tools: Playacting and focus troupes: theater techniques for creating quick, intense, immersive, and engaging focus group sessions. interactions, 6(5), 35-4I.

Scaife, M., \& Rogers, Y. (1996). External Cognition: how do Graphical Representations Work? International Journal of Human-Computer Studies, 45, I85-213.

Schneider, K. (1996). Prototypes as Assets, not Toys: Why and How to Extract Knowledge from Prototypes. Proceedings of the I8th international conference on Software engineering (pp. 522-531). Berlin, Germany: IEEE Computer Society.

Schön, D. A. (1983). The reflective practitioner: How prefessionals think in action. San Francisco, CA: Basic Books.

Schön, D. A., \& Bennett, J. (I996). Reflective conversation with materials. In T. Winograd, Bringing design to software (pp. I7I-I84). New York, NY: ACM Press. 
Schön, D. A., \& Wiggins, G. (1992). Kinds of Seeing and their Functions in Designing. Design Studies, I3(2), I35-I56.

Schrage, M. (1996). Cultures of Prototyping. In T. Winograd, Bringing Design to Software (pp. I9I-205). New York, NY: ACM Press.

Schrage, M. (2004). Never Go to a Client Meeting without a Prototype. Requirements 2I(2), $42-45$.

Secomandi, F., \& Snelders, D. (20II). The Object of Service Design. Design Issues, 27(3), 2034 .

Segelström, F. (2009). Communicating through Visualizations: Service Designers on Visualizing User Research. Proceedings of The First Nordic Conference on Service Design and Service Innovation 2009. Olso, Norway: Linköping University Electronic Press.

Segelström, F. (2010). Visualisations in Service Design. Linköping Studies in Science and Technology, Licentiate Thesis No. I450. Linköping, Sweden: Linköping University Electronic Press.

Segelström, F. (2013). Stakeholder Engagement for Service Design: How Service Designers Identify and Communicate Insights. Linköping Studies in Arts and Science, Dissertation No. 586. Linköping, Sweden: Linköping University Electronic Press.

Segelström, F., \& Holmlid, S. (2009). Visualization as tools for research: Service designers on visualizations. NorDes 2009 - Proceedings of Nordic Design Research Conference. Oslo, Norway.

Sellen, K. M., Massimi, M. A., Lottridge, D. M., Truong, K. N., \& Bittle, S. A. (2009). The People-Prototype Problem: Understanding the Interaction Between Prototype Format and User Group. Computer-Human Interaction (pp. 635-638). Boston, Ma, USA: ACM Press.

Shostack, L. (1977). Breaking Free from Product Marketing. Journal of Marketing, $4 I$ (April), 73-8o.

Shostack, L. (I982). How to Design a Service. European Journal of Marketing(I6I), 49-63.

Shostack, L. (1984). Designing Services that Deliver. Harvard Business Review, 62(I), I33-I39.

Solomon, M. R., Surprenant, C., Czepiel, J. A., \& Gutman, E. G. (1985). A Role Theory Perspective on Dyadic Interactions: The Service Encounter. Journal of Marketing, 49, 99-III.

Sternberg, R. J. (2003). Cognitive psychology (Third edition uppl.). Belmont, CA: Wadsworth. 
Stickdorn, M., \& Schneider, J. (Eds.). (2010). This is Service Design Thinking: Basics - Tools Cases. Amsterdam, The Netherlands: BIS Publishers.

Suchman, L. A. (1987). Plans and Situated Action: The Problem of Human-Machine Communication. New York, NY: Cambridge University Press.

Tan, L., \& Szebeko, D. (2009). Co-designing for dementia: The Alzheimer Ioo project. Australasian Medical Journal, I(I2), I85-I98.

Vaajakallio, K. (2009). Enacting design: understanding co-design as embodied practice. Engaging Artifacts, NorDes 2009. Oslo, Norway.

Vaajakallio, K., \& Mattelmäki, T. (2007). Collaborative Design Exploration: Envisioning Future Practices with Make Tools. Proceedings of the 2007 conference on Designing pleasurable products and interfaces (pp. 223-238). New York, NY, USA: ACM.

Vanstone, C., \& Winhall, J. (2006). Activmobs. London, UK: Design Council.

Vargo, S., \& Lusch, R. (2004). Evolving to a new dominant logic for marketing. Journal of Marketing, 68, I-I7.

Vargo, S., \& Lusch, R. (2008). Service-dominant logic: Continuing the evolution. Journal of the Academy of Marketing Science(36), I-Io.

Vera, A. H., \& Simon, H. A. (1993). Situated Action: A Symbolic Interpretation. Cognitive science, $17,7-48$.

Virzi, R. A., Sokolov, J. L., \& Karis, D. (1996). Usability Problem Identification Using Both Low- and High-Fidelity Prototypes. CHI' 96 (pp. 236-243). Vancouver, BC, Canada: ACM.

von Stamm, B. (2008). Managing Innovation, Design and Creativity (2nd Edition ed.). Chichester, United Kingdom: John Wiley \& Spns, Ltd.

Wagner, A. (1990). Prototyping: A Day in the Life of an Interface Designer. In B. Laurel, The Art of Human-Computer Interface Design (pp. 79-84). Reading, MA: AddisonWesley.

Wetter-Edman, K. (2014). Design for Service - A framework for articulating designers' contribution as interpreter of users' experience. $\mathrm{PhD}$ Thesis. Gothenburg, Sweden: Litorapid Media AB.

Wharton, C., Rieman, J., Lewis, C., \& Polson, P. (1994). The Cognitive Walkthrough: A practitioner's guide. In J. Nielsen, \& R. L. Mack, Usability Inspection Methods. John Wiley and Sons, Inc.

Wilkie, A. (20I0). User Assemblages in Design: An Ethnographic Study. London, UK: Goldsmiths. 
Wilson, M. (2002). Six views of Embodied Cognition. Psychonomic Bulletin \& Review, 9(4), 625-636.

Wong, Y. Y. (1992). Rough and Ready Prototypes: Lessons from Graphic Design. Posters and short talks of the I992 SIGCHI on human factors in computing systems (pp. 83-84). Monterey, California: ACM.

Zelkowitz, M. V. (1980). A case study in rapid prototyping. Software: Practice \& Experience, IO(I2), I037-I042.

Zhang, J., \& Norman, D. A. (I994). Representations in Distributed Cognitive Tasks. Cognitive Science, I8, 87-I22.

Zhang, J., \& Patel, V. L. (2006). Distributed Cognition, Representation, and Affordance. Pragmatics and Cognition, I4(2), 333-34I.

Zomerdijk, L. G., \& Voss, C. A. (2010). Service Design for Experience-Centric Services. Journal of Service Research, I3(I), 67-82. 



\section{Papers}

The articles associated with this thesis have been removed for copyright reasons. For more details about these see:

http://urn.kb.se/resolve?urn=urn:nbn:se:liu:diva-105499 



\section{Dissertations}

\section{Linköping Studies in Science and Technology \\ Linköping Studies in Arts and Science \\ Linköping Studies in Statistics \\ Linköpings Studies in Informatics}

\section{Linköping Studies in Science and Technology}

No 14 Anders Haraldsson: A Program Manipulation System Based on Partial Evaluation, 1977, ISBN 917372-144-1.

No 17 Bengt Magnhagen: Probability Based Verification of Time Margins in Digital Designs, 1977, ISBN 91-7372157-3.

No 18 Mats Cedwall: Semantisk analys av processbeskrivningar i naturligt språk, 1977, ISBN 91-7372$168-9$.

No 22 Jaak Urmi: A Machine Independent LISP Compiler and its Implications for Ideal Hardware, 1978, ISBN 91-7372-188-3.

No 33 Tore Risch: Compilation of Multiple File Queries in a Meta-Database System 1978, ISBN 91- 7372-232-4.

No 51 Erland Jungert: Synthesizing Database Structures from a User Oriented Data Model, 1980, ISBN 917372-387-8.

No 54 Sture Hägglund: Contributions to the Development of Methods and Tools for Interactive Design of Applications Software, 1980, ISBN 91-7372-404-1.

No 55 Pär Emanuelson: Performance Enhancement in a Well-Structured Pattern Matcher through Partial Evaluation, 1980, ISBN 91-7372-403-3.

No 58 Bengt Johnsson, Bertil Andersson: The HumanComputer Interface in Commercial Systems, 1981, ISBN 91-7372-414-9.

No 69 H. Jan Komorowski: A Specification of an Abstract Prolog Machine and its Application to Partial Evaluation, 1981, ISBN 91-7372-479-3.

No 71 René Reboh: Knowledge Engineering Techniques and Tools for Expert Systems, 1981, ISBN 91-7372489-0.

No 77 Östen Oskarsson: Mechanisms of Modifiability in large Softw are Systems, 1982, ISBN 91- 7372-527-7.

No 94 Hans Lunell: Code Generator Writing Systems, 1983, ISBN 91-7372-652-4.

No 97 Andrzej Lingas: Advances in Minimum Weight Triangulation, 1983, ISBN 91-7372-660-5.

No 109 Peter Fritzson: Tow ards a Distributed Programming Environment based on Incremental Compilation, 1984, ISBN 91-7372-801-2.

No 111 Erik Tengvald: The Design of Expert Planning Systems. An Experimental Operations Planning System for Turning, 1984, ISBN 91-7372- 805-5.

No 155 Christos Levcopoulos: Heuristics for Minimum Decompositions of Polygons, 1987, ISBN 91-7870133-3.

No 165 James W. Goodwin: A Theory and System for NonMonotonic Reasoning, 1987, ISBN 91-7870-183-X

No 170 Zebo Peng: A Formal Methodology for Automated Synthesis of VLSI Systems, 1987, ISBN 91-7870-225-9.

No 174 Johan Fagerström: A Paradigm and System for Design of Distributed Systems, 1988, ISBN 91-7870301-8.

No 192 Dimiter Driankov: Tow ards a Many Valued Logic of Quantified Belief, 1988, ISBN 91-7870-374-3.
No 213 Lin Padgham: Non-Monotonic Inheritance for an Object Oriented Knowledge Base, 1989, ISBN 917870-485-5.

No 214 Tony Larsson: A Formal Hardware Description and Verification Method, 1989, ISBN 91-7870-517-7.

No 221 Michael Reinfrank: Fundamentals and Logical Foundations of Truth Maintenance, 1989, ISBN 917870-546-0.

No 239 Jonas Löwgren: Knowledge-Based Design Support and Discourse Management in User Interface Management Systems, 1991, ISBN 91-7870-720-X.

No 244 Henrik Eriksson: Meta-Tool Support for Know ledge Acquisition, 1991, ISBN 91-7870-746-3.

No 252 Peter Eklund: An Epistemic Approach to Interactive Design in Multiple Inheritance Hierarchies, 1991 ISBN 91-7870-784-6.

No 258 Patrick Doherty: NML3 - A Non-Monotonic Formalism with Explicit Defaults, 1991, ISBN 917870-816-8.

No 260 Nahid Shahmehri: Generalized Algorithmic Debugging, 1991, ISBN 91-7870-828-1.

No 264 Nils Dahlbäck: Representation of DiscourseCognitive and Computational Aspects, 1992, ISBN 91-7870-850-8.

No 265 Ulf Nilsson: Abstract Interpretations and Abstract Machines: Contributions to a Methodology for the Implementation of Logic Programs, 1992, ISBN 917870-858-3.

No 270 Ralph Rönnquist: Theory and Practice of Tensebound Object References, 1992, ISBN 91-7870-873-7.

No 273 Björn Fjellborg: Pipeline Extraction for VLSI Data Path Synthesis, 1992, ISBN 91-7870-880-X.

No 276 Staffan Bonnier: A Formal Basis for Horn Clause Logic with External Polymorphic Functions, 1992, ISBN 91-7870-896-6.

No 277 Kristian Sandahl: Developing Knowledge Management Systems with an Active Expert Methodology, 1992, ISBN 91-7870-897-4.

No 281 Christer Bäckström: Computational Complexity of Reasoning about Plans, 1992, ISBN 91-7870-979-2.

No 292 Mats Wirén: Studies in Incremental Natural Language Analysis, 1992, ISBN 91-7871-027-8.

No 297 Mariam Kamkar: Interprocedural Dynamic Slicing with Applications to Debugging and Testing, 1993 , ISBN 91-7871-065-0.

No 302 Tingting Zhang: A Study in Diagnosis Using Classification and Defaults, 1993, ISBN 91-7871-078-2

No 312 Arne Jönsson: Dialogue Management for Natural Language Interfaces - An Empirical Approach, 1993, ISBN 91-7871-110-X.

No 338 Simin Nadjm-Tehrani: Reactive Systems in Physical Environments: Compositional Modelling and Framework for Verification, 1994, ISBN 91-7871-237-8.

No 371 Bengt Savén: Business Models for Decision Support and Learning. A Study of Discrete-Event Manufacturing Simulation at Asea/ ABB 1968-1993, 1995, ISBN 91-7871-494-X. 
No 375 Ulf Söderman: Conceptual Modelling of Mode Switching Physical Systems, 1995, ISBN 91-7871-5164.

No 383 Andreas Kågedal: Exploiting Groundness in Logic Programs, 1995, ISBN 91-7871-538-5.

No 396 George Fodor: Ontological Control, Description, Identification and Recovery from Problematic Control Situations, 1995, ISBN 91-7871-603-9.

No 413 Mikael Pettersson: Compiling Natural Semantics, 1995, ISBN 91-7871-641-1.

No 414 Xinli Gu: RT Level Testability Improvement by Testability Analysis and Transformations, 1996, ISBN 91-7871-654-3.

No 416 Hua Shu: Distributed Default Reasoning, 1996, ISBN 91-7871-665-9.

No 429 Jaime Villegas: Simulation Supported Industrial Training from an Organisational Learning Perspective - Development and Evaluation of the SSIT Method, 1996, ISBN 91-7871-700-0.

No 431 Peter Jonsson: Studies in Action Planning: Algorithms and Complexity, 1996, ISBN 91-7871-7043.

No 437 Johan Boye: Directional Types in Logic Programming, 1996, ISBN 91-7871-725-6.

No 439 Cecilia Sjöberg: Activities, Voices and Arenas: Participatory Design in Practice, 1996, ISBN 91-7871728-0.

No 448 Patrick Lambrix: Part-Whole Reasoning in Description Logics, 1996, ISBN 91-7871-820-1.

No 452 Kjell Orsborn: On Extensible and Object-Relational Database Technology for Finite Element Analysis Applications, 1996, ISBN 91-7871-827-9.

No 459 Olof Johansson: Development Environments for Complex Product Models, 1996, ISBN 91-7871-855-4.

No 461 Lena Strömbäck: User-Defined Constructions in Unification-Based Formalisms, 1997, ISBN 91-7871857-0.

No 462 Lars Degerstedt: Tabulation-based Logic Programming: A Multi-Level View of Query Answering, 1996, ISBN 91-7871-858-9.

No 475 Fredrik Nilsson: Strategi och ekonomisk styrning En studie av hur ekonomiska styrsystem utformas och används efter företagsförvärv, 1997, ISBN 917871-914-3.

No 480 Mikael Lindvall: An Empirical Study of Requirements-Driven Impact Analysis in Object-Oriented Softw are Evolution, 1997, ISBN 91-7871-927-5.

No 485 Göran Forslund: Opinion-Based Systems: The Cooperative Perspective on Knowledge-Based Decision Support, 1997, ISBN 91-7871-938-0.

No 494 Martin Sköld: Active Database Management Systems for Monitoring and Control, 1997, ISBN 917219-002-7.

No 495 Hans Olsén: Automatic Verification of Petri Nets in a CLP framew ork, 1997, ISBN 91-7219-011-6.

No 498 Thomas Drakengren: Algorithms and Complexity for Temporal and Spatial Formalisms, 1997, ISBN 917219-019-1.

No 502 Jakob Axelsson: Analysis and Synthesis of Heterogeneous Real-Time Systems, 1997, ISBN 91-7219-035-3.

No 503 Johan Ringström: Compiler Generation for DataParallel Programming Languages from Two-Level Semantics Specifications, 1997, ISBN 91-7219-045-0.

No 512 Anna Moberg: Närhet och distans - Studier av kommunikationsmönster i satellitkontor och flexibla kontor, 1997, ISBN 91-7219-119-8.
No 520 Mikael Ronström: Design and Modelling of a Parallel Data Server for Telecom Applications, 1998, ISBN 91-7219-169-4.

No 522 Niclas Ohlsson: Tow ards Effective Fault Prevention - An Empirical Study in Software Engineering, 1998, ISBN 91-7219-176-7.

No 526 Joachim Karlsson: A Systematic Approach for Prioritizing Software Requirements, 1998, ISBN 917219-184-8.

No 530 Henrik Nilsson: Declarative Debugging for Lazy Functional Languages, 1998, ISBN 91-7219-197-x.

No 555 Jonas Hallberg: Timing Issues in High-Level Synthesis, 1998, ISBN 91-7219-369-7.

No 561 Ling Lin: Management of 1-D Sequence Data - From Discrete to Continu ous, 1999, ISBN 91-7219-402-2.

No 563 Eva L Ragnemalm: Student Modelling based on Collaborative Dialogue with a Learning Companion, 1999, ISBN 91-7219-412-X.

No 567 Jörgen Lindström: Does Distance matter? On geographical dispersion in organisations, 1999, ISBN 917219-439-1.

No 582 Vanja Josifovski: Design, Implementation and Evaluation of a Distributed Mediator System for Data Integration, 1999, ISBN 91-7219-482-0.

No 589 Rita Kovordányi: Modeling and Simulating Inhibitory Mechanisms in Mental Image Reinterpretation - Towards Cooperative HumanComputer Creativity, 1999, ISBN 91-7219-506-1.

No 592 Mikael Ericsson: Supporting the Use of Design Knowledge - An Assessment of Commenting Agents, 1999, ISBN 91-7219-532-0.

No 593 Lars Karlsson: Actions, Interactions and Narratives, 1999, ISBN 91-7219-534-7.

No 594 C. G. Mikael Johansson: Social and Organizational Aspects of Requirements Engineering Methods - A practice-oriented approach, 1999, ISBN 91-7219-541$\mathrm{X}$

No 595 Jörgen Hansson: Value-Driven Multi-Class Overload Management in Real-Time Database Systems, 1999 , ISBN 91-7219-542-8.

No 596 Niklas Hallberg: Incorporating User Values in the Design of Information Systems and Services in the Public Sector: A Methods Approach, 1999, ISBN 917219-543-6.

No 597 Vivian Vimarlund: An Economic Perspective on the Analysis of Impacts of Information Technology: From Case Studies in Health-Care tow ards General Models and Theories, 1999, ISBN 91-7219-544-4.

No 598 Johan Jenvald: Methods and Tools in ComputerSupported Taskforce Training, 1999, ISBN 91-7219547-9.

No 607 Magnus Merkel: Understanding and enhancing translation by parallel text processing, 1999, ISBN 917219-614-9.

No 611 Silvia Coradeschi: Anchoring symbols to sensory data, 1999, ISBN 91-7219-623-8.

No 613 Man Lin: Analysis and Synthesis of Reactive Systems: A Generic Layered Architecture Perspective, 1999, ISBN 91-7219-630-0.

No 618 Jimmy Tjäder: Systemimplementering i praktiken En studie av logiker i fyra projekt, 1999, ISBN 917219-657-2.

No 627 Vadim Engelson: Tools for Design, Interactive Simulation, and Visualization of Object-Oriented Models in Scientific Computing, 2000, ISBN 91-7219709-9. 
No 637 Esa Falkenroth: Database Technology for Control and Simulation, 2000, ISBN 91-7219-766-8.

No 639 Per-Arne Persson: Bringing Power and Knowledge Together: Information Systems Design for Autonomy and Control in Command Work, 2000, ISBN 91-7219796-X

No 660 Erik Larsson: An Integrated System-Level Design for Testability Methodology, 2000, ISBN 91-7219-890-7.

No 688 Marcus Bjäreland: Model-based Execution Monitoring, 2001, ISBN 91-7373-016-5.

No 689 Joakim Gustafsson: Extending Temporal Action Logic, 2001, ISBN 91-7373-017-3.

No 720 Carl-Johan Petri: Organizational Information Provision - Managing Mandatory and Discretionary Use of Information Technology, 2001, ISBN-91-7373-1269.

No 724 Paul Scerri: Designing Agents for Systems with Adjustable Autonomy, 2001, ISBN 9173732079.

No 725 Tim Heyer: Semantic Inspection of Software Artifacts: From Theory to Practice, 2001, ISBN 91 73732087.

No 726 Pär Carlshamre: A Usability Perspective on Requirements Engineering - From Methodology to Product Development, 2001, ISBN 9173732125.

No 732 Juha Takkinen: From Information Management to Task Management in Electronic Mail, 2002, ISBN 91 73732583.

No 745 Johan Åberg: Live Help Systems: An Approach to Intelligent Help for Web Information Systems, 2002, ISBN 91-7373-311-3.

No 746 Rego Granlund: Monitoring Distributed Teamwork Training, 2002, ISBN 91-7373-312-1.

No 757 Henrik André-Jönsson: Indexing Strategies for Time Series Data, 2002, ISBN 917373-346-6.

No 747 Anneli Hagdahl: Development of IT-supported Interorganisational Collaboration - A Case Study in the Swedish Public Sector, 2002, ISBN 91-7373-314-8.

No 749 Sofie Pilemalm: Information Technology for NonProfit Organisations - Extended Participatory Design of an Information System for Trade Union Shop Stew ards, 2002, ISBN 91-7373-318-0.

No 765 Stefan Holmlid: Adapting users: Towards a theory of use quality, 2002, ISBN 91-7373-397-0.

No 771 Magnus Morin: Multimedia Representations of Distributed Tactical Operations, 2002, ISBN 91-7373-4217.

No 772 Pawel Pietrzak: A Type-Based Framew ork for Locating Errors in Constraint Logic Programs, 2002, ISBN 91-7373-422-5.

No 758 Erik Berglund: Library Communication Among Programmers Worldwide, 2002, ISBN 91-7373-349-0.

No 774 Choong-ho Yi: Modelling Object-Oriented Dynamic Systems Using a Logic-Based Framew ork, 2002, ISBN 91-7373-424-1.

No 779 Mathias Broxvall: A Study in the Computational Complexity of Temporal Reasoning, 2002, ISBN 917373-440-3.

No 793 Asmus Pandikow: A Generic Principle for Enabling Interoperability of Structured and Object-Oriented Analysis and Design Tools, 2002, ISBN 91-7373-479-9.

No 785 Lars Hult: Publika Informationstjänster. En studie av den Internetbaserade encyklopedins bruksegenskaper, 2003, ISBN 91-7373-461-6.

No 800 Lars Taxén: A Framework for the Coordination of Complex Systems' Development, 2003, ISBN 917373-604-X
No 808 Klas Gäre: Tre perspektiv på förväntningar och förändringar $i$ samband med införande av informationssystem, 2003, ISBN 91-7373-618-X.

No 821 Mikael Kindborg: Concurrent Comics programming of social agents by children, 2003, ISBN 91-7373-651-1.

No 823 Christina Ölvingson: On Development of Information Systems with GIS Functionality in Public Health Informatics: A Requirements Engineering Approach, 2003, ISBN 91-7373-656-2.

No 828 Tobias Ritzau: Memory Efficient Hard Real-Time Garbage Collection, 2003, ISBN 91-7373-666-X.

No 833 Paul Pop: Analysis and Synthesis of Communication-Intensive Heterogeneous Real-Time Systems, 2003, ISBN 91-7373-683-X.

No 852 Johan Moe: Observing the Dynamic Behaviour of Large Distributed Systems to Improve Development and Testing - An Empirical Study in Software Engineering, 2003, ISBN 91-7373-779-8.

No 867 Erik Herzog: An Approach to Systems Engineering Tool Data Representation and Exchange, 2004, ISBN 91-7373-929-4.

No 872 Aseel Berglund: Augmenting the Remote Control: Studies in Complex Information Navigation for Digital TV, 2004, ISBN 91-7373-940-5.

No 869 Jo Skåmedal: Telecommuting's Implications on Travel and Travel Patterns, 2004, ISBN 91-7373-935-9.

No 870 Linda Askenäs: The Roles of IT - Studies of Organising when Implementing and Using Enterprise System s, 2004, ISBN 91-7373-936-7.

No 874 Annika Flycht-Eriksson: Design and Use of Ontologies in Information-Providing Dialogue Systems, 2004, ISBN 91-7373-947-2.

No 873 Peter Bunus: Debugging Techniques for EquationBased Languages, 2004, ISBN 91-7373-941-3.

No 876 Jonas Mellin: Resource-Predictable and Efficient Monitoring of Events, 2004, ISBN 91-7373-956-1.

No 883 Magnus Bång: Computing at the Speed of Paper: Ubiquitous Computing Environments for Healthcare Professionals, 2004, ISBN 91-7373-971-5

No 882 Robert Eklund: Disfluency in Swedish humanhuman and human-machine travel booking dialogues, 2004, ISBN 91-7373-966-9.

No 887 Anders Lindström: English and other Foreign Linguistic Elements in Spoken Swedish. Studies of Productive Processes and their Modelling using Finite-State Tools, 2004, ISBN 91-7373-981-2.

No 889 Zhiping Wang: Capacity-Constrained Production-inventory systems - Modelling and Analysis in both a traditional and an e-business context, 2004, ISBN 9185295-08-6.

No 893 Pernilla Qvarfordt: Eyes on Multimodal Interaction, 2004, ISBN 91-85295-30-2.

No 910 Magnus Kald: In the Borderland between Strategy and Management Control - Theoretical Framework and Empirical Evidence, 2004, ISBN 91-85295-82-5.

No 918 Jonas Lundberg: Shaping Electronic News: Genre Perspectives on Interaction Design, 2004, ISBN 9185297-14-3.

No 900 Mattias Arvola: Shades of use: The dynamics of interaction design for sociable use, 2004, ISBN 91 85295-42-6.

No 920 Luis Alejandro Cortés: Verification and Scheduling Techniques for Real-Time Embedded Systems, 2004 ISBN 91-85297-21-6.

No 929 Diana Szentivanyi: Performance Studies of FaultTolerant Middlew are, 2005, ISBN 91-85297-58-5. 
No 933 Mikael Cäker: Management Accounting as Constructing and Opposing Customer Focus: Three Case Studies on Management Accounting and Customer Relations, 2005, ISBN 91-85297-64-X.

No 937 Jonas Kvarnström: TALplanner and Other Extensions to Temporal Action Logic, 2005, ISBN 9185297-75-5.

No 938 Bourhane Kadmiry: Fuzzy Gain-Scheduled Visual Servoing for Unmanned Helicopter, 2005, ISBN 9185297-76-3.

No 945 Gert Jervan: Hybrid Built-In Self-Test and Test Generation Techniques for Digital Systems, 2005, ISBN : 91-85297-97-6.

No 946 Anders Arpteg: Intelligent Semi-Structured Information Extraction, 2005, ISBN 91-85297-98-4.

No 947 Ola Angelsmark: Constructing Algorithms for Constraint Satisfaction and Related Problems - Methods and Applications, 2005, ISBN 91-85297-99-2.

No 963 Calin Curescu: Utility-based Optimisation of Resource Allocation for Wireless Networks, 2005, ISBN 91-85457-07-8.

No 972 Björn Johansson: Joint Control in Dynamic Situations, 2005, ISBN 91-85457-31-0.

No 974 Dan Lawesson: An Approach to Diagnosability Analysis for Interacting Finite State Systems, 2005, ISBN 91-85457-39-6.

No 979 Claudiu Duma: Security and Trust Mechanisms for Groups in Distributed Services, 2005, ISBN 91-85457$54-\mathrm{X}$.

No 983 Sorin Manolache: Analysis and Optimisation of Real-Time Systems with Stochastic Behaviour, 2005, ISBN 91-85457-60-4.

No 986 Yuxiao Zhao: Standards-Based Application Integration for Business-to-Business Communications, 2005, ISBN 91-85457-66-3.

No 1004 Patrik Haslum: Admissible Heuristics for Automated Planning, 2006, ISBN 91-85497-28-2.

No 1005 Aleksandra Tešanovic: Developing Reusable and Reconfigurable Real-Time Software using Aspects and Components, 2006, ISBN 91-85497-29-0.

No 1008 David Dinka: Role, Identity and Work: Extending the design and development agenda, 2006, ISBN 9185497-42-8.

No 1009 Iakov Nakhimovski: Contributions to the Modeling and Simulation of Mechanical Systems with Detailed Contact Analysis, 2006, ISBN 91-85497-43-X.

No 1013 Wilhelm Dahllöf: Exact Algorithms for Exact Satisfiability Problems, 2006, ISBN 91-85523-97-6.

No 1016 Levon Saldamli: PDEModelica - A High-Level Language for Modeling with Partial Differential Equations, 2006, ISBN 91-85523-84-4

No 1017 Daniel Karlsson: Verification of Component-based Embedded System Designs, 2006, ISBN 91-85523-79-8

No 1018 Ioan Chisalita: Communication and Networking Techniques for Traffic Safety Systems, 2006, ISBN 9185523-77-1.

No 1019 Tarja Susi: The Puzzle of Social Activity - The Significance of Tools in Cognition and Cooperation, 2006, ISBN 91-85523-71-2.

No 1021 Andrzej Bednarski: Integrated Optimal Code Generation for Digital Signal Processors, 2006, ISBN 9185523-69-0.

No 1022 Peter Aronsson: Automatic Parallelization of Equation-Based Simulation Programs, 2006, ISBN 9185523-68-2.
No 1030 Robert Nilsson: A Mutation-based Framework for Automated Testing of Timeliness, 2006, ISBN 9185523-35-6.

No 1034 Jon Edvardsson: Techniques for Automatic Generation of Tests from Programs and Specifications, 2006, ISBN 91-85523-31-3.

No 1035 Vaida Jakoniene: Integration of Biological Data, 2006, ISBN 91-85523-28-3.

No 1045 Genevieve Gorrell: Generalized Hebbian Algorithms for Dimensionality Reduction in Natural Language Processing, 2006, ISBN 91-85643-88-2.

No 1051 Yu-Hsing Huang: Having a New Pair of Glasses Applying Systemic Accident Models on Road Safety, 2006, ISBN 91-85643-64-5.

No 1054 Åsa Hedenskog: Perceive those things which cannot be seen - A Cognitive Systems Engineering perspective on requirements management, 2006, ISBN 91-85643-57-2.

No 1061 Cécile Åberg: An Evaluation Platform for Semantic Web Technology, 2007, ISBN 91-85643-31-9.

No 1073 Mats Grindal: Handling Combinatorial Explosion in Softw are Testing, 2007, ISBN 978-91-85715-74-9.

No 1075 Almut Herzog: Usable Security Policies for Runtime Environments, 2007, ISBN 978-91-85715-65-7.

No 1079 Magnus Wahlström: Algorithms, measures, and upper bounds for Satisfiability and related problems, 2007, ISBN 978-91-85715-55-8.

No 1083 Jesper Andersson: Dynamic Software Architectures, 2007, ISBN 978-91-85715-46-6.

No 1086 Ulf Johansson: Obtaining Accurate and Comprehensible Data Mining Models - An Evolutionary Approach, 2007, ISBN 978-91-85715-34-3.

No 1089 Traian Pop: Analysis and Optimisation of Distributed Embedded Systems with Heterogeneous Scheduling Policies, 2007, ISBN 978-91-85715-27-5.

No 1091 Gustav Nordh: Complexity Dichotomies for CSPrelated Problems, 2007, ISBN 978-91-85715-20-6.

No 1106 Per Ola Kristensson: Discrete and Continuous Shape Writing for Text Entry and Control, 2007, ISBN 97891-85831-77-7.

No 1110 He Tan: Aligning Biomedical Ontologies, 2007, ISBN 978-91-85831-56-2.

No 1112 Jessica Lindblom: Minding the body - Interacting socially through embodied action, 2007, ISBN 978-9185831-48-7.

No 1113 Pontus Wärnestål: Dialogue Behavior Management in Conversational Recommender Systems, 2007, ISBN 978-91-85831-47-0.

No 1120 Thomas Gustafsson: Management of Real-Time Data Consistency and Transient Overloads in Embedded Systems, 2007, ISBN 978-91-85831-33-3.

No 1127 Alexandru Andrei: Energy Efficient and Predictable Design of Real-time Embedded Systems, 2007, ISBN 978-91-85831-06-7.

No 1139 Per Wikberg: Eliciting Knowledge from Experts in Modeling of Complex Systems: Managing Variation and Interactions, 2007, ISBN 978-91-85895-66-3.

No 1143 Mehdi Amirijoo: QoS Control of Real-Time Data Services under Uncertain Workload, 2007, ISBN 978 91-85895-49-6

No 1150 Sanny Syberfeldt: Optimistic Replication with Forward Conflict Resolution in Distributed Real-Time Databases, 2007, ISBN 978-91-85895-27-4.

No 1155 Beatrice Alenljung: Envisioning a Future Decision Support System for Requirements Engineering - A Holistic and Human-centred Perspective, 2008, ISBN 978-91-85895-11-3. 
No 1156 Artur Wilk: Types for XML with Application to Xcerpt, 2008, ISBN 978-91-85895-08-3.

No 1183 Adrian Pop: Integrated Model-Driven Development Environments for Equation-Based Object-Oriented Languages, 2008, ISBN 978-91-7393-895-2.

No 1185 Jörgen Skågeby: Gifting Technologies Ethnographic Studies of End-users and Social Media Sharing, 2008, ISBN 978-91-7393-892-1.

No 1187 Imad-Eldin Ali Abugessaisa: Analytical tools and information-sharing methods supporting road safety organizations, 2008, ISBN 978-91-7393-887-7.

No 1204 H. Joe Steinhauer: A Representation Scheme for Description and Reconstruction of Object Configurations Based on Qualitative Relations, 2008, ISBN 978-91-7393-823-5.

No 1222 Anders Larsson: Test Optimization for Core-based System-on-Chip, 2008, ISBN 978-91-7393-768-9.

No 1238 Andreas Borg: Processes and Models for Capacity Requirements in Telecommunication Systems, 2009, ISBN 978-91-7393-700-9.

No 1240 Fredrik Heintz: DyKnow: A Stream-Based Knowledge Processing Middleware Framework, 2009, ISBN 978-91-7393-696-5.

No 1241 Birgitta Lindström: Testability of Dynamic RealTime Systems, 2009, ISBN 978-91-7393-695-8.

No 1244 Eva Blomqvist: Semi-automatic Ontology Construction based on Patterns, 2009, ISBN 978-91-7393-683-5.

No 1249 Rogier Woltjer: Functional Modeling of Constraint Management in Aviation Safety and Command and Control, 2009, ISBN 978-91-7393-659-0.

No 1260 Gianpaolo Conte: Vision-Based Localization and Guidance for Unmanned Aerial Vehicles, 2009, ISBN 978-91-7393-603-3.

No 1262 AnnMarie Ericsson: Enabling Tool Support for Formal Analysis of ECA Rules, 2009, ISBN 978-91-7393598-2.

No 1266 Jiri Trnka: Exploring Tactical Command and Control: A Role-Playing Simulation Approach, 2009, ISBN 978-91-7393-571-5.

No 1268 Bahlol Rahimi: Supporting Collaborative Work through ICT - How End-users Think of and Adopt Integrated Health Information Systems, 2009, ISBN 978-91-7393-550-0.

No 1274 Fredrik Kuivinen: Algorithms and Hardness Results for Some Valued CSPs, 2009, ISBN 978-91-7393-525-8.

No 1281 Gunnar Mathiason: Virtual Full Replication for Scalable Distributed Real-Time Databases, 2009, ISBN 978-91-7393-503-6.

No 1290 Viacheslav Izosimov: Scheduling and Optimization of Fault-Tolerant Distributed Embedded Systems, 2009, ISBN 978-91-7393-482-4.

No 1294 Johan Thapper: Aspects of a Constraint Optimisation Problem, 2010, ISBN 978-91-7393-464-0.

No 1306 Susanna Nilsson: Augmentation in the Wild: User Centered Development and Evaluation of Augmented Reality Applications, 2010, ISBN 978-917393-416-9.

No 1313 Christer Thörn: On the Quality of Feature Models, 2010, ISBN 978-91-7393-394-0.

No 1321 Zhiyuan He: Temperature Aware and DefectProbability Driven Test Scheduling for System-onChip, 2010, ISBN 978-91-7393-378-0.

No 1333 David Broman: Meta-Languages and Semantics for Equation-Based Modeling and Simulation, 2010, ISBN 978-91-7393-335-3.

No 1337 Alexander Siemers: Contributions to Modelling and Visualisation of Multibody Systems Simulations with
Detailed Contact Analysis, 2010, ISBN 978-91-7393317-9.

No 1354 Mikael Asplund: Disconnected Discoveries: Availability Studies in Partitioned Networks, 2010, ISBN 978-91-7393-278-3.

No 1359 Jana Rambusch: Mind Games Extended: Understanding Gameplay as Situated Activity, 2010 ISBN 978-91-7393-252-3.

No 1373 Sonia Sangari: Head Movement Correlates to Focus Assignment in Swedish,2011,ISBN 978-91-7393-154-0.

No 1374 Jan-Erik Källhammer: Using False Alarms when Developing Automotive Active Safety Systems, 2011, ISBN 978-91-7393-153-3.

No 1375 Mattias Eriksson: Integrated Code Generation, 2011, ISBN 978-91-7393-147-2.

No 1381 Ola Leifler: Affordances and Constraints of Intelligent Decision Support for Military Command and Control - Three Case Studies of Support System s, 2011, ISBN 978-91-7393-133-5.

No 1386 Soheil Samii: Quality-Driven Synthesis and Optimization of Embedded Control Systems, 2011, ISBN 978-91-7393-102-1.

No 1419 Erik Kuiper: Geographic Routing in Intermittentlyconnected Mobile Ad Hoc Networks: Algorithms and Performance Models, 2012, ISBN 978-91-7519981-8.

No 1451 Sara Stymne: Text Harmonization Strategies for Phrase-Based Statistical Machine Translation, 2012, ISBN 978-91-7519-887-3.

No 1455 Alberto Montebelli: Modeling the Role of Energy Management in Embodied Cognition, 2012, ISBN 978-91-7519-882-8.

No 1465 Mohammad Saifullah: Biologically-Based Interactive Neural Network Models for Visual Attention and Object Recognition, 2012, ISBN 978-91-7519-838-5

No 1490 Tomas Bengtsson: Testing and Logic Optimization Techniques for Systems on Chip, 2012, ISBN 978-917519-742-5.

No 1481 David Byers: Improving Software Security by Preventing Known Vulnerabilities, 2012, ISBN 97891-7519-784-5.

No 1496 Tommy Färnqvist: Exploiting Structure in CSPrelated Problems, 2013, ISBN 978-91-7519-711-1

No 1503 John Wilander: Contributions to Specification, Implementation, and Execution of Secure Software, 2013, ISBN 978-91-7519-681-7.

No 1506 Magnus Ingmarsson: Creating and Enabling the Useful Service Discovery Experience, 2013, ISBN 978 91-7519-662-6.

No 1547 Wladimir Schamai: Model-Based Verification of Dynamic System Behavior against Requirements: Method, Language, and Tool, 2013, ISBN 978-917519-505-6.

No 1551 Henrik Svensson: Simulations, 2013, ISBN 978-917519-491-2.

No 1559 Sergiu Rafiliu: Stability of Adaptive Distributed Real-Time Systems with Dynamic Resource Management, 2013, ISBN 978-91-7519-471-4.

No 1581 Usman Dastgeer: Performance-aware Component Composition for GPU-based Systems, 2014, ISBN 978-91-7519-383-0.

Linköping Studies in Arts and Science

No 504 Ing-Marie Jonsson: Social and Emotional Characteristics of Speech-based In-Vehicle 
Information Systems: Impact on Attitude and Driving Behaviour, 2009, ISBN 978-91-7393-478-7.

No 586 Fabian Segelström: Stakeholder Engagement for Service Design: How service designers identify and communicate in sights, 2013, ISBN 978-91-7519-554-4.

No 618 Johan Blomkvist: Representing Future Situations of Service: Prototyping in Service Design, 2014, ISBN 978-91-7519-343-4.

\section{Linköping Studies in Statistics}

No 9 Davood Shahsavani: Computer Experiments Designed to Explore and Approximate Complex Deterministic Models, 2008, ISBN 978-91-7393-976-8.

No 10 Karl Wahlin: Roadmap for Trend Detection and Assessment of Data Quality, 2008, ISBN 978-91-7393$792-4$.

No 11 Oleg Sysoev: Monotonic regression for large multivariate datasets, 2010, ISBN 978-91-7393-412-1.

No 13 Agné Burauskaite-Harju: Characterizing Temporal Change and Inter-Site Correlations in Daily and Subdaily Precipitation Extremes, 2011, ISBN 978-91-7393110-6.

\section{Linköping Studies in Information Science}

No 1 Karin Axelsson: Metodisk systemstrukturering- att skapa samstämmighet mellan informationssystemarkitektur och verksamhet, 1998. ISBN-9172-19-296-8.

No 2 Stefan Cronholm: Metodverktyg och användbarhet en studie av datorstödd metodbaserad systemutveckling, 1998, ISBN-9172-19-299-2.

No 3 Anders Avdic: Användare och utvecklare - om anveckling med kalkylprogram, 1999. ISBN-91-7219606-8.

No 4 Owen Eriksson: Kommunikationskvalitet hos informationssystem och affärsprocesser, 2000, ISBN 917219-811-7.

No 5 Mikael Lind: Från system till process - kriterier för processbestämning vid verksamhetsanalys, 2001, ISBN 91-7373-067-X.

No 6 Ulf Melin: Koordination och informationssystem i företag och nätverk, 2002, ISBN 91-7373-278-8.

No 7 Pär J. Ågerfalk: Information Systems Actability - Understanding Information Technology as a Tool for Business Action and Communication, 2003, ISBN 917373-628-7.

No 8 Ulf Seigerroth: Att förstå och förändra systemutvecklingsverksamheter - en taxonomi för metautveckling, 2003, ISBN91-7373-736-4.

No 9 Karin Hedström: Spår av datoriseringens värden Effekter av IT i äldreomsorg, 2004, ISBN 91-7373-9634.

No 10 Ewa Braf: Knowledge Demanded for Action Studies on Knowledge Mediation in Organisations, 2004, ISBN 91-85295-47-7.

No 11 Fredrik Karlsson: Method Configuration method and computerized tool support, 2005, ISBN 91-8529748-8.

No 12 Malin Nordström: Styrbar systemförvaltning - Att organisera systemförvaltningsverksamhet med hjälp av effektiva förvaltningsobjekt, 2005, ISBN 91-8529760-7.

No 13 Stefan Holgersson: Yrke: POLIS - Yrkeskunskap, motivation, IT-system och andra förutsättningar för polisarbete, 2005, ISBN 91-85299-43-X.
No 14 Benneth Christiansson, Marie-Therese Christiansson: Mötet mellan process och komponent - mot ett ramverk för en verksamhetsnära kravspecifikation vid anskaffning av komponentbaserade informationssystem, 2006, ISBN 91-85643$22-\mathrm{X}$. 